\title{
Just A Hunch:
}

\section{ReAding, Writing, ... AND ArChitecture}

\author{
Submittedin Partial fulfilment of the Master of Architecture(Professional)Degree
}

School of Architecture - Victoria University of Wellington - December 2010

\author{
ELSPEth Jane Simms
}





\section{Abstract}

Victor Hugo's character, Claude Frollo, expressed Hugo's linguistic analogy for architecture in his novel of 1831, Notre-Dame de Paris. Frollo directs the eyes of his companions from the book resting on his desk to the shadow of the nearby Notre-Dame cathedral, stating: 'This will kill that'. Hugo expressed the belief that prior to the printing press, the communication of mankind occurred through architecture. His concern was for the fate of architecture following the invention of a new form of communication; the printed text.

This thesis questions the concern that print will 'kill' architecture through an exploration of architectural research and design led by text. A validity of print as an experimental tool for architectural design is established through a range of output; visual and physical expression, creative writing, and formal writing. These design modes reveal unique architecture from within Hugo's Notre-Dame de Paris.

The outcomes of this research draw attention to the imaginative possibilities that text provides for architecture. It finds that architecture exists within text and allows for interpretation and conversion, into both real and imagined space. It provides a framework through which this can occur within other text, not just Notre-Dame de Paris. The conclusion is reached that text is a design tool which offers significant opportunities to the experimentation and design of architecture. 


\section{Acknowledgements}

I wish to take this opportunity to acknowledge those who have supported me throughout the course of my studies and in completion of this thesis.

For professional support; I thank Dr. Peter Wood, whose supervision, insight and encouragement has been invaluable for me throughout this year.

I am also grateful to my fellow classmates, who have provided a fun and supportive environment and whose friendship has made the last five years that much more enjoyable. Particular thanks go to Jansen Aui, Nick Roberts, and Jimmy Gray, whose feedback and dialogue this year has provided valuable perspective when it was most necessary. Special thanks to Jim for your skill and assistance with a Pentax 67.

To my family, Gerald, Christine, Erica and Michaela; your care and support throughout the past five years has been unconditional. Thank you for your encouragement. 


\section{Contents}

$\begin{array}{ll}\text { Introduction } & 1\end{array}$

Part One - Background 11

1.1. Ceci tuera cela $\quad 15$

1.2. Responses to Notre-Dame de Paris

Part Two - Analysis $\quad 45$

2.1. Reading Architecture $\quad 51$

2.2. Writing Architecture 61

2.3. The Role of Text in Research by Design 199

2.4. Discussion on Textual Experiment 73

2.5. 'Writing' Architecture Experiment 77

$\begin{array}{lr}\text { Part Three - Reflection } & 89\end{array}$

3.1. $\quad$ Site Writing 97

3.2. $\quad$ Diagramming Notre-Dame de Paris - Drawings 101

3.3. Diagramming Notre-Dame de Paris - Gothic Arch 121

3.4. Spatial Photographs 129

$\begin{array}{ll}\text { Conclusion } & 141\end{array}$

Bibiography 145

Appendix 153 


\section{List of Figures}

\section{Part One}

1. The Casquets Lighthouse 14

2. Victor Hugo and the Ruins of a Fortress 14

3. Tourgue Castle 14

4. Hugo's Funeral Procession 16

5. Victor Hugo $1872 \quad 16$

6. Drawing of Notre-Dame de Paris 20

7. Bibiothèque Ste-Geneviève 'Reading Room' 30

8. Bibiothèque Ste-Geneviève Longitudinal Section 32

9. Bibiothèque Ste-Geneviève Library Monogram 34

10. Bibiothèque Ste-Geneviève Facade 34

\section{Part Two}

11. Early design exploration 46

12. Early design exploration 46

13. Early design exploration 46

14. Early design exploration 46

15. Character and space exploration 48

16. Character and space exploration 48 
$\begin{array}{llr}\text { 17. } & \text { Design experimentation } & 48 \\ \text { 18. } & \text { Design experimentation } & 48 \\ 19 . & \text { Fallingwater House } & 52 \\ 20 . & \text { Villa Savoye } & 52 \\ 21 . & \text { Black Tent Artwork } & 56 \\ 22 . & \text { An Embellishment } & 58 \\ 23 . & \text { An Embellishment: Purdah } & 58 \\ 24 . & \text { Haga Park } & 62 \\ 25 . & \text { Haga Park } & 64 \\ 26 . & \text { out of focus (in distraction) } & 66 \\ 27 . & \text { Haga Park } & 74\end{array}$

\section{Part Three}

29. Writing Without Words

30. Data Recording

31. Bound Diagrammes

32. Top of Arch

33. Arch Elevation

34. Experimentation with Diagrammes

35. Mock-up models

36. Arch Construction

37. Completed 'Physigramme'

38. Book Seven: Esmeralda's Downfall

39. Book Four: Quasimodo 
40. Book Ten: Quasimodo Deconstructs his Sacred Universe

41. Book Nine: Esmeralda and the Cathedral

42. Book Six: The Recluse in the Hole

43. Book Four: Quasimodo

44. Book Eleven: Claude Frollo’s Demise

45. Book Ten: Quasimodo Deconstructs the Cathedral

46. Book Eight: Esmeralda’s Fate 


\section{Introduction}

\section{Problem Statement}

In one of these chapters, the author expresses and enlarges upon the current decadence of architecture and the now, in his view, almost inevitable demise of this king of the arts, a view, unhappily, deeply rooted in him and deeply pondered. But he feels the need to say here that he very much wants the future one day to prove him wrong... But in any case, whatever the future of architecture and however our young architects may one day settle the question of their art, while we wait for new monuments we must conserve the old. We must, if it be possible, inspire the nation with a love of its national architecture. That, its author here declares, is one of the chief aims of this book; it is one of the chief aims of his life.
Victor Hugo's novel of 1831, Notre-Dame de Paris, is written in support of Gothic architecture, which had long been in decline in France. Hugo expressed his concerns for the future of architecture in Book Five of the novel, in the chapter titled, Ceci tuera cela, literally; 'This Will Kill That'. In this chapter, character Claude Frollo expressed Hugo's linguistic analogy which signified the demise of Gothic architecture. Frollo directs the eyes of his companions from the book resting on his desk to the shadow of the nearby Notre Dame cathedral, stating "this will kill that". Hugo held the view that prior to the printing press, the expression of human knowledge was delivered through architecture. It was his concern that each generation's ideas would no longer be written in 'stone', but on paper, and that the creation of the printing press enabled a communication more enduring and resistant than architecture. ${ }^{2}$ Paradoxically, Hugo used the novel to campaign in support of an architecture which he believed was suffering an injustice of suppression. His devotion to Gothic architecture was clear throughout
1. Note Added to the Definitive Edition of 1832 Victor Hugo, Notre-Dame De Paris, trans. John Sturrock, ed. John Sturrock (London: Penguin Books, 1978) $27-8$

2. Although stone has obvious physical qualities which suggest its resistance over printed paper, prin has the benefit of cheap and fast reproduction and distribution, making it difficult to entirely eradicate. 
Notre-Dame de Paris, not only in terms of the aesthetic appeal of the architecture, but also the much wider cultural shift in thinking which it represented. Gothic architecture was important to the humanist temperament of Hugo $;^{3}$ it embodied a move towards a more contemporary, open frame of mind which embraced the spirit of Romanticism, expressing ideas of populism and aspiration. Hugo was attempting to protect Gothic architecture not only for its significant ideological representation but also in concern of an insecure future of architecture, caused by the invention of the printing press. The most significant and compelling suggestion raised in the novel was the possibility that print will 'kill' architecture, it is through a questioning of this that the aim of the research is established.

Aim

This research pursues an exploration in architectural design which questions Victor Hugo's concern that print will kill architecture. This will test the validity of print as an experimental tool for architectural research and design, by utilising visual, physical and creative writing representations which all derive from text and which allow for the creation of architecture.

\section{Research Approach}

In order to achieve this, the research is broken into three parts. The intent with these parts is that they progressively build towards a more interpretive, experimental form of communication of a range of information. This will vary from formal background analysis to discussion and reflection on conceptual design explorations.

Part One - Background establishes a position on Victor Hugo's ideas and concerns expressed in This Will Kill That. This is achieved through an analysis of his background and literary style, followed by a comprehensive reading of the specific chapter and its relation to the context of the novel. The success of the novel and prominence of Hugo's ideas on architecture caused an inevitable influence over both architectural practice and theory of the

3. Hugo was a humanitarian. He had liberal ideals and strived for social justice and equality. He denounced the death penalty and use of the guillotine. 
time. This influence is presented through the case study of Labrouste's Bibliotheque Ste-Genevieve. In response to this, and through a reading of historian Lewis Mumford, a critique of this case study will cement the validity of this thesis' intention to explore alternative experimentation informed by print.

Part Two - Analysis develops a contemporary theoretical position through which to explore the potential of text as an experimental tool for design. It is proposed here that print can inform the design of architecture, and that this design is not restricted to purely visual creations. Text is a design material which can not only be used for the creation of architecture, but also as a means of entering a critical engagement with the design. It offers an important opportunity for research in architectural design and can provide unique insight for both the designer and interpreter. In Part 2.1: Reading Architecture, the importance of the reader will be established through an interpretation of work by writers Roland Barthes and Michel Foucault, followed by Jane Rendell. This section considers the role of the author within a text (or building) and how their presence fades, with the reader playing a significant role in endowing a text with meaning. Part 2.2, Writing Architecture, considers the potential of creating architecture through text, by reflecting on the work of architect Katja Grillner. A response to this section leads to a challenge of academic convention, in which Part 2.3 encourages the role of text in research by design, suggesting writing should not be limited to the formal academic text typical of the architecture thesis. From here the role of text shifts into a more experimental and creative position. Following a discussion on the exercise of 'writing' architecture (Part 2.4), a written architectural design is presented, titled Santa Claus, Concrete Steps and Dirty Feet. This design is evidence of the imaginative possibilities which text can contribute to architectural research and design.

Part Three - Reflection returns to Notre-Dame de Paris in order to gain direction for the application of ideas established in Part Two, into design experimentation. The novel provides a rich basis from which to draw design 
inspiration when pursuing the intention of establishing a validity of print as an experimental design tool for architecture. The site in which the design of space occurs is maintained within a fictional realm, presented through the written design of the architectural context. This site 'writing' offers a design of space, interpreted through the novel's main characters, Quasimodo and Esmeralda. It is presented at the beginning and conclusion of Part 3. Part 3.1 provides a discussion on this textual design. Following this, Part 3.2 uses drawings to diagramme NotreDame de Paris, revealing architecture which is latent in the novel but which would not be revealed through a typical reading. Part 3.3 develops these diagrammes into a physical creation of architecture. This takes the form of a 2.4 metre tall Gothic arch which within its walls holds a representation of every word within Hugo's novel This representation is a continuation of the diagramme drawings, but introduces a qualitative reading of the novel, resulting in spaces within the arch which are a re-design of the Notre-Dame Cathedral through an interpretation of the relationship between characters and the architecture. Part 3.4 further explores and develops the design of these spaces through spatial images which encourage an engagement of the reader's imagination. Discussion occurs within each section on the role of the design work and its significance to the objective of validating text as an experimental tool for architectural design.

Design images are placed throughout the three part structure in the anticipation that, as understanding of the research develops so too does a developing interpretation of the architecture within the images. The importance of the reader is consistently raised within the research. The intention with the inclusion of these images is that the interpretations will develop in unique ways for each reader, as the thesis structure shifts from the more formal to the more experimental communication of ideas. The thesis structure puts into practice the importance of challenging the role of text in architectural design. Here, text is used formally, creatively and interpretively to reveal the imaginative possibilities of writing architecture. 


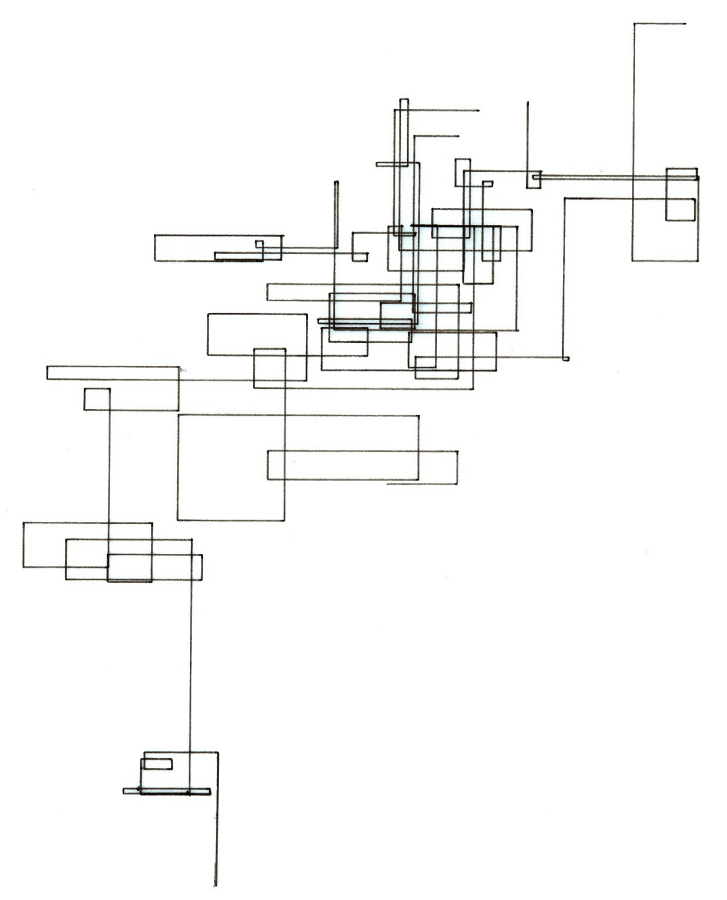





\section{Part One}

Background 


\section{Part One}

\section{Introduction}

Part One provides the foundations for a rationale explaining this experimental research by design project. By selecting a subject, identifying an opportunity within this subject and committing to the exploration which that opportunity provides the potential for, the resultant output is inherently connected to the intricacies of the subject. This section is vital in that it displays both the logic behind the shift into a design realm and also the framework which guides and restrains these design explorations. An understanding of Victor Hugo and his ideas within Notre-Dame de Paris identifies the subject topic. Analysis of the responses to these ideas identifies an opportunity within this subject topic. Finally, a commitment to the exploration of this opportunity guides the transition into the subsequent Part Two - Analysis. 

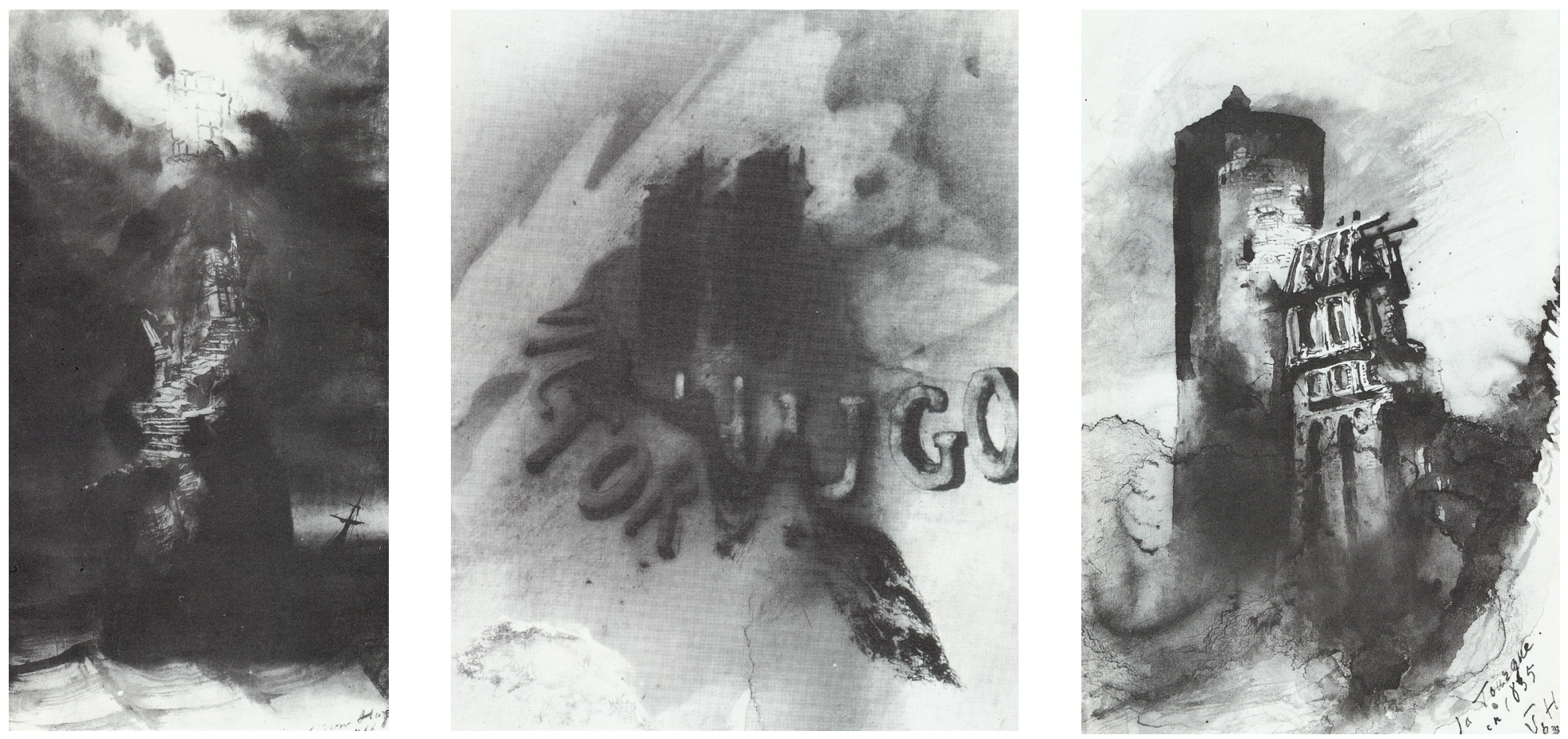


\subsection{Ceci tuera cela}

Victor Hugo

Notre-Dame de Paris, published in 1831, is one of the most loved of Victor Hugo's novels. It revealed not only Hugo's great skill in developing fiction, but also his dedication to sending a moral and social message. These social intentions are conveyed through Hugo's incorporation of architecture, revealing his passion for the arts which were evident in Hugo from a young age.

Born in France in 1802, Hugo is widely considered as the greatest French writer of the nineteenth century. He authored novels, poetry, plays, criticism and journalism, maintaining an enormous output of work throughout the majority of his life, until his death in 1885. In addition to the success of Notre-Dame de Paris, work such as Les Misérables and Les Contemplations are internationally renowned. Hugo's popularity within his homeland of France spread extensively both during and after his lifetime, not only as a response to his writing but also because of his position as a socialist and philanthropist. Hugo yearned for a political career; he held liberal ideals and was an advocate for universal suffrage, equality and freedom for all. In 1848 he became mayor of the district of Paris in which he lived and was also elected to the Constituent Assembly. In December of that year, Louis-Napoléon became the first President of the new Republic. Hugo disagreed with the president's authoritarian approach and attempted to organize resistance against him, but was forced to leave France in 1851 in disguise. ${ }^{4}$ Hugo lived in exile for the following nineteen years, and although he was offered an amnesty by the Emperor in 1859 , he refused to return to France until the return of liberty and the reconstitution of the republic. ${ }^{5}$ This attitude gained him huge popularity and he was considered around the world as a "champion of freedom". ${ }^{6}$ The Times of London wrote: "We are proud that Victor Hugo elects to live on British soil, which is enriched and nourished by his
Figures 1,2,3: Victor Hugo also had great artistic talent. A majority of his drawings were landscapes or seascapes and his full name or initials would often dominate the image, reflecting his personal motto 'Ego Hugo'.

From L to R. 'The Casquets Lighthouse', 'Victor Hugo and the ruins of a fortress' and 'Tourgue Castle'. In: Victor Brombert, Victor Hugo and the Visionary Novel (Harvard University Press, 1984) Images 22, 25,23

4. John Sturrock, "Chronology," Notre-Dame De Paris, ed. John Sturrock (London: Penguin Group, 2004) 497.

5. Samual Edwards, Victor Hugo - a Biography (New York: David McKay Company, Inc., 1971) 200.

6. Edwards, Victor Hugo - a Biography 200 

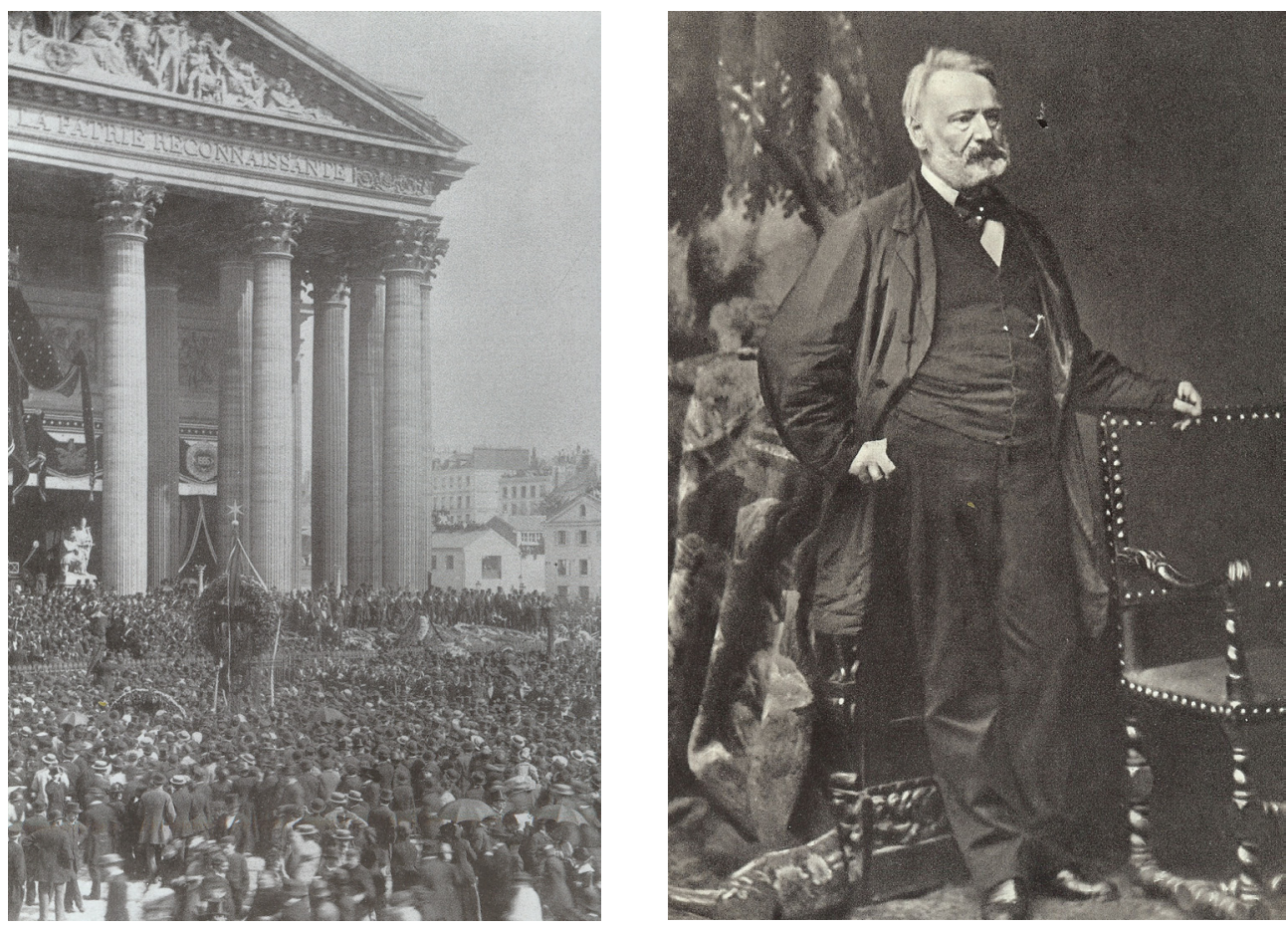
presence", 7 which clearly reflected the stretch of his influence outside of France. In 1870, following the eventual deposing of Napoleon III by the French Third Republic, Hugo immediately returned to Paris and was greeted by thousands of supporters, chanting 'Vive Victor Hugo' (Great Victor Hugo) and reciting verses from his poetry of freedom: Les Châtiments.

Victor Hugo was a hero. His moral and political ambitions were visionary at the time and he portrayed this both as a public and a literary figure. His death in 1885 was cause for a National Funeral which drew an estimated two million attendees, confirming quite clearly the impact his life made at the time. ${ }^{8}$

\section{Literary Style}

In his literary work, Hugo broke free from the classical French literature at the time and was a catalyst behind a shift towards romanticism. ${ }^{9}$ The early years of the nineteenth century had seen a revival of Classicism; however Hugo's passion for romanticism and his position as a socialist and philanthropist enabled him to create a new type of fictional work that would develop the moral and social consciousness of his time. ${ }^{10}$ He rallied in support of romanticism and encouraged all writers to follow his example; he associated it with freedom and the expression of natural human emotions. Hugo enthusiastically presented himself as the leader of the literary strain within France, augmenting his position within the French literary scene of the early nineteenth century. The 1831 publication of Notre-Dame de Paris, written in the genre of romanticism, saw Hugo cement his defense of Gothic architecture resulting in the popular revolution in French architecture: "People seemed to realize, for the first time, that Notre Dame was a magnificent cathedral. ${ }^{11}$ New constructions pursued the medieval styles with an insistence for houses decorated with gargoyles.
Figure 4: Hugo's funeral procession arriving at the Pantheon.

In: Graham Robb, Victor Hugo (London: Picador, 1997) Image 35.

Figure 5: Victor Hugo in 1872

In: Andre' Mauras, Victor Hugo (London: Jonathan Cape, 1956) 424

7. Edwards, Victor Hugo - a Biography 200

8. Guernsey Information Centre, Victor Hugo, Available: http://www.victorhugo.gg/contact-us/, 6 May 2010.

9. Edwards, Victor Hugo - a Biography 6.

10. Victor Brombert, Victor Hugo and the Visionary Novel (Harvard University Press, 1984) 1.

11. Edwards, Victor Hugo - a Biography 85 
Although Hugo was trying to send visionary messages of social progress, he always made sure to communicate his ideas clearly. His articulation of ideas was a response to his commitment to engage with the greater society:

More intensely and more consistently than others, he believed that writers had a mission, that they were to be the educators and leaders of the recently awakened peuple, ${ }^{2}$ that they were to regenerate society, prepare the future, and write, as it were, on paper and in life, the immanent epic of humanity's progress. ${ }^{13}$

Hugo often took a keen and progressive interest in writing about history. His work emphasised the socio-historic context, and moved away from the trend which glorified the heroic exploit of the man, instead following a moral adventure. ${ }^{14} \mathrm{He}$ aimed for a condition in which the older generation looked towards the future while the younger learned an appreciation for the past. "Hugo does not mean to compete with historians in the interpretation of grea events or the possible motivations of historical figures; he is preoccupied with what in recent years in France has come to be known as the 'history of mentalities', or the state of mind of a population at a given historical period." ${ }^{15}$ Hugo saw more potential in the possibilities of historical fiction then many other writers of the time, wishing to approach it from a different perspective. ${ }^{16}$

Hugo's literary approach to romanticism enabled him to develop awareness of the importance of architecture in a historical context. Architecture was, for Hugo, the backdrop to history. It was the representation of society's ideas and therefore reflection on architecture was a key tool in developing the moral and social consciousness of the time.
12. French for 'people'

13. Brombert, Victor Hugo and the Visionary Novel 12.

14. Brombert, Victor Hugo and the Visionary Novel 7.

15. John Sturrock, "Introduction," Notre-Dame De Paris, ed. John Sturrock (London: Penguin Group, 1978) 13

16. His approach varied from that taken by his peers, for instance that of the highly-esteemed novelist Sir Walter Scott, author of Quentin Durward. At age twenty-one Hugo produced a critique of Scott's work, which did contain some level of praise, but also criticised Scott's approach to portraying the past. 


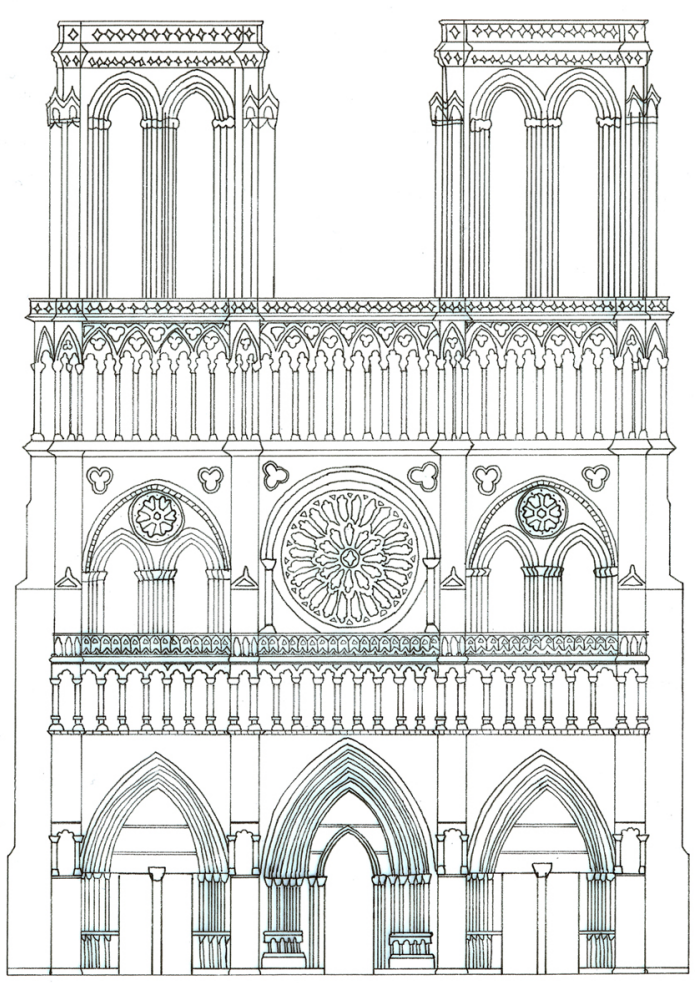


Hugo developed his vision for historical fiction when he wrote Notre-Dame de Paris (1831). The story is set in the year 1482, in the city of Paris. However, unlike most historical novels, the text does not provide a description of the overall significant events of recorded history. Hugo instead preferred to present more of a general idea of life at that time and convincingly represented the various classes within Paris. Therefore, the history aspect of Hugo's work is very much in favour of the attitudes and social tendencies of the common people of the time, reflecting his attitude as a humanist. "The plot of a novel like Notre-Dame is contrived in part to display his own great range of interests and skills; he engages with every social class: royalty, gentry, burgess, students, clerics, the lower orders" ${ }^{\prime 17}$ Notre-Dame de Paris is focused on three main characters; Quasimodo - a hideously deformed hunchback, Dom Claude Frollo - the Archdeacon of Notre-Dame who adopted the infant Quasimodo after he had been abandoned as a foundling in the Cathedral's parvis, and Esmeralda - the beautiful young gypsy who attracts Quasimodo's love and adoration and Claude Frollo's inappropriate obsession and jealous infatuation. The story leads to Quasimodo's attempts to protect Esmeralda within the walls of Notre-Dame Cathedral, after she was framed for a murder she did not commit.

The original French title, Notre-Dame de Paris, reveals the importance of architecture to the novel. Unfortunately most English translations identify the novel as The Hunchback of Notre-Dame, which shifts attention from the novel's strengths to its weaknesses; from its ideas and the cathedral to the plot and the character Quasimodo. The vast majority of the story was set within the context of the Gothic Cathedral and its immediate surroundings. The implications of this focus coupled with the popular reception of the novel led to the historical preservation and renovations of Notre-Dame cathedral. ${ }^{18}$ Writer, critic and translator John Sturrock interprets Hugo's perception of Gothic architecture through the emphasis he places throughout the novel on the vertical nature of the buildings.
Figure 6: own drawing of western facade, NotreDame Cathedral, Paris.

17. Sturrock, "Introduction," 15.

18. These major renovations of the Cathedral were initiated in 1845, following the success of Hugo's novel, and continued on for twenty-five years. They were led by Eugène Viollet-le-Duc, who was a centra figure in the architecture of Gothic Revival in France. 
Sturrock sees Hugo's descriptions of the spires, steeples, staircases and lancets as another reflection of Hugo's humanist philosophy and optimism for the future: "he saw humanity as engaged on a long but inevitably triumphant ascent from ignorance and crime to a harmonious state of grace on earth."

Hugo uses the architecture of Notre-Dame cathedral to link all aspects of the plot together, so that the dramas of individual characters intermingle. The cathedral, a creation in stone, represents for Hugo a hybrid form. The cathedral is a historical document of an extended period of time. The construction begun in a Romanesque age and extended into Gothic, grafting together to reflect not only a transition in style, but also a shift in thinking: "Her hybrid edifice bears the mark of bygone values, yet as such stands as a monument to the transformative sweep of time. ${ }^{, 20}$ Hugo sees architecture as a representation of larger ideological shifts, therefore framing his text to reflect this. He capitalises on the aspects of Gothic which allow for the grotesque, such as the gargoyles which decorate the cathedral. The combination of aesthetic beauty and the grotesque is mirrored in the characters of Esmeralda and Quasimodo. The contrast between these characters emphasise their own identities. The relationship developed between Quasimodo with both Esmeralda and the cathedral represents Hugo's ultimate aim of social reconciliation, "[Quasimodo] is a plea for a more enlightened aesthetic."21

The hybrid form of the cathedral is further represented in the novel Notre-Dame de Paris through the blending of both fact and fiction. As discussed earlier, Hugo's literary style of recounting history is intended to reflect both actual events and fictional events, introducing the requirement of the reader to perceive when the author acts as historian or as artist. However, Hugo acknowledged he was more interested in a belief of fiction: the 'moral' rather than 'historical' truth. ${ }^{22}$ Hugo's re-creation of history is a pursuit of his goal to encourage a more enlightened future society.
19. Sturrock, "Introduction", 17

20. Bradley Stephens, "Reading Walter Benjamin's Concept of the Ruin in Victor Hugo's Notre-Dame De Paris," French Studies LXI. 2 (2007): 155.

21. Sturrock, "Introduction," 18.

22. Brombert, Victor Hugo and the Visionary Novel 52 


$$
\text { 四昌 }
$$


The cathedral of Notre-Dame played an important role in every aspect of Hugo's novel. It provides both the main setting for the narrative and the most significant theme of the novel - which is, of course, his concern for the future of architecture.

\section{This Will Kill That}

In the definitive edition, published December 1832, Hugo added to the novel three previously unpublished chapters which are claimed to have been missing at the time of first print. One of the chapters was titled "Ceci tuera cela, ${ }^{23}$ and follows directly on from a pointed message Hugo expressed in the previous chapter, through his character Claude Frollo:

The archdeacon contemplated the gigantic cathedral for a time in silence, then he sighed and stretched out his right hand towards the printed book lying open on his table and his left hand towards Notre-Dame, and looked sadly from the book to the church: 'Alas,' he said, 'this will kill that. ${ }^{24}$

Hugo acknowledges within this subsequent chapter that the statement made by Claude Frollo contains two facets of meaning intended by the author. The first, 'simpler' thought was that of the apprehension felt by the priesthood resulting from Gutenberg's invention of the printing press, an undermining of sacerdotal ${ }^{25}$ authority: "It meant that one power was going to succeed another power. It meant: the press will kill the church." ${ }^{26}$ The second notion involved not only the priest but also the scientist and artist; the idea that as human thought changed it would change its "mode of expression". ${ }^{27}$ Hence ideas would no longer be recorded in stone but instead in the book of paper: "one art was going to dethrone another art. It meant: printing will kill architecture. ${ }^{28}$ Hugo explains in his prefatory note included with the definitive edition, that the chapter 'This Will Kill That' describes his views

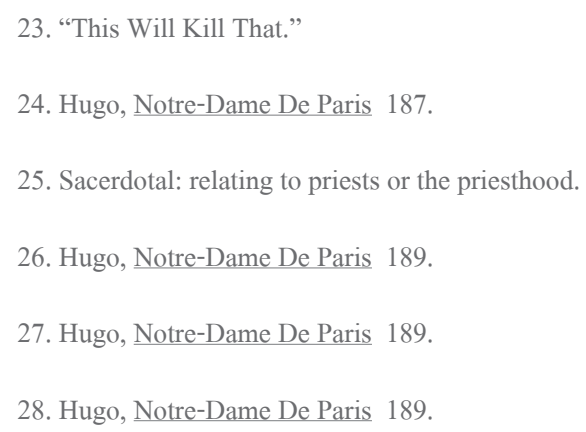


on the potential demise of architecture - the "king of the arts". ${ }^{29}$ This conclusion, according to Neil Levine in his essay The Romantic Idea of Architectural Legibility, was based on the suggestion that "literature, through the proliferation of the printed book, had sapped architecture of its powers of expression. Were architecture to regain any significant form, it would have to do so under the dominion of the printed word." ${ }^{30}$ This was of great concern for Hugo given his attitude towards architecture and its ability to express the thoughts and emotions of its people.

Simultaneously, Hugo presents a differing view through the narrator's opinion. The narrator refers to Gutenberg's invention of the printing press as "the greatest event in history. It was the mother of revolutions. It was the total renewal of man's mode of expression." ${ }^{31}$ For the narrator, the printing press represented a major shift from theocracy to democracy. The book allowed a greater representation of the people; so what Frollo feared was the end of the world, was actually the beginning of a new one. ${ }^{32}$ It is evident then, that underlying the novel is a message about the responsibility of the printed word and its importance to a political revolution. This is validated when considering what has already been discussed regarding Hugo's political view, he was passionate about a movement away from theocracy and towards democracy and saw the transformation from Romanesque architecture of the early Middle Ages to the Gothic architecture of the thirteenth century as an ideal representation of this: "Gothic architecture is thus seen by Hugo as the symbol of the people's newly-acquired status and power. ${ }^{, 33}$ In his description of the responsibility and power of the printed word, Hugo describes architecture as a metaphor for print:
29. Hugo, Notre-Dame De Paris 27

30. Arthur Drexler, ed., The Architecture of the Ecole Des Beaux-Arts (London: Martin Secker \& Warburg Ltd, 1977) 356.

31. Hugo, Notre-Dame De Paris 196.

32. Brombert, Victor Hugo and the Visionary Novel 58.

33. Odile Boucher-Rivalain, "Attitudes to Gothic in French Architectural Writings of the 1840s," Architectural History 41 (1998): 145 
is an edifice of a thousand storeys...The printing-press, that giant machine,

tirelessly pumping the whole intellectual sap of society, is constantly spewing

out fresh materials for its erection. The entire human race is on the scaffolding.

Each mind is a mason...This is the human race's second Tower of Babel. ${ }^{34}$

Hugo is therefore suggesting the opportunity which the printing press offered to further progress human minds, parallel to his belief that Gothic architecture was a built reflection of this progress. Although Hugo identifies the positive opportunities which the printing press offered, underlying this was a level of apprehension over the impact of the printing press on the future of architecture. Hugo's concerns in 1832 were well-placed. This is discussed by Mario Carpo in his 1998 book Architecture in the Age of Printing: "The mechanical reproduction of images was to have important and long-lasting consequences for the transmission of scientific knowledge, and even more for technical subjects and for the visual arts. Architecture was no exception." ${ }^{\prime 35}$ This impact on architecture is because images cannot be copied precisely by memory, given that they are not of a standardised form. Unlike words, which have the alphabet to assist in reproduction, images rely on mechanical means in order to gain a faithful reproduction. ${ }^{36}$ Gutenberg's press, therefore, was hugely significant to the practice and dissemination of architectural representation.

The dedication of an entire chapter within Notre-Dame de Paris to the explanation of Claude Frollo's outburst "this will kill that... the book will kill the building!" ${ }^{37}$ reflects the importance of the statement to the novel. Given the popularity of the novel, Hugo's views on the fate of architecture following the proliferation of the printing press were widely broadcast, somewhat ironically thanks to the printing press itself. They therefore undoubtedly had an impact on the subsequent architecture of the time.

34. Hugo, Notre-Dame De Paris 201-2.

35. Mario Carpo, Architecture in the Age of Printing, trans. Sarah Benson (Cambridge, Massachusetts: The MIT Press, 1998) 6

36. Carpo, Architecture in the Age of Printing.

37. Hugo, Notre-Dame De Paris $187-8$ 


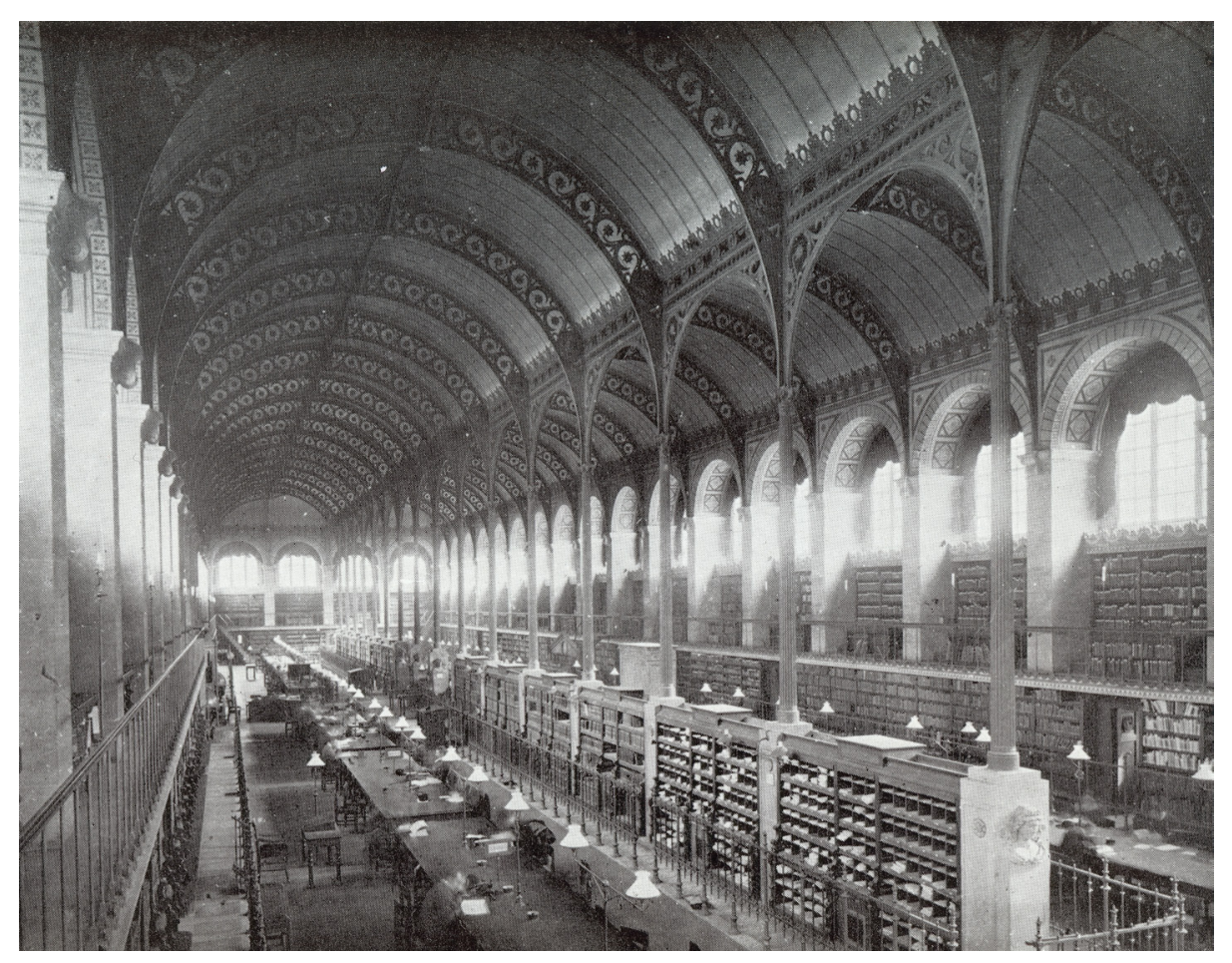




\subsection{Responses to Notre-Dame de Paris}

\section{Built Example - Bibiothèque Ste-Geneviève}

Victor Hugo's statement "this will kill that" had significant influence on architects and the student generation of the 1830s. It is through analysis of this influence that the opportunity for further interpretation and experimentation with Hugo's ideas is revealed.

Ultimately, Hugo's novel formed an argument for the relationship between architecture and literature, identifying architecture as the first means of writing and then the shift into consideration of the "architectonic qualities of literature". ${ }^{38}$ This relationship is fundamental as no other architecture has been as criticized for being 'literary' than that of the Romantic French architecture of the nineteenth century. ${ }^{39}$ Although Hugo pointedly stated in Notre-Dame: "Let there be no mistake, architecture is dead, dead beyond recall, killed by the printed book, killed because it is less enduring, killed because it is more expensive", ${ }^{40}$ he simultaneously did not extinguish all hope for the future of architecture: "should architecture accidentally revive, it will no longer be master. It will be subject to the law of literature, which once received the law from it. The respective positions of the two arts will be reversed." ${ }^{41}$ However, this hope was actually met by a decline in architecture - in the form of classical architecture. By drawing attention to it, Hugo is offering an opportunity for architecture beyond the context of the novel, and reflecting his ambition for a movement away from Classicism and towards architecture of Gothic influence. $^{42}$

An application of similar ideas to Hugo's can be identified in the Romantic architects of the nineteenth century, such as Henri Labrouste, Félix Duban and Louis Duc. Neil Levine's essay, The Book and the Building; Hugo's
Figure 7: Henri Labrouste's Bibiothèque SteGeneviève, 'Reading Room'

In: Nikolaus Pevsner, Some Architectural Writers of the Nineteenth Century (Oxford: Clarendon Press, 1972) 372.

38. Brian McLaren, "Under the Sign of the Reproduction," Journal of Architectural Education (1984-) $45.2(1992): 105$.

39. Romantic Nationalism started in late eighteenth century and coincided with the Neo-Gothic architectural movement

40. Hugo, Notre-Dame De Paris 199.

41. Hugo, Notre-Dame De Paris 200

42. Gothic architecture is characterized by ribbed vaulting, pointed arches, tall spires, gargoyles and stained glass windows. The engineering of Gothic architecture made possible the ability to enclose large spaces with less material, encouraging lighter spaces then those of Classicism. However, as Michael Lewis wrote of the Gothic Revival, it is "more than a fashio craze for pointed arches and pinnacles. During its years of greatest influence, it subjected every aspect of art, belief, society and labor to intense intellectual scrutiny, using the Middle Ages as a platform from which to judge the modern world." In: Michael J. Lewis, The Gothic Revival (New York: Thames \& Hudson, 2002). 105 


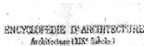

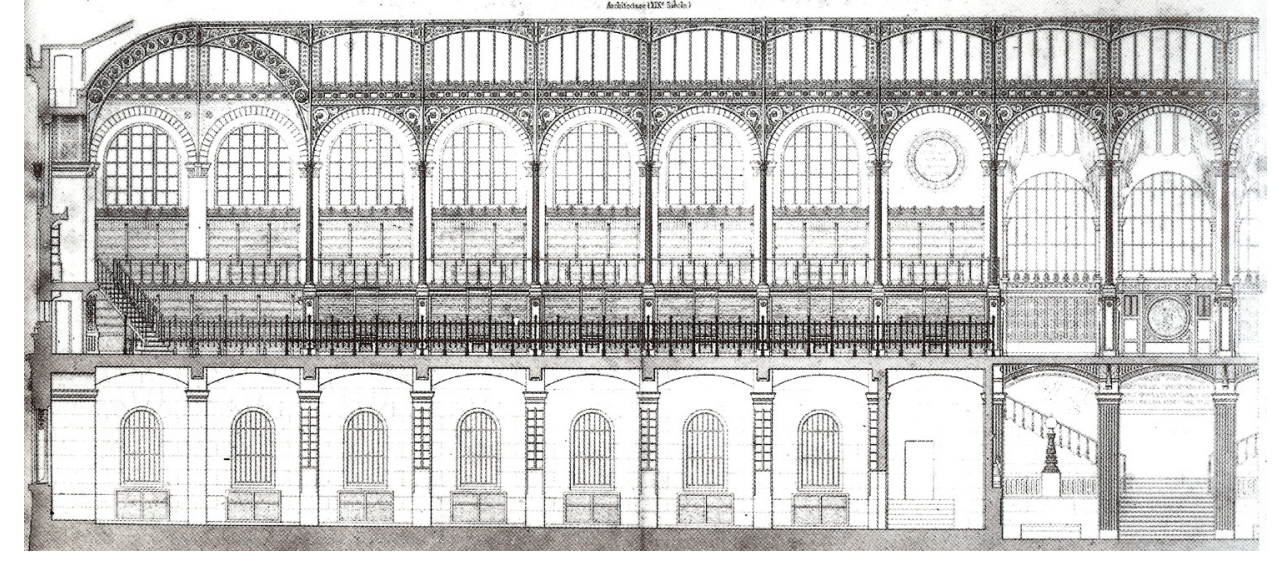


Theory of Architecture and Labrouste's Bibliotheque Ste-Genevieve, explains the Romantic Movement as a rethinking of architectural craft acknowledged by the Gothic, into an approach which could be literary. ${ }^{43}$ Levine wrote of Hugo's message:

In the future, buildings would be literary in form and resemble books. Whereas books had once been verbal constructions, now buildings would become a form of imprinted matter. ${ }^{44}$

Henri Labrouste appears to have taken this textual influence literally in his design of the Bibiothèque SteGeneviève in which he used Gothic architecture as inspiration for a "new tectonic expression"45 (refer Figure 7) Labrouste, who was in close association with Victor Hugo during his writing of Notre-Dame, had been both a student and teacher at the famous École des Beaux Arts school of architecture. The Bibiothèque Ste-Geneviève was his first significant commission and the design of this occurred in 1838, six years after the publication of Notre-Dame, marking the first notable architectural reflection of Hugo's ideas. Labrouste had drawn similar conclusions to Hugo about the future of architecture. ${ }^{46}$ Unlike the classical architecture which Hugo criticized, Labrouste's design of the building did not conceal its uniform bareness with "superfluous pediments." ${ }^{47}$ His primary intent was to design a library which had the appearance of a book. ${ }^{48}$ In Levine's description of the design the "decoration seems to be appliquéd or printed on the surface, and the repetitive and mechanical quality of it gives one the impression of looking at a sheet of newsprint." ${ }^{49}$ The exterior decoration of the building is focused on a chronology of 810 authors' names inscribed onto the façade - a "monumental catalogue" ${ }^{\text {"50 }}$ which physically represented the authors whose books were contained within. The inscribed façade forms the three public faces of the building and back onto the shelving inside which contain the authors' books: "Labrouste considered the stacked books to be the principle ornament of the interior of the Bibiothèque." "51 Further to this "bookish" 52
Figure 8: Bibiothèque Ste-Geneviève, longitudinal section of western half.

In: The Beaux-Arts and Nineteenth-Century Architecture, ed. Robin Middleton (London: Thame and Hudson, 1977). 168.

43. McLaren, "Under the Sign of the Reproduction," 98.

44. Neil Levine, "The Book and the Building; Hugo's Theory of Architecture and Labrouste's Bibliothequ Ste-Genevieve," The Beaux-Arts and NineteenthCentury Architecture, ed. Robin Middleton (London: Thames and Hudson, 1977) 154.

45. McLaren, "Under the Sign of the Reproduction," 98.

46. Drexler, ed., The Architecture of the Ecole Des Beaux-Arts 357.

47. Levine, "The Book and the Building; Hugo's Theory of Architecture and Labrouste's Bibliotheque Ste-Genevieve," 155

48. Marvin Trachtenberg and Isabelle Hyman, Architecture, from Prehistory to Post-Modernism :The Western Tradition (N.J: New York: Englewood Cliffs, 1986) 480.

49. Levine, "The Book and the Building; Hugo's Theory of Architecture and Labrouste's Bibliotheque Ste-Genevieve," 155

50. Levine, "The Book and the Building; Hugo's Theory of Architecture and Labrouste's Bibliotheque Ste-Genevieve," 156

51. Paul Walker, "Semiotics and the Discourse of Architecture,” University of Auckland, 1987, 225.

52. Trachtenberg and Hyman, Architecture, from Prehistory to Post-Modernism :The Western Tradition 447. 

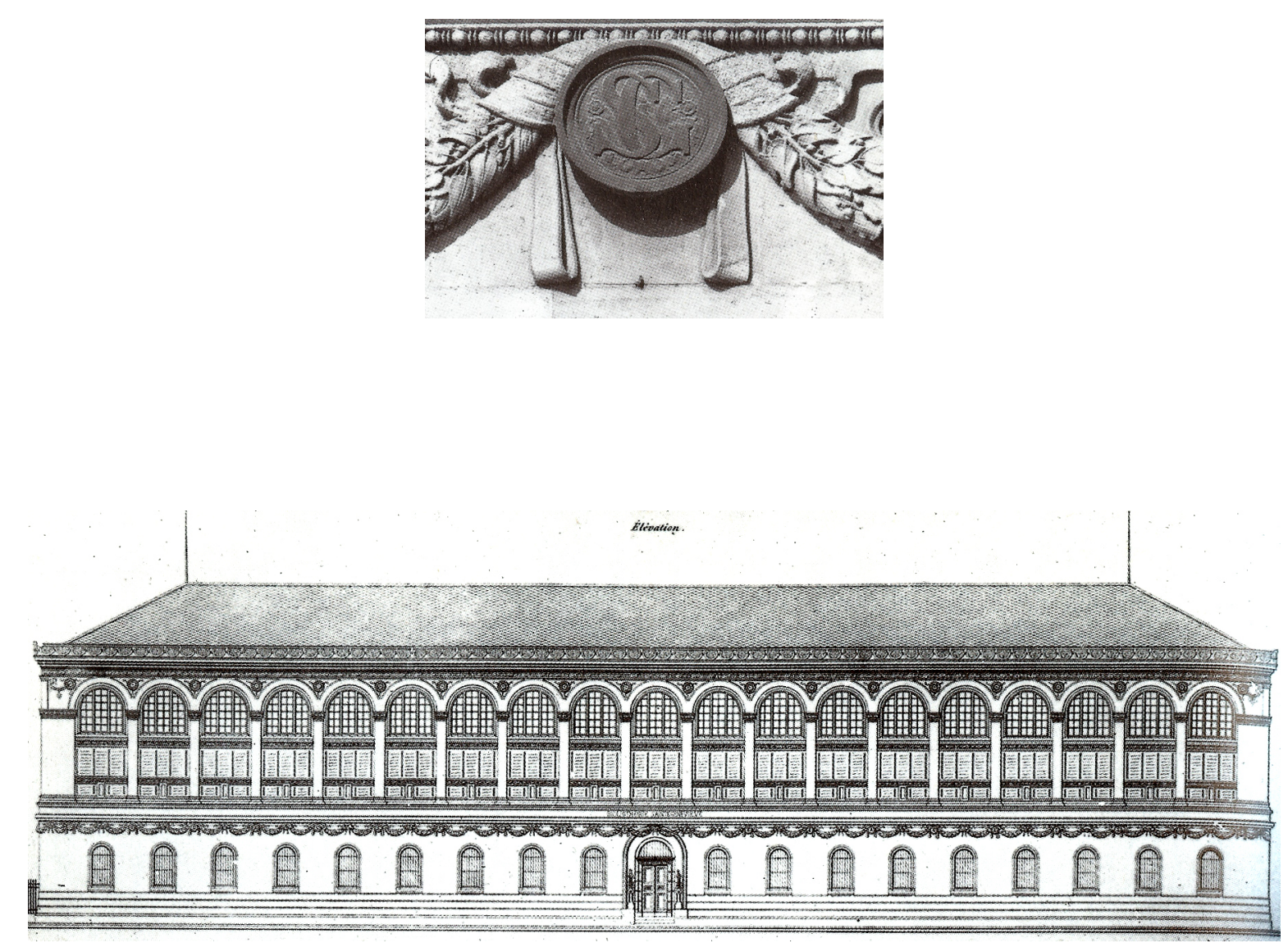
façade, the spaces within the building are also said to unfold "like the pages of a book." ${ }^{, 53}$ Labrouste's design of the building was drawn using sectional views (refer Figure 8) which reinforces the layering up of information within the building; the walls form the pages of the book which progressively reveal more information. The exterior form of the building binds these layers together in a continuous, rigid surface. This is lined on the ground floor of the façade with a row of punctuation, black iron disks imprinted with the SG of the library's book-stamp: "a black deposit on the surface like print on paper and stamps the building as a book" ${ }^{, 54}$ (refer figures 9,10).

The way in which Labrouste endowed the Bibiothèque Ste-Geneviève with meaning was, at that time, both quite radical and novel. His very literal translation of ideas of text into his design could be regarded as simply a response to the building programme - a library. However, given the timing of the project, and in reflection of other libraries designed in the previous decade, ${ }^{55}$ it is reasonable to consider this building an indication of the influence of Hugo's text on the architecture of the period. Labrouste's intentions with the building were clearly in parallel with Hugo's thoughts communicated in Notre-Dame de Paris; however, the design response does suggest a limited interpretation of his ideas. Hugo believed that Gothic architecture served as an important cultural representation and, therefore, supported architecture returning to a reflection of Gothic ideas. The Bibiothèque Ste-Geneviève embraced this, taking inspiration from Gothic through a literal approach, "The book of the Gothic cathedral was, in this case, a metaphor for the building". ${ }^{56}$ Labrouste's design was a physical display of his support of the literary potentials of architecture. Nonetheless, the general understanding of Hugo's views was somewhat partial at the time and hence the architectural response sought a literal translation from text to building.

Although it can be acknowledged that Notre-Dame de Paris had a great impact and popularity with both students and practitioners at the time, and that this design by Labrouste was a reflection of Hugo's novel, the translation
Figure 9: (top) Bibiothèque Ste-Geneviève, cast-iron imprints of the library's monogram.

Figure 10: Bibiothèque Ste-Geneviève, facade. In: Middleton, ed., The Beaux-Arts and NineteenthCentury Architecture, 155, 166.

\footnotetext{
53. McLaren, "Under the Sign of the Reproduction," 98

54. Levine, "The Book and the Building; Hugo's Theory of Architecture and Labrouste's Bibliotheque Ste-Genevieve," 155

55. For example: Schinkel's National Library of Berlin (1835), Visconti's projects for the Bibiothèque Nationale (1829), Jules de Joly's Chambre des Députés (1828-38).

56. McLaren, "Under the Sign of the Reproduction," 98.
} 
of ideas into design appears very limited. It is possible to conclude from this that greater exploration of the translation of Hugo's ideas could produce responses which do not present such a literal representation.

\section{Architectural Treatises and a Critique of Classicism}

A further understanding of Hugo's ideas was developed late in the nineteenth century which suggested that his words be interpreted as purely a criticism of classical architecture, not architecture as a whole. ${ }^{57}$ Lewis Mumford, an American historian and literary critic, acknowledged this anti-classical understanding of Hugo through a different interpretation of the implications of the printing press:

The real misdemeanour of the printing-press, however, was not that it took literary values away from architecture, but that it caused architecture to derive its value from literature. ${ }^{58}$

In saying this, Mumford was criticising the fact that the printing press encouraged architecture to be designed "by the book", ${ }^{59}$ referring to the printed architectural treatise of the Renaissance. "Renaissance architectural design is based on the imitation, with varying degrees of creative license, of a certain number of ancient models.",60 An architect was considered great if he knew the theories of Palladio, Vignola and Vitruvius well and could demonstrate this in his buildings through accuracy and symmetry. This meant that the architect would need to own these books in order to perform the imitation of these models.

Prior to the printing press, the only reliable way in which an architect could view a building was to physically go and see it, which undoubtedly imposed considerable constraint on the spread of trends in architecture. The invention of the printing press provided a significant boost in the effectiveness of communicating design
57. Levine, "The Book and the Building; Hugo's Theory of Architecture and Labrouste's Bibliotheque Ste-Genevieve," 141

58. Lewis Mumford, Sticks and Stones: A Study of American Architecture and Civilization, 2nd ed. (New York: Dover, 1955) 41.

59. Mumford, Sticks and Stones: A Study of American Architecture and Civilization 42

60. Carpo, Architecture in the Age of Printing 6.

61. This constraint was eased slightly for early Renaissance architects as they were able to access woodcuts which provided reproductions of images However these images were often not intended for reproduction and it was not until the introduction of the printing press that the spread of these images became much more viable 
precedents. Architectural theory was developed to be more appropriate for the new printed communication; the Renaissance theory of the five architectural orders underpinned the ideas of the treatises. The five orders (Tuscan, Doric, Ionic, Corinthian, Composite) was a system which provided a standardised catalogue of components for architectural design: "every element in this system was designed for being reproduced wholesale and then assembled or reassembled with other matching elements." ${ }^{, 62}$ The architect's limited creative licence which came as a result of this system was acceptable at the time; the system represented a pedagogical intent of producing middle range building professionals who could make available "normaliz[ed] world architecture via an illustrated manuscript." ${ }^{63}$ Mumford relates this to rules of linguistics: "the Five Orders became as unchallengeable as the eighty-one rules of Latin syntax." ${ }^{, 64}$ Architecture became a standardized language as repeatable as words on a page. As a result of this commitment to architectural text, buildings lost variety and originality - "Classicism became the 'imperial' death mask." ${ }^{65}$ Mumford is suggesting that Hugo's assertion 'Ceci tuera cela' was in fact suggestive that print would kill the vitality of architecture by means of neo-classicism.

Mumford's literal twist of Hugo's anticlassical intentions was particularly favoured by Frank Lloyd Wright. Notre-Dame de Paris made a great impression on Wright and he saw the novel as paving the way for modern architecture. ${ }^{66}$ The extensive availability of the classical treatises meant that architecture, according to Mumford, "became a mere matter of grammatical accuracy and pronunciation." course, did not favour as he saw classical buildings as bland replicas, referring to them as having "nothing remain(s) but the impassive features of a dead face. ${ }^{968}$ This description of classicism clearly does not align with Hugo's desires for architecture, which he hoped would reflect society's developing attitudes and attainment of knowledge.
62. Carpo, Architecture in the Age of Printing 7.

63. Carpo, Architecture in the Age of Printing 7.

64. Mumford, Sticks and Stones: A Study of American Architecture and Civilization 42.

65. Levine, "The Book and the Building; Hugo's Theory of Architecture and Labrouste's Bibliotheque Ste-Genevieve," 141

66. Levine, "The Book and the Building; Hugo's Theory of Architecture and Labrouste's Bibliotheque Ste-Genevieve.” 141.

67. Mumford, Sticks and Stones: A Study of American Architecture and Civilization 42.

68. Frank Lloyd Wright, The Future of Architecture (New York: New American Library, 1953) 98. 
Hugo supported a rejection of classicism as he believed it would result in limited and repetitive architectural responses which lacked creativity. The spread of this 'catalogued' architecture relied heavily on the printing press, which links Hugo's concerns of a future of classical architecture with the proliferation of printed architectural treatises. This concern validates the intention of this thesis to further explore an architectural response to Victor Hugo's ideas in Notre-Dame de Paris. Hugo's popularity and influence was immense, and although responses to his ideas reflect this influence, the significance of his work justifies further exploration. In Part Two further exploration will occur by establishing ways in which Notre-Dame de Paris can be 'read' and re- 'written' in order to produce architecture in a contemporary theory-based context 


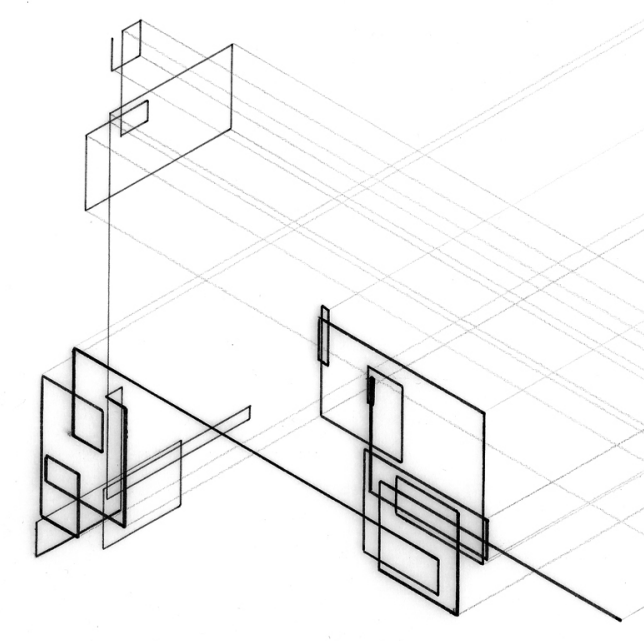





\section{Part Two}

Analysis 


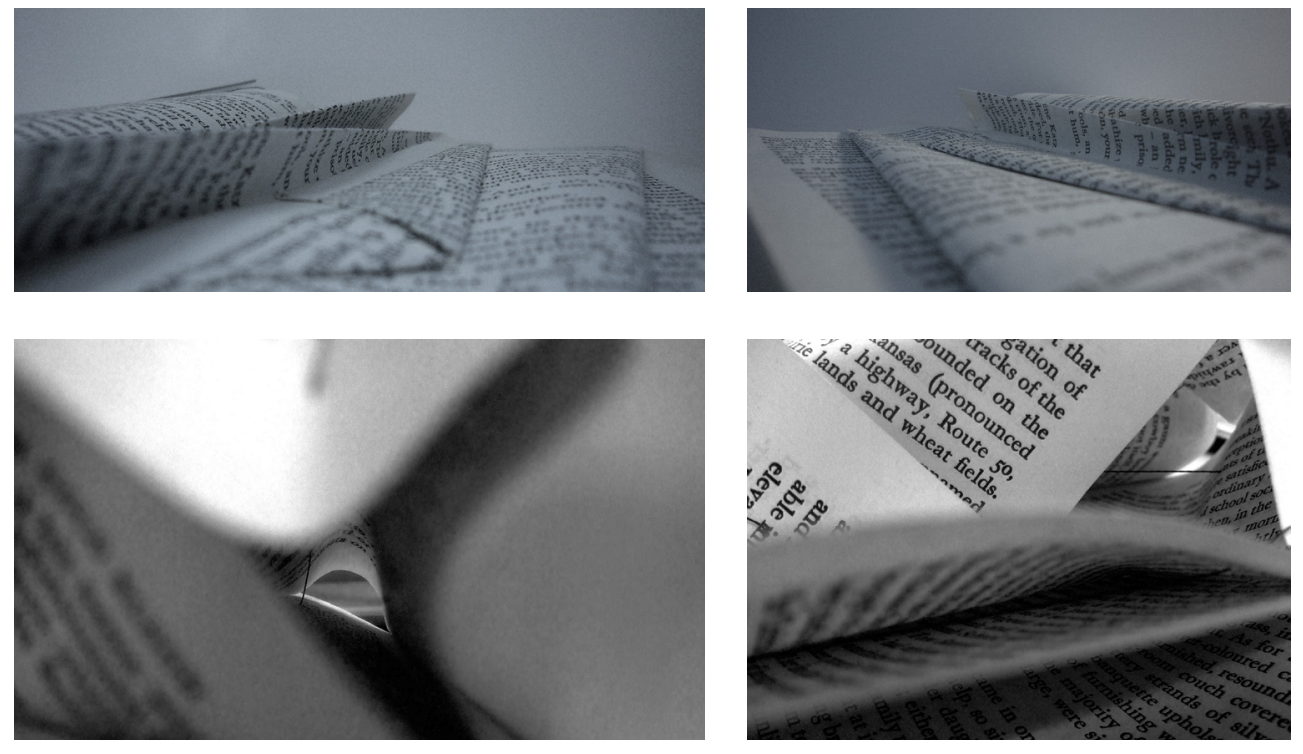




\section{Part Two}

\section{Introduction}

Reading of Victor Hugo's Notre-Dame de Paris provided the opportunity to explore the validity of print as an experimental tool for architectural research and design. Part Two - Analysis pursues this opportunity in a contemporary context. By investigating the presence of architecture in fictional writing it is confirmed that the author constructs architectural space with their text. The author is an architect. The reader forms a personal understanding of this space through the experience and interpretation of the author's design. However, the author is not the only designer in this relationship. The reader too has inherent control over the architecture constructed within a text. The author sets up a framework, while the reader endows the text with its meaning, through their own personal reading and understanding. It is this author-reader relationship which holds such vast access to the imagination and which I suggest has great potential to the exploration of simultaneously real and imagined space and how this space can be represented.

The following section looks at a range of contemporary figures relevant to this research, in order to discuss varied ways in which authors allow the reader to enter into a creative mode of imaginative participation. The initial section 'Reading Architecture' considers the theories of Roland Barthes and Michel Foucault, followed by the work of architect Jane Rendell, in order to form an understanding of the importance of the reader and a questioning of the author. The subsequent section, 'Writing Architecture', shifts the investigation into a study of application of these ideas through the work of Katja Grillner with the assistance of theory from Walter Benjamin.

Figures 11-14: Early design explorations. Creating space within the pages of a novel. 

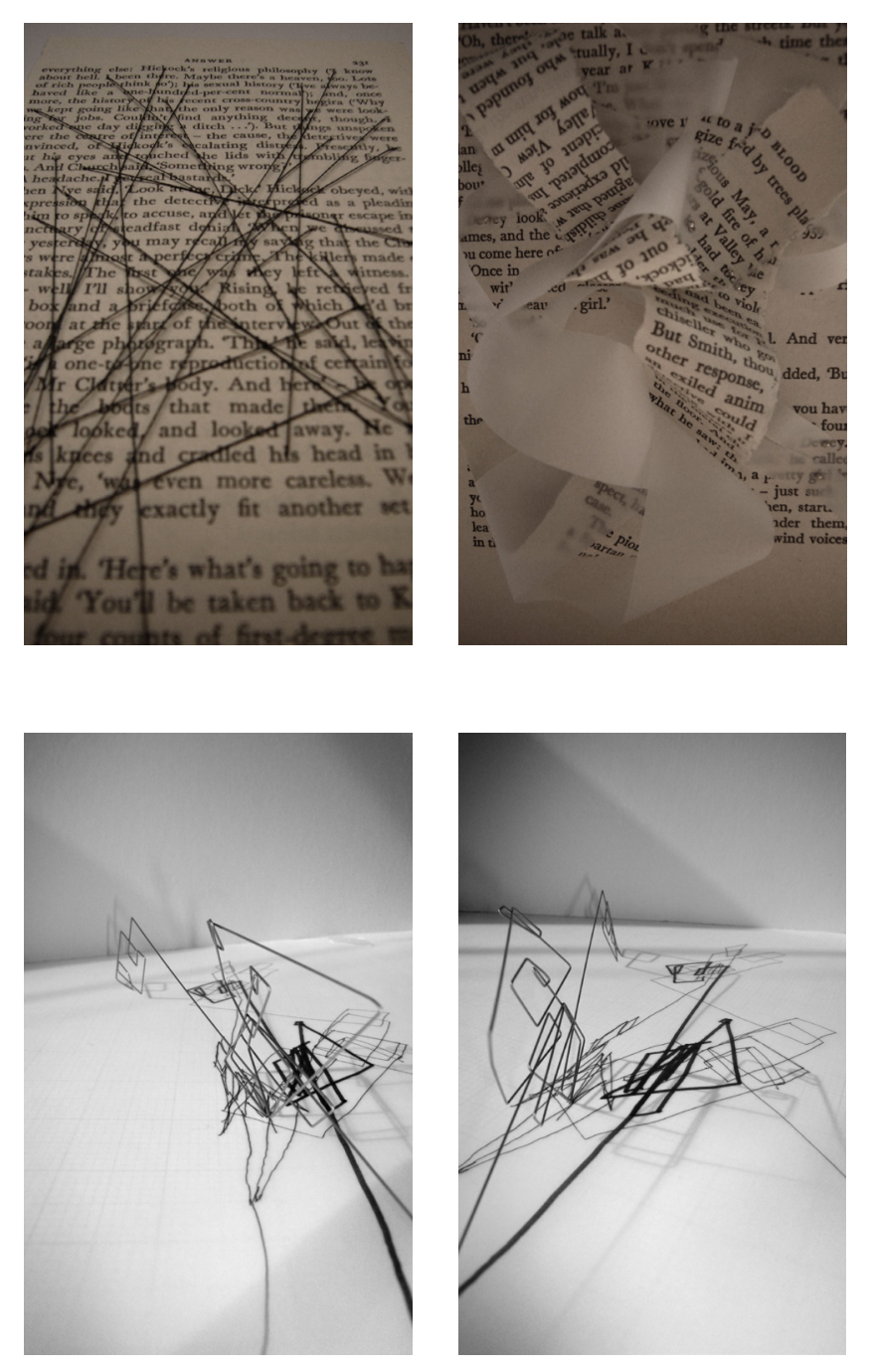
The position formed within 'Writing Architecture' provokes a challenge of the output of a research by design thesis. The idea of text as a design tool is developed and explored through my own personal experimentation with writing architecture. A discussion precedes this, which evaluates my goal to engage the reader in the architecture of my textual exploration. The theoretical framework established in this section and the subsequent experimentation with text, forms a solid foundation by which to shift into a design realm - to be explored in Part Three - Reflection
Figures 15, 16: (top) Exploring character and space relationships.

Figures 17, 18: (bottom) Early design experimentation representing the build up of knowledge which occurs while progressing through a text. Own photographs. 


\subsection{Reading Architecture}

\section{Roland Barthes}

In one of his most notable and influential pieces of writing, The Death of the Author, Roland Barthes identifies

the author as a uniquely 'modern figure' created by society:

The explanation of a work is always sought in the man or woman who produced

it, as if it were always in the end, through the more or less transparent allegory

of the fiction, the voice of a single person, the author 'confiding' in us. ${ }^{69}$

Barthes' essay, first published in 1967, suggested that society attempted to find the answer in contemporary

literature by looking towards the author and his or her passions, history and beliefs. In doing this, the text is limited, closing down opportunities in the multiple layers of meaning associated with that text. Instead, by liberating the text from the author there are no longer permanent or privileged meanings; an understanding can be formed that explores ideas wider than the author's (or 'scriptor's') fixed intentions. ${ }^{70}$

It is the writing that makes an author, as opposed to the author who creates the writing. Barthes argues that the author does not hold complete authority over the text as there are many influences which manipulate their output and intentions. For Barthes, it is the reader, not the writer who endows a text with its meaning. ${ }^{71}$ The author, in this understanding, exists only as the producer of the text which in turn creates the author, and once this is released to the reader the author has no control or authority over its reception. This line of thought introduces the notion that the reader inherits control over their own personal reading of the text. In reading Barthes' essay, the 'author' is understood not only as the writer or producer of textual output, but of a range of media: including the author of architecture - the architect.
69. Roland Barthes, "The Death of the Author," trans. Stephen Heath, Image Music Text, 1st ed. (London: Fontana/Collins, 1977) 142

70. "We know now that a text is not a line of words releasing a single 'theological' meaning (the 'message' of the Author-God) but a multidimensional space in which a variety of writings, none of them original, blend and clash. The text is a tissue of quotations drawn from the innumerable centers of culture." Barthes, "The Death of the Author," 146.

71. Tim Anstey, Katja Grillner and Rolf Hughes, eds. Architecture and Authorship, vol. 1 (London: Black Dog Publishing 2007) 7. 

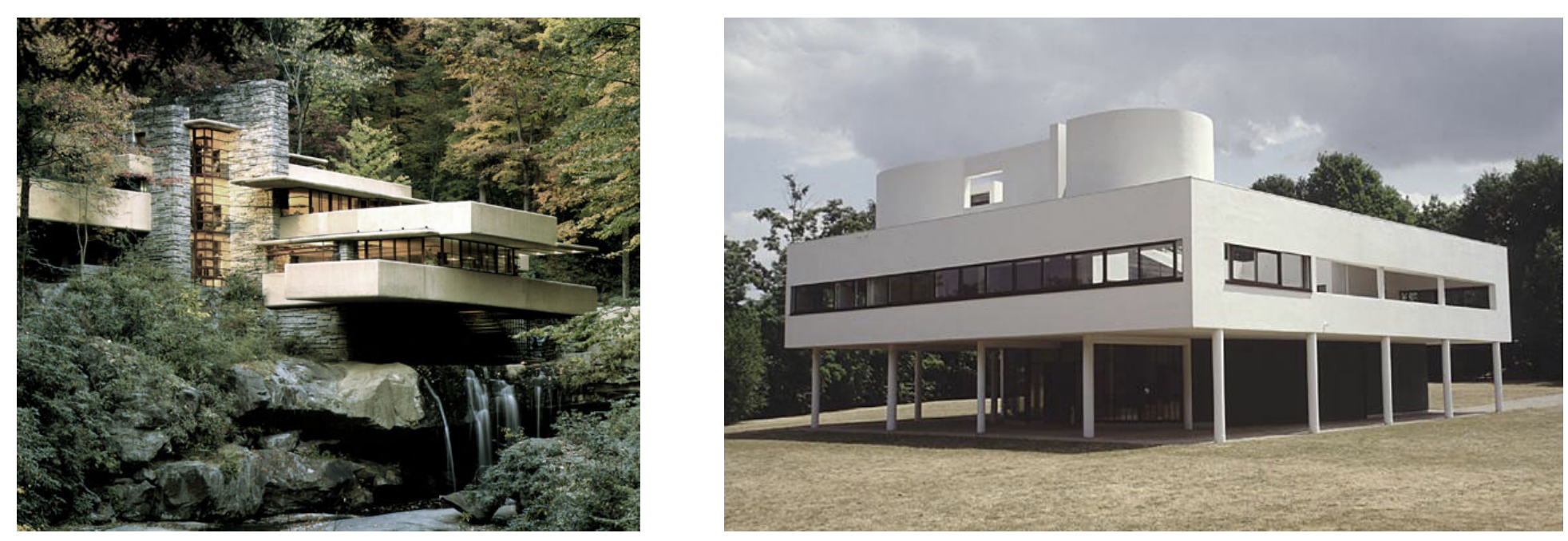
In 1969 French philosopher Michel Foucault wrote What is an Author? effectively in response to Barthes' earlier work. Here Foucault does not disagree with Barthes, but examines how it is that an author exists. Foucault assesses the function of the author (or 'author-function') as a means of providing description and significance - the author's name is functional in its ability to provide classification. ${ }^{72}$ The author's name may also provide a standard of superiority. For instance, Shakespeare being a measure against which other writers are judged. Foucault suggests that the 'author' is never entirely dead; they themselves contribute somewhat to the interpretation of the text as a result of association. If, however, the author does not hold the 'author-function' which Foucault identified, then it can be assumed that the author never existed; the meaning lies solely with the reader. The design of architecture is a form of recording or representing an idea formed by the architect. Once it is designed the meaning generally no longer relies on the designer and their presence in the design fades. There is only a very small minority of buil architecture in which the architect maintains a level of 'author-function' for both an ongoing period of time and over the majority of the 'readers'.

The rarity of the 'author-function' in architecture should not be seen as negative. Like written text, buildings are read in multiple ways, not limited by the architect's design intentions. Although, ultimately, the meaning is provided by the reader, the voice of the author (architect) can translate at varied degrees to the reader. Professor Jane Rendell, of the Bartlett School of Architecture, writes:

The way a writer positions herself in her writing is architectural and has implications for the way in which the writer meets the reader. Certain forms of writing make walls, others create meeting points; some stories close down possibilities for discussion, while others invite participation. ${ }^{74}$
Figure 19: (Left) Frank Lloyd Wright's famous Fallingwater House.

In: Fallingwater pictures: "Kaufmann house above waterfall, Frank Lloyd Wright": http://www. wright-house.com/frank-lloyd-wright/fallingwaterpictures/22SW-path-fallingwater.html. (Accessed 30.10.2010).

Figure 20: Le Corbusier's famous Villa Savoye in Poissy, Paris.

In: Jeffery Howe, "Le Corbusier - Villa Savoye". Boston College, Art on the Web. http://www. bc.edu/bc_org/avp/cas/fnart/Corbuhtml. (Accessed 30.10.2010).

72. Michel Foucault, "What Is an Author?," Critica Theory since 1965, eds. Hazard Adams and Leroy Searle (Florida: University Presses of Florida, 1989) 138

73. For instance, Frank Lloyd Wright's Fallingwater or Le Corbusier's Villa Savoye are buildings in which the architect has maintained a significant presence over the experience and interpretations of the architecture.

74. Jane Rendell, "From Architectural History to Spatial Writing," Rethinking Architectural Historiography, eds. Dana Arnold, Elvan Altan Ergut and Belgin Turan Ozkaya, 1st ed. (Oxon: Routledge, 2006) 142. 
A writer can appear distant or intimate within a text, determining the relationship between writer and reader.

Barthes, in his text The Grain of the Voice, described the position of the author in four ways; 'I', the pronoun of the self, 'he', the pronoun of distance and 'you', as a pronoun of accusation, or to disengage the writer from the subject. $^{75}$

In Victor Hugo's Notre-Dame de Paris, the majority of the novel is portrayed through a third person narrator who maintains a non-participative and omniscient role within the narrative. Past tense is used to relay the narrative in a mostly linear plot structure. Importantly, Hugo appears more intimate and personal within Chapter Two; Book Five, This Will Kill That. This shift occurs at the beginning of the chapter placing the narrator in first person. It engages the reader personally. The chapter opens with: "Our female readers will forgive us if we pause for a moment in order to see what the thought might be that lay concealed beneath the archdeacon's enigmatic words" ${ }^{76}$ In creating this shift in person, the narrator is drawing particular attention to the chapter, capturing the reader's attention by involving them personally. The first person narrative engages the reader by using terms such as 'we' ,'our' and 'us'. In using a plural first person narration, Hugo is attempting to portray the need for a collective understanding of the chapter. The entire first person narrative of This Will Kill That is purely written as an excursus, developing and explaining Claude Frollo's statement "this will kill that", and avoiding any development of the plot whatsoever. In changing between narrative styles Hugo is alternating the relationship between himself and the reader. In this instance he is conditioning the reader, allowing for a more implicit understanding of his ideas. The remainder of the novel is more interpretative in its relationship with the reader.

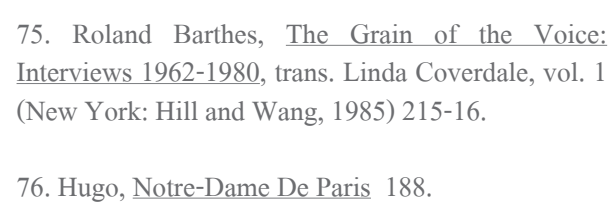




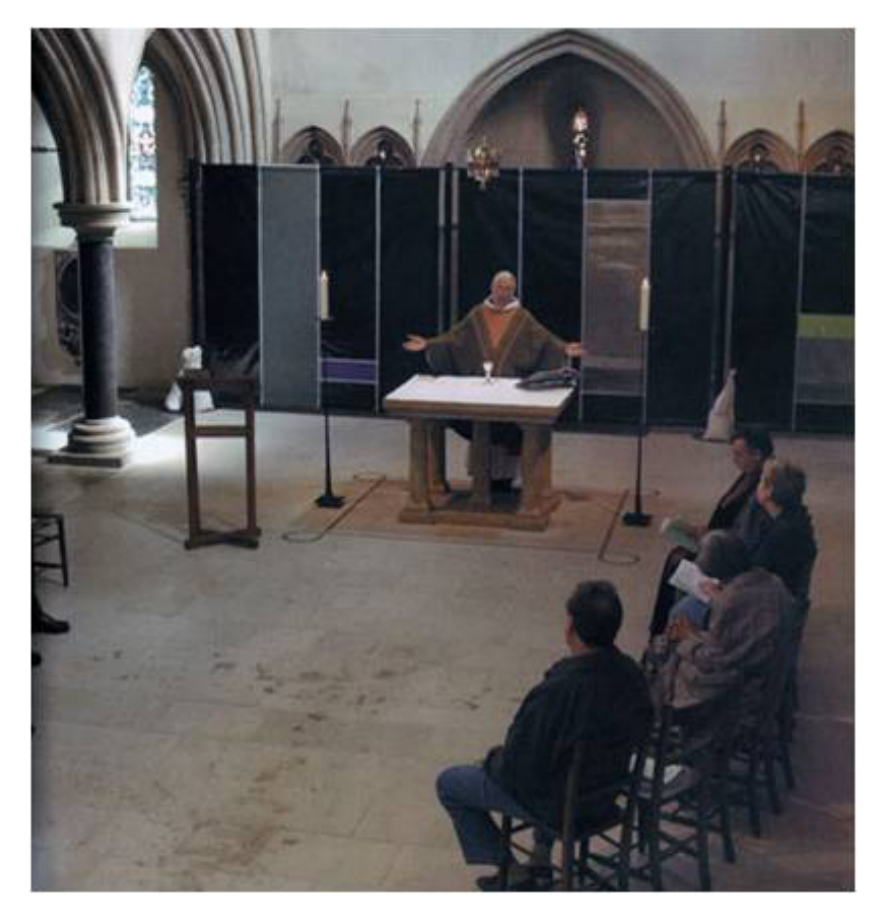


Rendell's experiments with the combining of text and architecture further highlight the importance of the reader to the understanding of text. Rendell produced a piece of writing which discussed a place where she had previously lived. ${ }^{77}$ In the text, her own life was the subject for theoretical reflection. She wrote the piece using first person, emphasising the personal nature of the writing. She experimented in the text using different personal voices from her experiential to intellectual ${ }^{78}$ - which resulted in different responses depending on the reader. ${ }^{79}$ Her peers appreciated the new impression of herself in the text, while those close to her personally took some offence to her words; "The responses I received made me aware that words do not mean the same thing for writer and reader and raised many questions about storytelling. ${ }^{, 80}$ Likewise, the act of telling the story offers further opportunity for the construction of meaning in text. A storyteller may express words in new ways, placing different emphasis which subtly affects and alters meaning. There is an active participation in which the reader must decide when to pause, how long for, whether to "privilege metrical or syntactical breaks." ${ }^{.81}$ The reader and listener build up visual impressions as they progress through the sequence of lines. The atmosphere in which the reader positions themselves can impact their interpretations. In Hugo's time, poetry in particular was generally read silently by a solitary reader. ${ }^{82}$ The silent, solitary reader experiences a state of loneliness which can be related to ideas of death, Lunn-Rockliffe notes; "As there is an implicit parallel between the solitude of the reader and the solitude of the dead, Hugo obliges the reader to share the poet's affinity with death." ${ }^{, 83}$ Not only do the reader's personal experiences and ideas of space influence their personal interpretation of a reading, so too does the nature in which they conduct the reading.

Rendell's writing explores the author's ability to draw on both conscious and unconscious memories, and subjective personal experiences of architecture. Simultaneously, Rendell endeavours to join this with a more
Figure 21: Nathan Coley artwork titled Black Tent In: Jane Rendell, To miss the desert, 2009, London Available: http://www.janerendell.co.uk/to-miss-thedesert, 6 May 2010.

77. Rendell's text is titled Doing it, (Un) Doing it (Over) Doing it Yourself: Rhetorics of Architectural Abuse, in Jonathan Hill (ed.), Occupying Architecture, London, 1998.

78. Jane Rendell stated: "I come to writing as an architect." Her writing is a juxtaposing her persona voice which speaks of experience and emotion, against her academic voice which is conditioned by critical theory. Cited in: Jane Rendell, "Writing in Place of Speaking," Transmission: Speaking and Listening, eds. Sharon Kivland and Lesley Sanderson (Sheffield: Sheffield Hallam University, 2003).

79. Rendell, "From Architectural History to Spatial Writing," 141

80. Rendell, "From Architectural History to Spatial Writing," 141

81. Katherine Lunn-Rockliffe, "Death and the Aesthetic of Continuity: Reading Victor Hugo's Contemplations," French Studies LXII.1 (2008): 17.

82. Lunn-Rockliffe, "Death and the Aesthetic of Continuity: Reading Victor Hugo's Contemplations." Although, Hugo himself suggested that his lyrical work was at its best when read aloud in front of an open fire, accompanied by wine and cheese. As cited in: Edwards, Victor Hugo - a Biography 7

83. Lunn-Rockliffe, "Death and the Aesthetic of Continuity: Reading Victor Hugo's Contemplations," 18. 

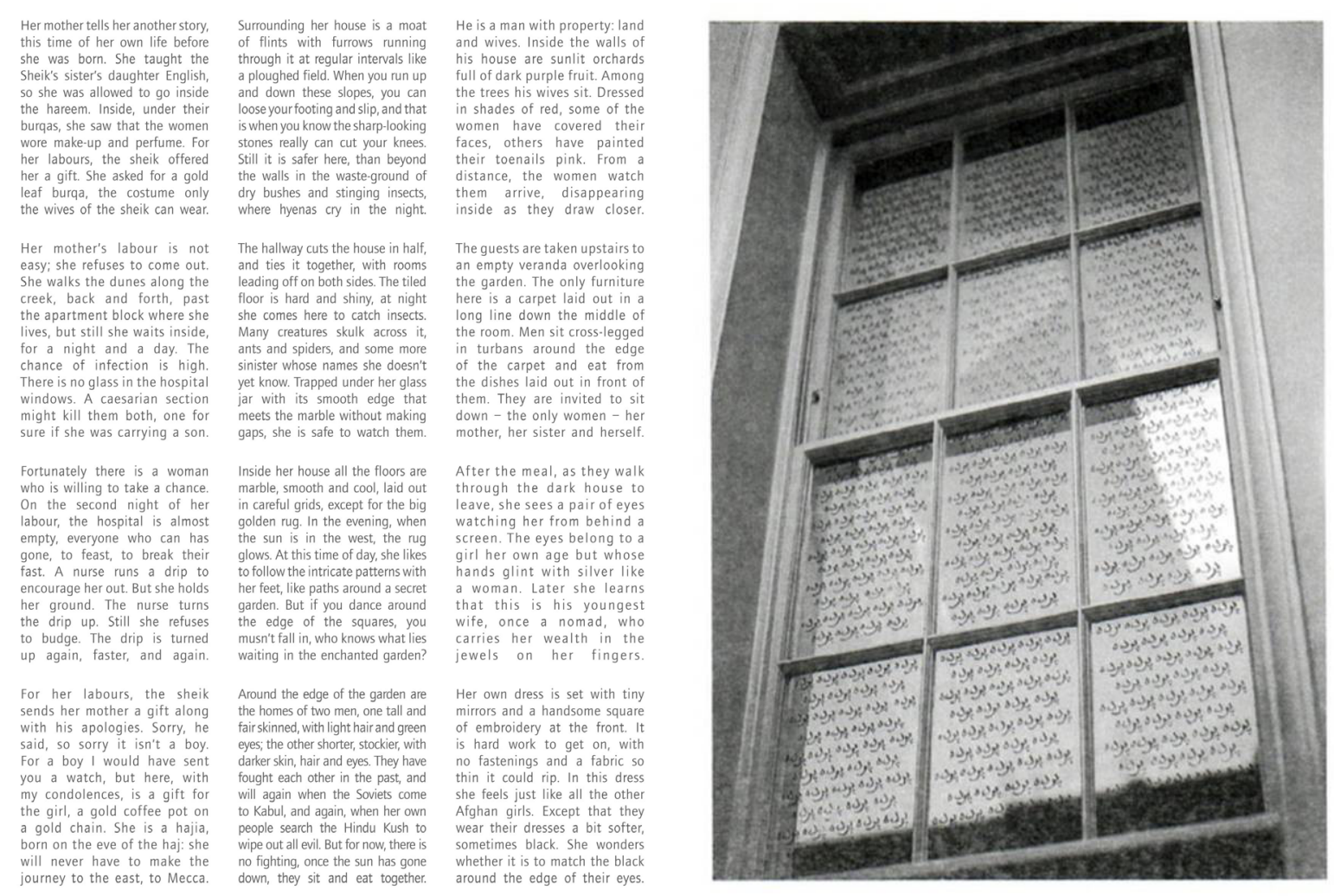
'professional' voice. ${ }^{84}$ An example of this is in her essay titled To Miss the Desert in which she wrote in relation to a work of art called Black Tent by Nathan Coley. She structured the essay to relate both in form and content to Coley's artwork: "The narrative I composed was spatial, like the squares, it had two sides, two voices... The two voices were pitched against one another to create a dynamic between personal and public sanctuary." ${ }^{85}$ As a response to this essay, Rendell later created a gallery installation. For this she used twelve short extracts from the essay and rewrote them as scenes laid out in a grid of twelve, matching a window in the gallery. On the panes of glass she repeated the word 'purdah' in Afghanistan's official languages, Dari and Pashto. The term describes the cultural practice of separating women from the public gaze through the use of veils, screens and walls. Rendell wrote of her installation,

By day or by night, from inside the gallery or from outside on the street, the work changed according to the viewer's position - transparent/opaque, concealing/revealing - this embellishment or decorative covering invited the viewer to imagine beyond the places she/he could see. ${ }^{86}$

Rendell's writing physically created the architecture. It was a result of both her personal, and her trained professional understanding of architecture. By locating the architectural outcome in the frame of a window which is exposed to the outside world, Rendell released it to the reader. The reader ultimately controlled their own understanding of the work

Rendell's approach to develop her writing on architecture into a 'physical architecture' is one that is adopted in this research. Her installation project shows conversion from a written output to a physical creation which further explores the role of the reader, giving meaning to the architecture. In both textual and physical form, Rendell's work invites the reader/interpreter to engage with imaginative interpretation of her architectural design.
Figure 22: (Left) 'An Embellishment', Rendell's presentation of extracts from her 'To Miss the Desert' essay.

Figure 23: 'An Embellishment: Purdah', Rendell's installation for Spatial Imagination in Design 2006 domoBaal Gallery, London. Both in: Rendell, Hill, Fraser and Dorrian, eds. Critical Architecture 158-159.

84. Jane Rendell, Jonathan Hill, Murray Fraser and Mark Dorrian, eds., Critical Architecture, vol. 1,3 vols. (Abingdon, Oxon: Routledge, 2007) 155.

85. Rendell, Hill, Fraser and Dorrian, eds., Critical Architecture 155

86. Rendell, Hill, Fraser and Dorrian, eds., Critical Architecture 157 


\subsection{Writing Architecture}

\section{Katja Grillner}

In her contribution to Jane Rendell's 'Architecture-Writing' strand at the 2004 'Critical Architecture' conference, ${ }^{87}$ Katja Grillner made the point of linking the words of the title to instead read 'Writing Architecture' This change is significant as it suggests that the act of writing can create architecture, rather than just describe or reflect it. Grillner considers that 'Writing Architecture' can provide a way for experimenting with the design and representation of space. Additionally, she proposes that this writing output allows the architectural critic to engage with the architecture, providing a lens through which the analysis occurs.

Of importance to Grillner's work is Walter Benjamin's notion that the experience of architecture is through a distracted and de-focused condition. Grillner perceives Benjamin's comments as representing the challenge which architectural critics face when examining architecture. According to Grillner, Benjamin's 1936 essay 'The Work of Art in the Age of Mechanical Reproduction' argues for the "potential of new media technology to liberate the subject by creating a new mode of perception, a new viewing position that combines distraction, absorption, criticality and distanciation. ${ }^{\circ 8}$ Benjamin suggests that architecture shies away from attentive contemplation and states:

The distracted mass absorbs the work of art... Architecture has always represented the prototype of a work of art the reception of which is consummated by a collectivity in a state of distraction. ${ }^{89}$
87. Held in November 2004 at The Bartlett School of Architecture, University College London.

88. Katja Grillner, "In the Corner of PerceptionSpatial Experience in Distraction," arq: Architectural Research Quarterly 9.3-4 (2006): 245.

89. Walter Benjamin, "The Work of Art in the Age of Mechanical Reproduction," llluminations, ed. Hannah Arendt (New York: Schocken Books, 1936) 239. 

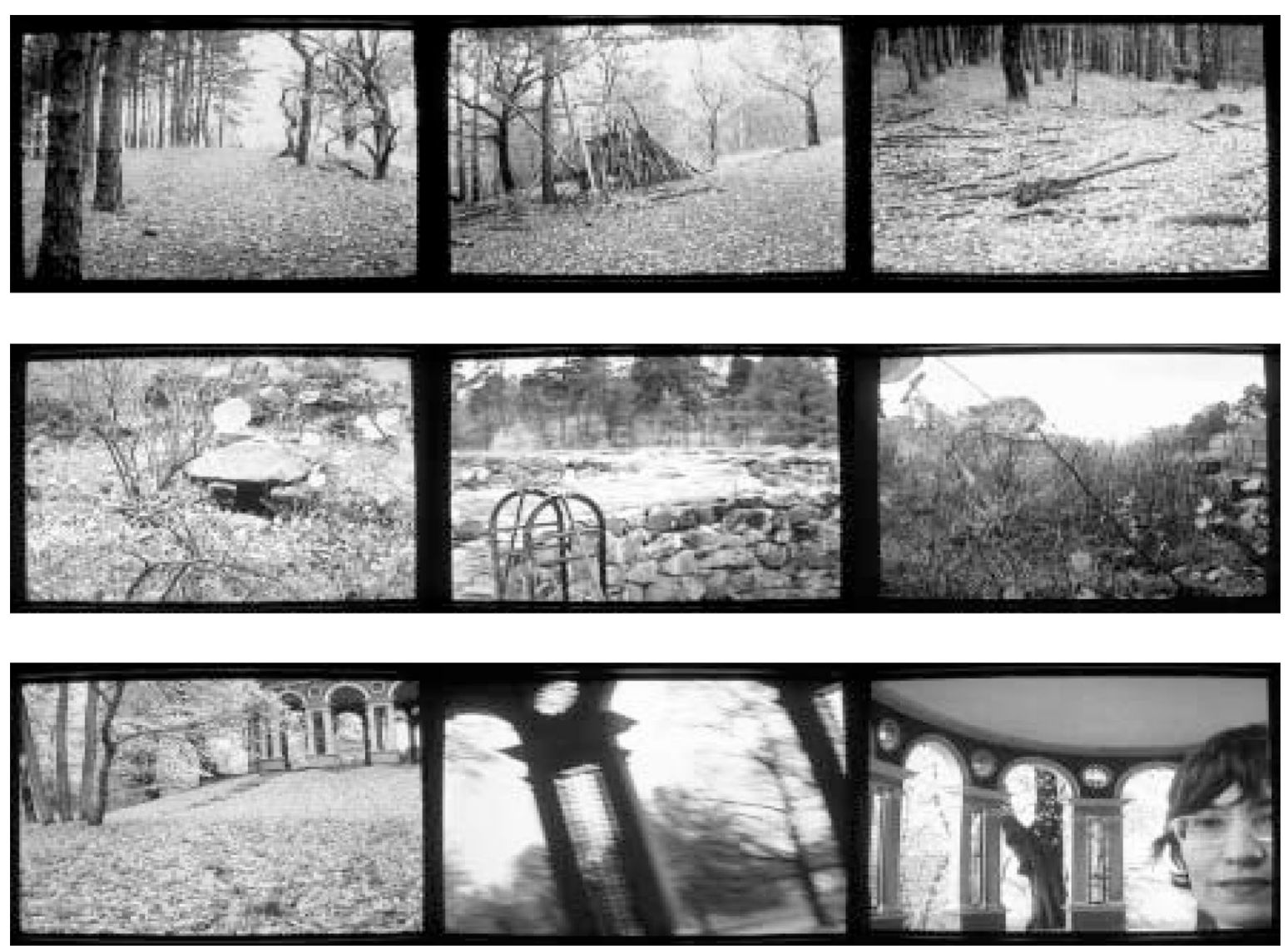
For Grillner, architecture is not an object. Instead it insists on maintaining a perception as a backdrop to our existence. ${ }^{90}$ This can be understood when considering films (as Benjamin suggests), poetry, and also novels. The presence of architecture in these examples is often 'out of focus', while plot and characters are at the forefront. It is these 'out of focus' glimpses of 'architecture' that are most important to our understanding. They place the architecture in a context wider than just the physical built environment. In Hugo's novel, Notre-Dame de Paris, the characters create this "distracted" ${ }^{, 91}$ state for the reader. The characters demand attention from the reader by developing the plot, therefore, causing the architecture to be the backdrop rather than the object. Architecture remains strong as a result of the character's relationship to the Notre-Dame Cathedral. ${ }^{92}$ Hugo's descriptions of characters and events contribute to the reader's experience of the architecture through this de-focused state, reiterating Grillner's application of Benjamin onto the writing of architecture.

Katja Grillner explores in her research the creation of this distracted and defocused experience in order to produce architecture which the architectural critic is able to critically engage with. Grillner wrote an essay titled 'Fluttering Butterflies, a Dusty Road, and a Muddy Stone', in 2004, in which she attempts criticality in distraction by recounting Haga Park in Stockholm. In the text Grillner initially recalls the park from school trips in the late 70s. In the next paragraph she transfers her writing to present day. She continues, throughout the text, to switch between different perspectives; at times a young school girl, or a teenager, and also directly reports to the reader on what her intentions are. Grillner identifies Walter Benjamin's notion of distraction and states that the text seeks to explore the "inside from within". ${ }^{93}$ It is a mode of critical writing that allows for both: "distracted experientia engagement with a particular place and a critical engagement with that same distraction." ${ }^{94}$ Her writing makes use of personal recollection. The park was chosen as the site on the basis of her "rather vague (unimportant) persona memories" ${ }^{\prime 95}$ from her own 'distracted' use of the park earlier in life:
Figure 24: Haga Park. Images by Katja Grillner. These were presented on screens for the installatio she created following the writing of 'Fluttering Butterflies, a Dusty Road, and a Muddy Stone'. The images are stills from a video recording of a visit to the park.

In: Grillner, "In the Corner of Perception-Spatial Experience in Distraction," 249

90. Grillner, "In the Corner of Perception-Spatial Experience in Distraction," 247.

91. Benjamin, "The Work of Art in the Age of Mechanical Reproduction."

92. In particular, the relationship between the Cathedral and the characters: Quasimodo, Dom Claude Frollo and Esmeralda.

93. Katja Grillner, "Fluttering Butterflies, a Dusty Road, and a Muddy Stone: Criticality in Distraction," Critical Architecture, eds. Jane Rendell, Jonathan Hill, Murray Fraser and Mark Dorrian, vol. 1 (Abingdon, Oxon: Routledge, 2007) 139.

94. Grillner, "Fluttering Butterflies, a Dusty Road, and a Muddy Stone: Criticality in Distraction," 139.

95. Grillner, "In the Corner of Perception-Spatial Experience in Distraction," 248 


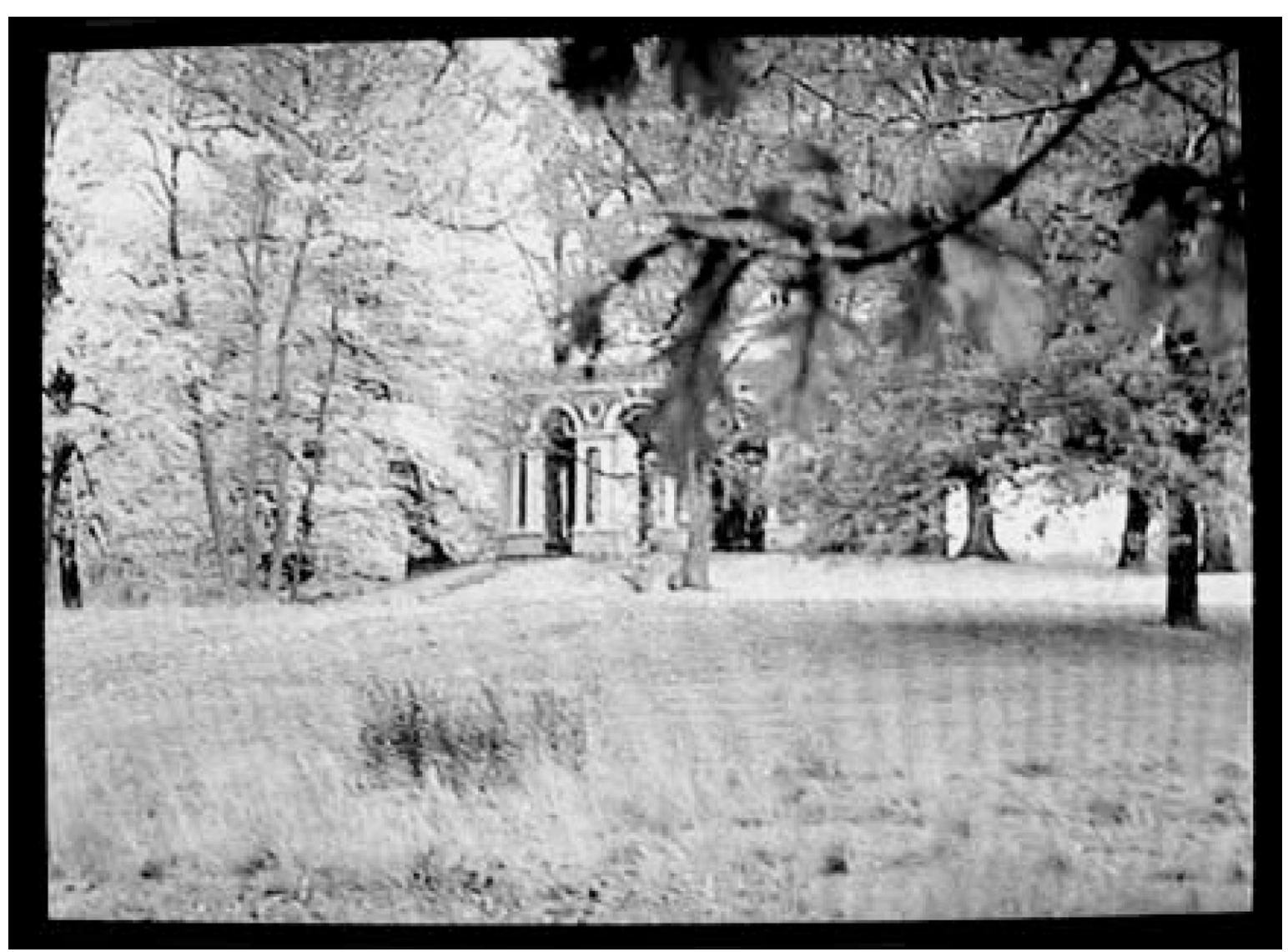


Memories of past use were called forth by writing, in an attempt to 'defocus' the scholarly gaze of the grown-up critic, but also to invite the reader to imagine and simultaneously reflect on the park in terms of distraction. It challenges... the relative 'ease' with which we 'imagine a world without distraction', and which continues to reproduce that idealistic model. ${ }^{96}$

These intentions are apparent through the textual layers. Grillner's writing is compelling. The reader is intrigued by the way in which they are being led through the author's recollections. These impressions skip between remembered and current, drawing the reader into the author's train of thought. Grillner is very honest in her approach. She reveals to the reader her intentions of distracting them within the work and the theoretical basis which this is drawn from. These corresponding layers distract the reader, allowing the space through which the reader can input their own imagination, therefore, forming their own experience of the architecture.

Grillner developed her focus on Haga Park into a spatial installation exhibited in London in 2006. She describes the installation as;

conveying a sensation of a de-focused, distracted, perception through a play with layers of mediation - still images and sound distributed in space. Horizontal light boxes are distributed in the stairwell of the gallery space. These boxes display three triptychs made up from photographs of TV-stills from DV-camera footage filmed in Haga Park... Three settings within this park are presented: The Temple of Echo, the ruins of the never-completed royal palace, and a hut in the woods (Eeyore's House). Listening closely, the sounds of these places (traffic, birds and rustling leaves) and fragments of their stories trickle out. The installation calls for the attention of visual, aural and corporeal senses, while carefully steering away from any sense of a 'complete' or 'whole' experience.
Figure 25: Haga Park. Images by Katja Grillner. This image was also part of the installation. In presenting these as photographs taken directly from stills of video footage, Grillner is achieving a surveillance camera aesthetic.

In: Grillner, "In the Corner of Perception-Spatial Experience in Distraction," 250 .

96. Grillner, "In the Corner of Perception-Spatial Experience in Distraction," 248.

97. Grillner, "In the Corner of Perception-Spatial Experience in Distraction," 248. 

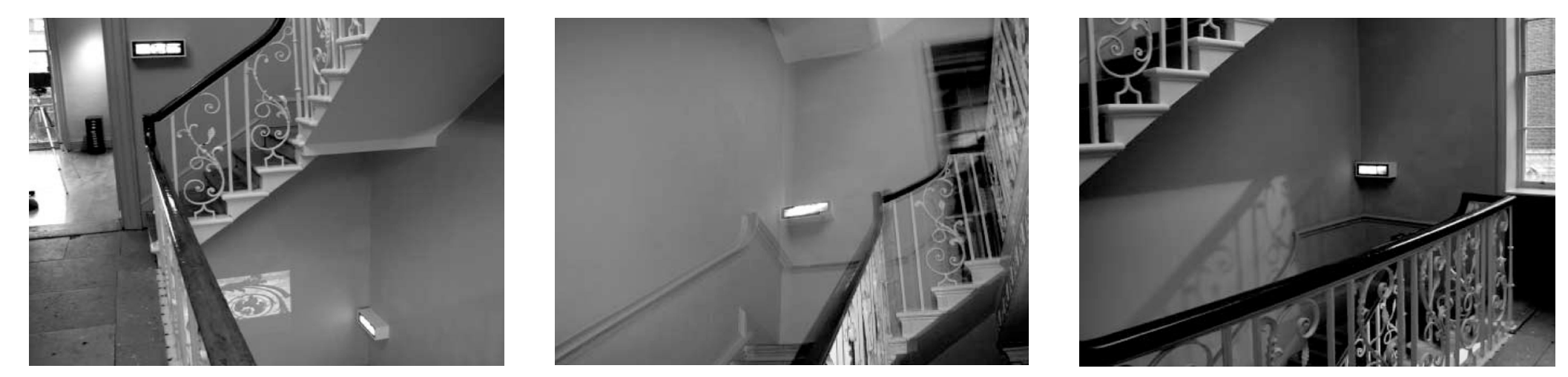
Grillner set the sound leaking out of the light boxes to a volume that was not easily heard from afar. Instead, they invite concentration. There are two separate tracks; first, the background noises taken from the video recording of the site. These give a temporality to the still-images presented in the boxes. The second track of sound is a reading of Grillner's essay. By combining these multiple tracks of sound Grillner develops the atmospheric qualities of the space within the essay. The background sounds operate in a similar way to Grillner's approach to writing the essay. It provides another layer in which to develop de-focused attention to the architecture. Combining these layers of sound with images creates a space that could be anywhere, for the viewer, both fictional as well as real. ${ }^{98}$ By carefully presenting an experience which maintains space for imagination and interpretation, there is a fictional quality created within the installation.

The additional layers of mediation provided by the installation are able to move the experience away from its very autobiographical foundations within the text. The fragmentation of sound and image distance the author and the viewer/listener, requiring further concentration. In doing this, Grillner creates a representation of the distracted and de-focused architectural experience. She developed her account of Haga Park through several conversions. It shifts from an essay of 'written' architecture to a spatial experience portraying her account of the park.
Figure 26: 'out of focus (in distraction)'. Installation by Grillner in the Spatial Imagination group exhibition, Gallery domoBaal, London 2006.

In: Grillner, "In the Corner of Perception-Spatial Experience in Distraction," 245-6.

98. Katja Grillner, Abstract: Writing Architecture out of Focus, 2004, Available: http://www.bartlett.ucl. ac.uk/architecture/events/conferences/grillner.htm, 20 August 2010. 


\subsection{The Role of Text in Research by Design}

The concept of 'Writing' Architecture, which Grillner adopts, leads me to challenge what the Architecture 'Research by Design' thesis actually is. Typically, a thesis by research produces a formal, critical text. The thesis by design produces a work of design, or art, along with a formal, critical text which provides a background, explanation and reflection on the piece of art produced. This format begs to question an overlapping between these different outputs - can the design/art work actually be presented through a textual artefact, for instance a piece of creative writing? Is the act of writing not in itself a form of creative exploration? This research explores text as a design tool, proposing that the writing created on a local hall building creates architecture for the reader.

According to Grillner, the traditional thesis "appears to consider the text as a stable and perhaps also more objective or critical medium than the art work. Unless the artist in question works with specifically textual works, writing in itself is not expected to be explored as an experiential medium." ${ }^{, 99}$ However, writing can provide an alternative approach to establishing a critical perspective in design. Grillner explored the textual artefact in her $\mathrm{PhD}$-dissertation Ramble, linger, and gaze - Dialogues from the landscape garden, and says of the work: "It may well read as a novel, but the demands and expectations arising from the academic context of its production, has furnished it with different vehicles for critical distanciation: the dialogue is furnished with endnotes, a post-script, a bibliography..." ${ }^{100}$ This unique approach to a dissertation provides another realm of opportunity in exploring ideas and communicating them for interpretation. In Grillner's work the access to creativity and complexity is immense when approaching the text like an author might approach the writing of a novel. Simultaneously, the theory and logic is inherent in the text as a result of the process undertaken in the production of a thesis.

99. Katja Grillner, "The Textual Artefact in Research by Architectural Design," Working Papers in Art and Design 3 (2004)

100. Grillner, "The Textual Artefact in Research by Architectural Design." 
Writing provides another tool for exploration and experimentation when developing a research project. Text and language are design materials. The textual artefact allows for the layering of objective and subjective ideas, reflecting the designer's understanding of space both in physical and imaginative terms. 'Imagined' space and 'real' space are able to exist simultaneously. ${ }^{101}$ Space can be designed through the textual artefact and language can then be used in order for the designer to shift into the role of the critic: "By developing a critical perspective on her or his work, the author/architect behind a project invites others to participate, not in awe, but in critical discussion. ${ }^{102}$ This forms a significant asset to the research by opening up the opportunities for discussion and emphasising the designer's reasoning through a critical position. Not only can controlled language assist the interpreter's understanding, it helps the designer distance themselves from the work; providing clarity within the complex territory of research. Exploration with tone and reflective approaches to writing allows the designer to analyse their work from a different position. Writing is explored as an experimental medium which produces the textual artefact. This is further analysed through text, at a critical distance from the work.

Jonathan Hill emphasises that the academic site (the thesis), provides space for experimentation and speculation located at an important distance from the practice of architecture. ${ }^{103}$ The outcomes of this speculation do not need to directly influence the practice of architecture. Instead they take a more indirect route by influencing our "habitual ways of thinking architecture." 104 I consider the site of my thesis as accommodating to this approach. The following discussion is in response to an experiment completed for this research that tests the 'writing' of architecture, based on the approach Katja Grillner took in producing her essay Fluttering Butterflies, a Dusty Road, and a Muddy Stone. ${ }^{105}$ Like Grillner, the topic of my 'written' architecture - a community hall nearby where I grew up - was chosen for the experiment because of the vague and seemingly unimportant memories I have of it, which have accumulated over my lifetime.
101. Peg Rawes and Jane Rendell, "Spatial Imagination," ed. Bartlett School of Architecture (London: Bartlett School of Architecture, 2005), vol. 1,3

102. Katja Grillner, "The "Halt at the Door of the Boot Shop"," 0.1 Akad - Experimental Research in Architecture and Design - Beginnings, eds. Katja Grillner, Per Glembrandt and Sven-Olov Wallenstein, vol. 1 (Stockholm: AKAD through AXL Books, 2005) 69

103. Jonathan Hill, "Building a Drawing and Drawing a Building," Nordic Journal of Architectural Research 4 (2002): 19

104. Katja Grillner, "Writing and Landscape - Setting Scenes for Critical Reflection," The Journal of Architecture 8.2 (2003): 246

105. Rendell, Hill, Fraser and Dorrian, eds., Critical Architecture 135-42. 


\subsection{Discussion on Textual Experiment}

The process of creating this piece of 'written' architecture contributes another layer of experience to the space in my memory dedicated to the Tarurutangi Hall. The experiment required spending an extended period of time remembering and re-constructing the spaces and building, to an extent which is not typical of my everyday recollections. It caused for me awareness that the architecture which I created is unique and specific to my life, my influences, and my experiences at the time of writing. Had I attempted this writing five years earlier or later, I believe the outcome would vary significantly. The architecture created in this experiment is also a reflection of me through the style with which I write. The tone and skill of my writing has an impact on its translation of meaning The decisions I made in the placement of words in relation to each other has implications on their understanding "writing constructs as well as reflects meaning." ${ }^{106}$ This is represented through my attempt to draw on thoughts and feelings from different ages, and to reflect this in the manner with which I constructed the sentences.

Of course, to repeat my view, the point at which I completed the writing and passed it onto the reader is the point at which my presence and control over the writing fades into the background. It is the reader who enriches the text with meaning. Because of this I had to determine the extent to which I identify both myself and the architecture within the text. At no point is the regional location of the hall identified. However, given the obscurity of the Tarurutangi district I included the name of the hall (which hints at the Maori significance of the area). My intention was to communicate a personal account of the architecture, both through reflecting my experiences over the years and through my analysis from an academic viewpoint. Simultaneously I sought to provide enough imaginative description to allow the reader space in which they could personally draw their own architecture of the hall. Although I based my writing on the work of Katja Grillner, I did not follow her lead in including

106. Jane Rendell, "Introduction: ArchitectureWriting," Critical Architecture, eds. Jane Rendell, Jonathan Hill, Murray Fraser and Mark Dorrian, vol. 1 (Abingdon, Oxon: Routledge, 2007) 88 


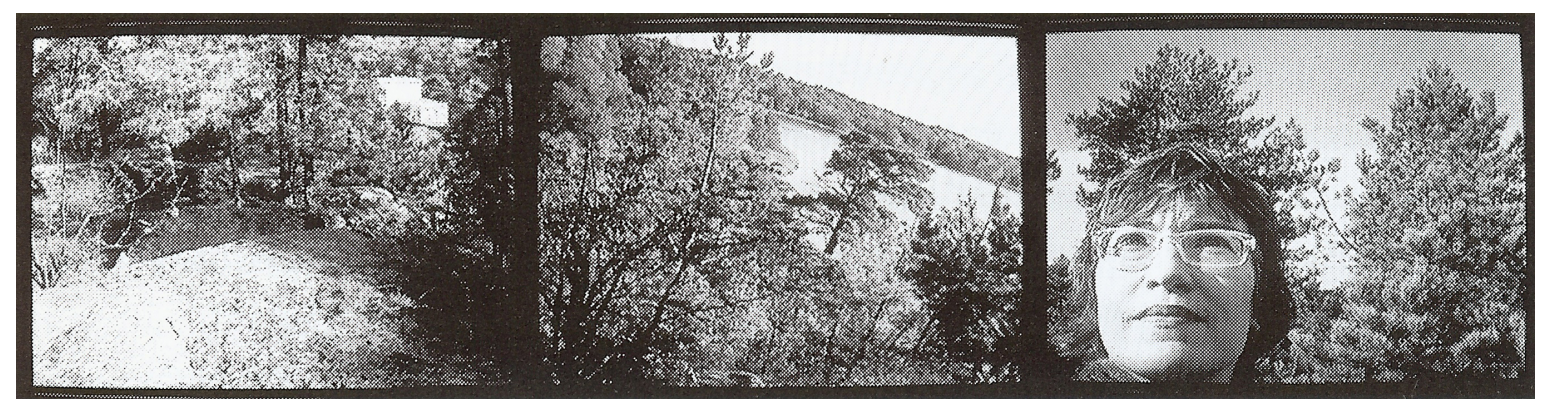


images of the subject. Grillner identifies in her writing the site of Haga Park, which is a fairly well-known and popular nature area in Stockholm. She accompanies her text with images (refer Figure 27) which provide for the reader a visual reality of both the park and the author (confirming her gender). I am proposing that my writing is the architecture. Images do not need to be incorporated into the text because the words are successfully able to generate imaginative engagement with the architecture.

The main presentation of my writing was through a reading to a group of fellow students. The response was positive. Listeners were able to form their own interpretations of the architecture. The group suggested that this was as a result of the limited descriptions of the architecture; for instance they could imagine the concrete steps and metal handrail anywhere in the world. The listeners drew on their own experiences and related them to the experiences described in the text, each creating a unique and personal understanding. Although the reading provided positive results, the form with which the presentation took may well have stunted its success. As identified earlier, the reading aloud of a text can in itself alter understanding. By personally reading my own piece of writing aloud to the group I was able to control the way in which the architecture was verbally presented. If certain words required emphasis then I was able to portray this through my tone or momentum. In addition, existing knowledge of my background could potentially had influenced some of the listener's interpretations of the architecture. As many of the audience members have known me for several years, they may well have had pre-conceived ideas about the environment and location which I was describing. 
2.5 'Writing' Architecture Experiment 


\section{Santa Claus, Concrete Steps and Dirty Feet}

In attempting to write this piece of architecture, I aim to reflect Benjamin's ideas of distraction by translating Tarurutangi Hall into an account informed by use and perception. My own experiences and memories are the primary source of material for creating this account; each experience provides an additional layer to the perception of the building and therefore informs the writing of this architecture. The 1990s: the Christmas parties, Santa Claus with local teenage girls dressed as Santa's helpers, car rallies and Chinese dinners, pot-lucks and quiz nights. 2005: Hall parties, alcohol, friends, cars, dark lighting. 2007: the hall becomes a tool that assists my education; an interest is developed into its history, an analytical understanding. ${ }^{107} 2010:$ I reflect on my 2007 study of the architecture with a developed perspective, identifying flaws and considering my approach in light of Benjamin's theory.

Tarurutangi Hall, December 1993: The annual Children's Christmas Party. Each year, a week or two before Christmas, the Hall Society holds the children's party. As a family we drive in the car, halfway down our road to where the Hall is located. It is at the bottom of the biggest, steepest hill I think I have ever seen (only 
once having attempted to walk it in sweltering heat with my greataunt). We park the car on the grass verge across the road from the hall, lining the roadside alongside other cars from around the area. Cows cluster in the adjacent paddock, showing interest in the gathering taking place. I must hold someone's hand to cross the road. I keep holding to climb the steps - big concrete steps. There are older children milling around the entranceway. I am inside the hall; it has a distinctive smell, and dark wood everywhere. The dusty wooden floor reminds me of the hall by my primary school, where we went to practice our class folk dance for the showcase night, always finishing practice with black soled feet. I sit with my sisters, amongst all the children of neighbouring farms. We are in one corner of the hall - I remember it being big - I am unsure where my parents are and have to check the other three corners to lay eyes on them. My impressions of this evening are formed by other similar community events held here: they merge together in my mind. However, the impressions are clearly focused around three spaces: the grass area outside the hall (amongst the cars, arrival, departure, the beginnings of hide-and-seek with other children), the concrete steps (older children talking - too big for games, perched on the metal handrail), and the front right corner of the hall by the stage (where Santa Claus sits with the children) which
07. In my second year of architecture studies (2007) completed an essay titled Theorizing the Local for ARCH 380, an Architectural Theory \& Criticism paper. The topic of my essay was Tarurutangi Hal and this is drawn on here as a contributor to my experiences of the architecture. 
is reached after having crossed a huge expanse of timber flooring.

"Buildings are appropriated in a twofold manner: by use and by perceptions - or rather by touch and sight. Such appropriation cannot be understood in terms of the attentive concentration of a tourist before a famous building." ${ }^{\text {"108 }}$ This statement was made by Walter Benjamin in 1936. At Tarurutangi Hall, August 2007, I attempt to study this building as though I am a tourist. My purpose is to use the Tarurutangi community hall as the subject of an essay, 'Theorizing the Local' in which I intend to demonstrate how this simplistic building is worthy of the title 'Architecture'. I construct photographs of the building standing alone, with only the surrounding environment included to allow study of the aesthetic characteristics. I enter the building with a key lent to me for this exercise. I explore the empty spaces of the hall during a sunny winter day, with only the sounds of passing cars driving up the hill to distract me. Back at home, 1.4 kilometres away I delve through historical records for the hall, lent to me by the longest-standing resident of the community - records that date back to 1926 when the hall committee was first established. I attempt to evaluate the hall through my current evolving understanding of architecture, something I have never considered before. 
"Rural halls have in the past gone fairly unnoticed as their simple forms and often mundane colour schemes demand little consideration of their architectural qualities. Tarurutangi Hall is no different. Its basic linear shape rises from the ground in an unobtrusive way, its aesthetic qualities not far different from many of the local country houses scattered nearby. However, it is not the building's aesthetics that I argue are architectural, but more its significance to its surroundings. The spaces which form its interior shell and the spirit which the hall's presence generates are all, I believe, contributors to the building architecturally. The hall has provided for many decades both a social hub and a functional space for local residents of all ages... Other than the alteration from a supper room to a kitchen, no spatial changes have occurred to the hall and it is the building's ability to provide for the many functional requirements of its inhabitants which reinforce my belief that this building is architecture. At present, the hall is used for Tarurutangi community functions such as car rally evenings, pot-luck dinners and seasonal dances. The building's facilities still accommodate the community's requirements, and the continuously positive turn-outs for these events suggest a general feeling of appreciation towards the hall and the opportunities which its spaces provide. ,109
108. Benjamin, "The Work of Art in the Age of Mechanical Reproduction,” 240.

109. Elspeth Simms, "Theorizing the Local," (Wellington: Victoria University of Wellington, 2007), 3-4. 
"With regard to Tarurutangi Hall, it could be concluded that the building does hold 'pleasing' attributes as it has maintained the ability to bring the district together, and has sustained a level of respect. The second component in the statement, which deals with proportion and symmetry, can be applied to the hall. The elevation shows the building is well proportioned, with additional spaces on either side of the main horizontal form, balancing the building. Symmetry can be seen in this elevation in the locations of the windows. This simple form therefore can be considered to reflect the principles of attractiveness. ",110

Katja Grillner writes in her essay: "Benjamin's thesis on appropriation by use and by perception has fascinating implications for architectural representation... Architectural writing tends to describe visual, sometimes tactile, qualities. The text may be flavoured with experiential exclamations and metaphors to fully capture an architectural idea - always under full concentration. Architectural criticism thereby falls into the habit of a tourist's (even though professional) mode of contemplation. Useless according to Benjamin.,"111

Tarurutangi Hall, September 2005: As a group we drive in the car, halfway back along my road from my house. It's pitch-black. The 
boys in the front are laughing - one dares the driver to close his eyes as he drives along the straight. We are parked outside the hall; there is a lot of noise. We dawdle across the road, there are cars around, tooting, jeering, revving. I hold the metal handrail as I climb the concrete steps. Ifeel a sense of entitlement or ownership as I enter to see so many people crowded into my local hall. I am pleased everyone is here. It is dimly lit. The dusty timber floor is slippery in parts from spilt drinks. The corners are dark. I am outside: people cluster everywhere - fights start, people stumble, couples disappear, racing cars come and go. The glass door into the kitchen is smashed. It was new after being replaced recently following the last hall party. Right now it doesn't really bother me.

While considering Benjamin's thesis on appropriation by use and perception I have found cause to reflect on my 2007 study of the hall, undertaken in order to complete an essay requirement for my architecture studies. In this study I was attempting to be the 'tourist' and to see the Tarurutangi Hall with different eyes. My attempts at this can be identified by three distinct approaches. Firstly: photographing the hall. In completing this, the camera lens encouraged me to look at the building differently. I was recording only the building in its surroundings. The photographs

110. Simms, "Theorizing the Local," 5.

111. Grillner, "Fluttering Butterflies, a Dusty Road, and a Muddy Stone: Criticality in Distraction,” 137 
were unique in that I had never previously taken any of the hall, my only photographic recordings of the building were of events such as the Children's Christmas party in which the interior acts merely as an incidental backdrop. My second approach was to explore the interior spaces of the building with the intent of finding something meaningful within the four walls. The experience of it empty in the middle of a winter's day was something I had never done before. It forced a reflection of the building which did not come naturally and that Ihadnever attempted before. I was viewing the interior as a wideeyed second year architecture student, waiting to be enlightened by some all-encompassing understanding. My third approach to study the building was through exposure to the hall committee's historical records. Likewise, this was something I had never pursued before and it simply provided physical evidence of what I should have been able to present anyway - the family and community spirit evidenced through the lasting commitment to the hall's existence. Although in completing the study of the hall I attempted to act as a 'tourist', it was (on reflection) actually impossible to do so. I have an inherent loyalty and attachment to the building, which has built up as a result of these many years of experience. This meant that in writing the 'Theorizing the Local' essay my response was biased. Benjamin's distraction (use and perception) idea supports 
my essay analysis because of my experience and therefore my understanding of the architecture-however it does not support the way in which I approached the analysis. Through photographing, exploring and studying the historical data of the building, I was generating a formal interpretation which had little relevance to my existing understanding attained through use and perception of the architecture.

There is a Tarurutangi Hall that stays with me. I attach its meaning to other buildings: other community spaces I see lead me to consider the spirit and history embedded in their spaces. My impressions of the building are constantly evolving, memories are remembered and forgotten; my understanding develops just as my experiences do. I know now that the parents of the local families were instructed to arrive at the Children's Christmas Party by $6.45 \mathrm{pm}$ at the latest, with the "man in red" arriving at $7 \mathrm{pm}$ : "there will be a box at the door for depositing small gifts for distribution by the guest of honour later in the evening" Had I known this in December 1993 my impressions and experience of the space may have varied significantly. Yet I don't let my newfound knowledge disturb my memories. They simply build a bigger picture. 


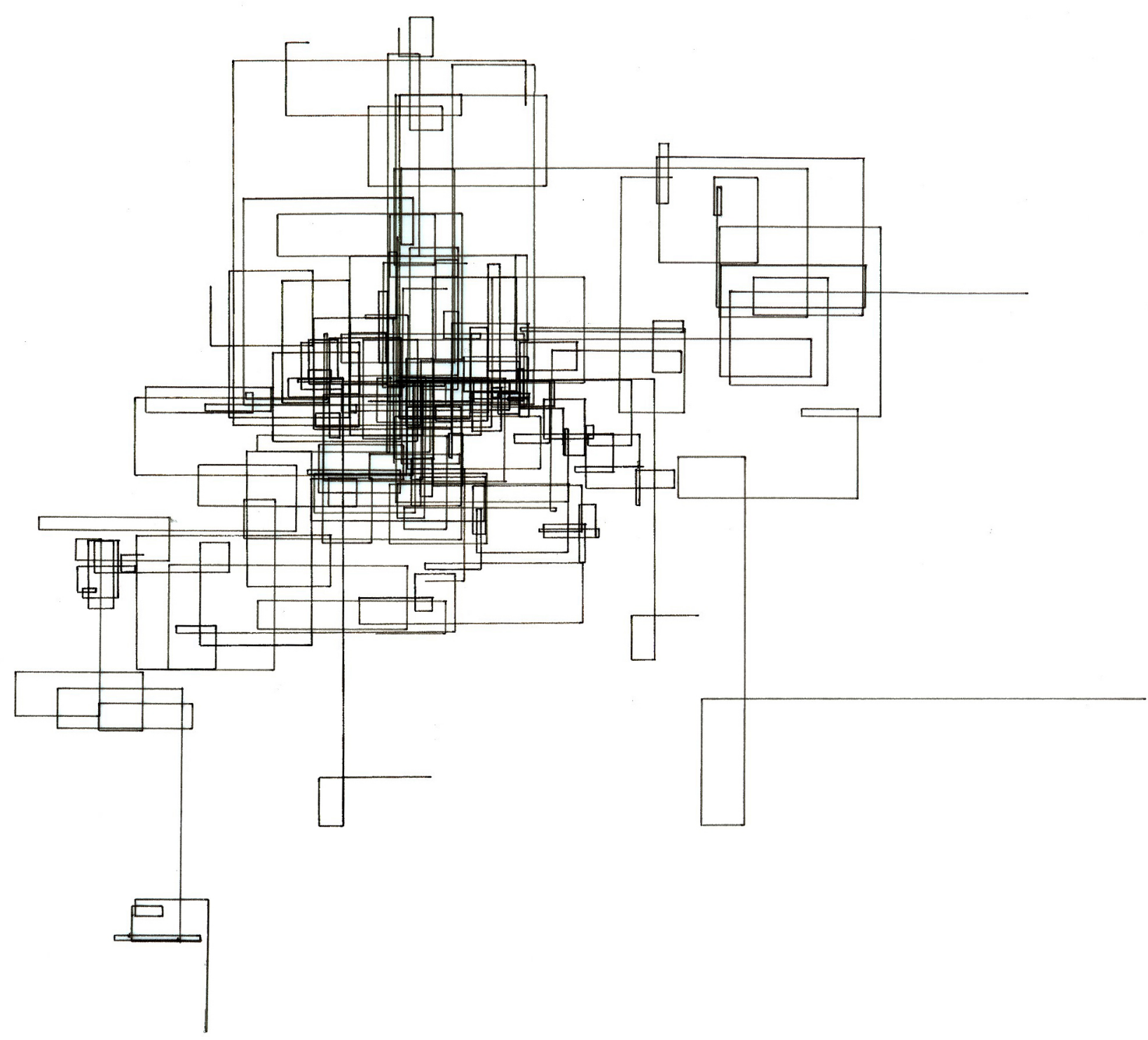





\section{Part Three}





\section{Quasimodo}

The sun leers down on me. I must find an escape. A shadow. I see my safety, but it is so far away. I stare down at the many paving stones as I hurry. Shoved. Pushed. Harassed. The paving stones seem endless. There is no shade anywhere. Quick. Quick!

The safety hits my body with a blast of cool air. I can't remember where I've been. I'm safe. I'm free. The sun likes me here. It sends beautiful colours down from above. It warms my friends. My family. They light up when they see me coming. And remain still and silent as I talk to them, listening intently. I leave them behind and start climbing. The stone moulds into my hands and feet. The walls greet me with their soft, cool comfort. I'm up. The ropes cling to me as I move up and down. I can feel the walls shaking with laughter. They are happy I'm here. Looking out, the paving stones are still there. But I am here. I'm safe. 


\section{Part Three}

\section{Introduction}

Notre-Dame de Paris is a captivating novel loaded with inherently architectural meaning. For this research it provides textual information from which the design work can take direction. Reference to the novel is maintained consistently throughout the design stages. This reflects both the novel's importance to the formal, primary output of the thesis, but also its contribution as a creative inspiration in pursuing the principle objective of the research

The significance of this research is evident in the success of the project's ability to draw attention to the imaginative possibilities of writing and architecture. The design work presented here contributes to architectural knowledge through a variety of design outputs. Experimentation with design tools (such as text and diagrammatic visualisations) produced design which validates the relationship between architecture and print. Attention is drawn to the unique opportunities which textual modes of design provide in exploring understandings of imagined and real space. Due to the ongoing importance of Victor Hugo's novel to the research objective, it was logical to use the novel as direction for the visual design. However, this research does not limit its significance to Notre-Dame de Paris. Architecture is latent in all novels. In order to uncover this, the text requires 'reading' and 'writing' of the architecture inherent in the words. This project has discovered ways in which to read and write the architecture of Notre-Dame de Paris which could then be applied to other novels, forming unique results each time.

The issue of judgement is consistently raised in each section of this design work. The concern is in determining the 
point at which the reading and writing of architecture ceases, and an end result is found. This concern identifies

that work based on proposition and experimentation is never actually complete, and is evidence of the distinction between design-led research and research-led design. This work commits itself to uncovering architecture which has never been seen before. It is architectural space which maintains both a real and imagined presence, revealing the architecture of Notre-Dame de Paris in an unprecedented way. Had the attempt been made to reduce the project into something which is more typically recognisable 'architecture' (for instance pursuing a translation of the work into a square box form), it would risk losing the poetic quality.

The following Part Three Reflection combines a range of communicative formats; formal reflective writing, creative writing and visual experimentation, to express the experimental and creative possibilities of text within the architecture thesis. It documents and discusses how the architecture, contained in the words of Notre-Dame de Paris, is revealed and developed and why these processes are significant to the design of architecture. 


\subsection{Site Writing}

\section{Discussion}

Having established that this research provides an ideal location for accommodating the exploration of writing as a design tool, the site and context of the project has been retained for experimentation with creative writing. By designing the site and context in text, the project maintains a presence within a fictional realm which reflects the imaginative possibilities for this propositional work.

In his 1936 essay, The Work of Art in the Age of Mechanical Reproduction, Walter Benjamin described his notion that the experience of architecture is through a distracted and de-focused condition. ${ }^{112}$ This led to the conclusion in Part Two that it is the characters within Notre-Dame de Paris that create the 'distracted' state for the reader.

Architecture forms the backdrop rather than the object of attention as the characters maintain their presence in the development of the plot.

In attempting to write the site and context for the visual experimentation, Benjamin's concept of distraction is reflected through an account informed by use and perception. My own experiences, memories and readings are the primary source of material for creating this account. The site is written from two contrasting view points, through the characters Quasimodo and Esmeralda, and relies heavily on my personal interpretation of these characters. Their relationships to the same spaces are vastly different, however the opposing perceptions work together to build an architecture within the reader's imagination. The intention is to capture the architecture through a de-focused lens. The characters provide a detour which allows just glimpses of the architecture. The design of the text also reflects the characters themselves through varied momentum and sentence structure.

112. Benjamin, "The Work of Art in the Age of Mechanical Reproduction." 239. 
The architecture of the writing reflects my reading of Notre-Dame de Paris, and my current understanding of the cathedral, but it does not limit the architecture. The control over identification and specific site description means that each reader can engage in their own imaginative exploration. Those who have read the novel will form different architectural understandings than those who have not. Likewise, those who are familiar with, or have visited the Cathedral will also engage with the writing in different ways. 

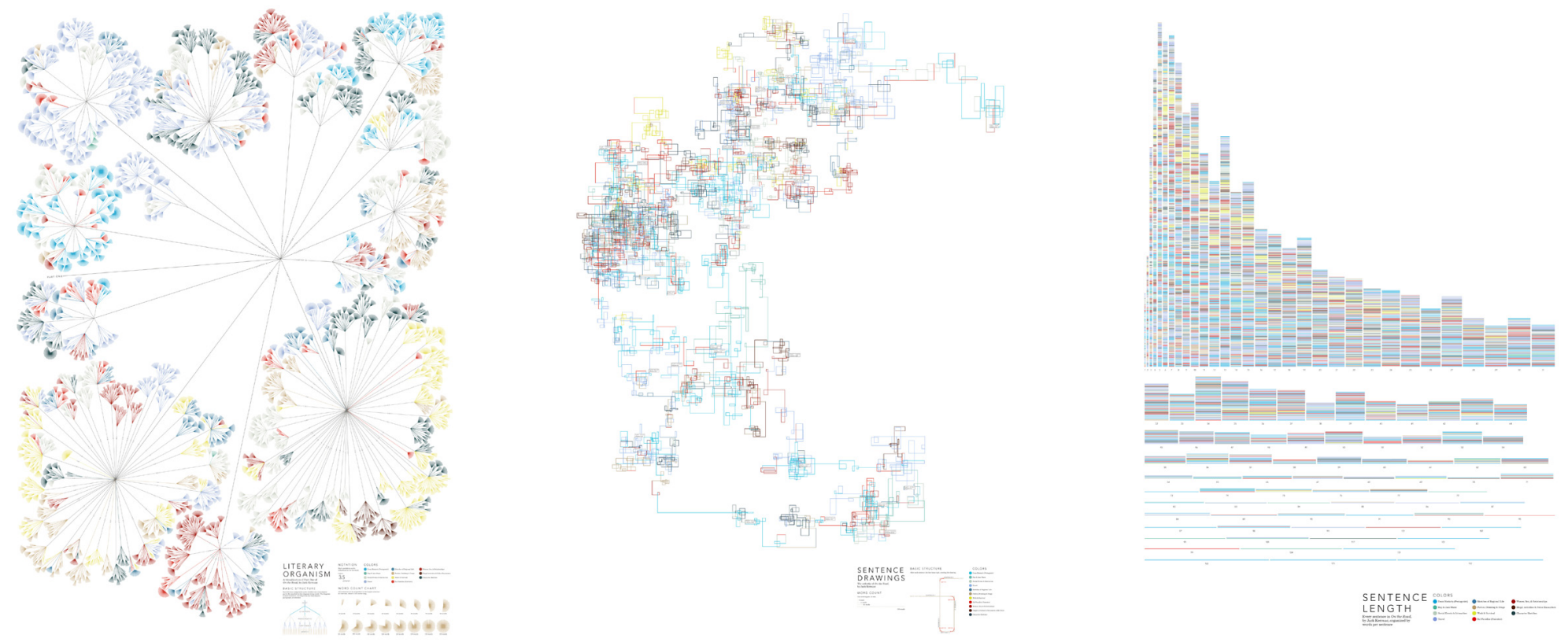


\subsection{Diagramming Notre-Dame de Paris - Drawings}

Notre-Dame de Paris is a unique formation of nearly two hundred thousand words. The placement of these words was designed by Victor Hugo and presents numerous ideas and meaning, accessible through a literary reading of the novel. I believe that this is not the only way to access ideas within his text. Hugo's formation of words into sentences, paragraphs, chapters and books is architectural. I propose that through a diagramming of NotreDame de Paris it is possible to draw out Hugo's words into a visual 'expression'. These diagrammes look to uncover the architecture latent in the novel. They reveal architectural qualities which are a direct result of Hugo's own design of the text, but, which have never before been explored through a traditional literary reading of the novel. A literary reading of the novel creates architecture within the imagination. The diagramming of the novel has discovered a way in which to shift this architecture from the imagination into a physical, spatial and visual representation.

The work of Stefanie Posavec assists in forming a methodology through which to visually represent architecture within the novel. Posavec is an American artist, based in London, who produces artwork ranging from datadriven design to the design of book covers. ${ }^{113}$ She considers the methodological use of data as a tool which designers can employ to produce meaningful aesthetic solutions creating shapes and forms: "Generating visuals from meaningful data invests the aesthetic with an additional meaning, and suffuses the aesthetic with importance and a talismanic quality." ${ }^{, 14}$ Her project, titled Writing Without Words, explores methods of visually representing variations between the writing styles of different authors ${ }^{115}$ (refer Figure 29). This approach to data visualization presents an interpretation of data which reveals complex patterns and correlations between authors. Posavec states: "this rigorous method of feeding data through aesthetic parameters to arrive at a visual outcome provides a

Figure 29: Stefanie Posavec's project Writing Without Words. Images are titled from L to R: Literary Organism, Sentence Drawings, Sentence Lengths. Available: http://www.itsbeenreal.co.uk/index.php? about-me/, 19 July 2010.

113. Stefanie Posavec, About Me: Stefanie Posavec, 2007, Indexhibit, Available: http://www.itsbeenreal co.uk/index.php?/about-me/, 19 July 2010.

114. Stefanie Posavec cited in: Imperica, Stefanie Posavec: Artists and Data, 2010, Perini Networks Europe Ltd, Available: http//www imperica.com/ viewsreviews/artistsdata, 3 November 2010

115. Stefanie Posavec, Writing without Words, 2007, Indexhibit, Available: http://www itsbeenreal.co.uk/ 19 July 2010. 

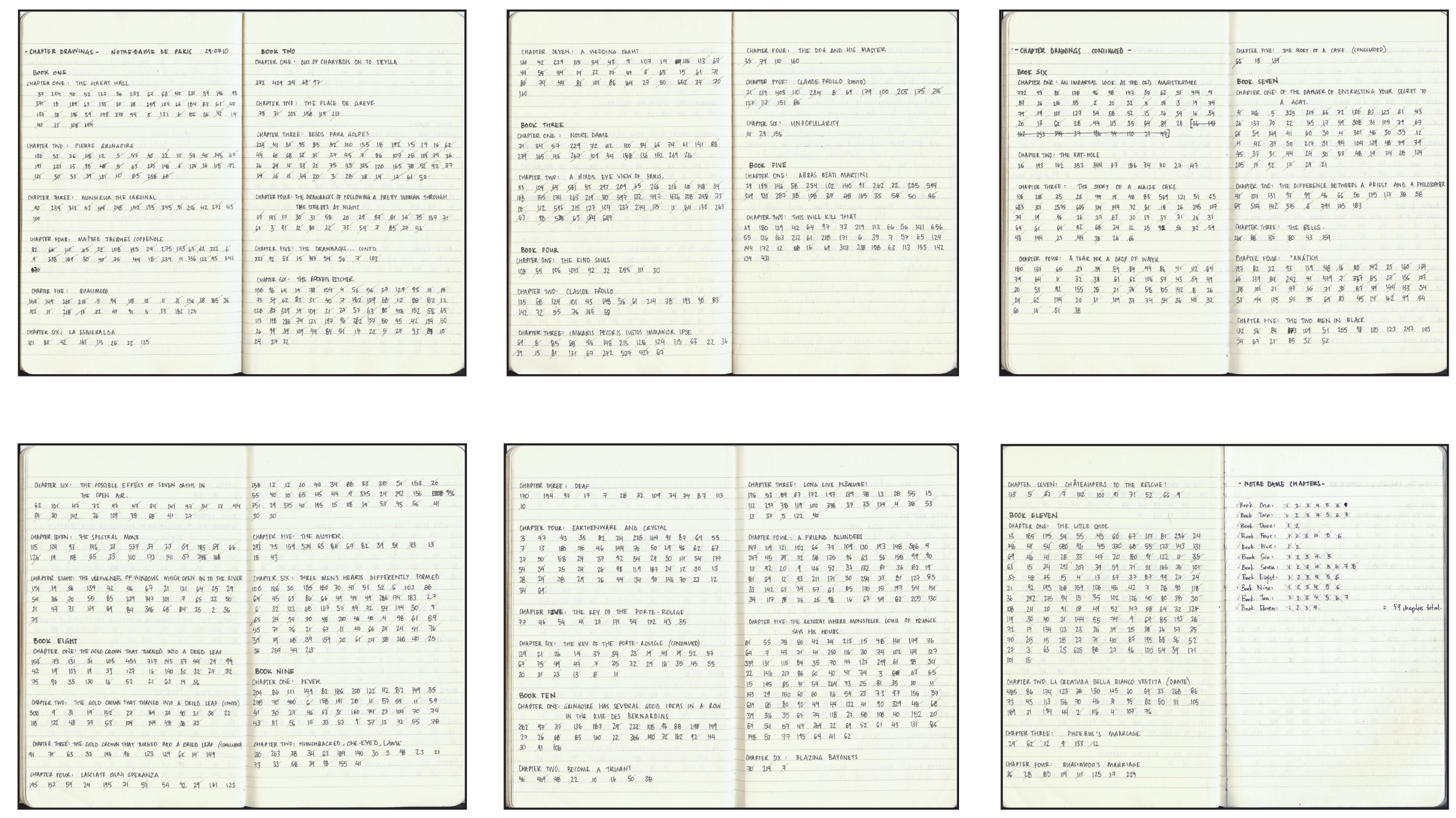
feeling of looking into the unknown for the designer, as one doesn't know what the visual outcome of the dataset will be until the whole visual is generated." ${ }^{, 16}$ By adopting a similar approach and applying it to Notre-Dame de Paris, it is possible to visualize the style of Hugo's writing. I am able to uncover a diagrammatic representation of the novel which is architectural in form.

Notre-Dame de Paris $^{117}$ is written in the Romantic genre and is formed of eleven books and a total of fifty-nine chapters. The diagrammes convert and transform these chapters and books to be individually legible as interpretive architectural representations. I propose that each of the fifty-nine chapters contains unique architecture which varies from chapter to chapter. In order to reflect these differences, emphasis is placed on the importance of every paragraph and every word. Every word in the novel is contributing to the creation of spaces. A 'reading' of the novel has taken place, in order to uncover the architecture which I suggest exists undiscovered within the words. This is not a typical literary approach, instead I use a quantitative process which reads the number of words within each paragraph. The conversion which occurs through this comprehensive 'reading' gives equal emphasis to every word and paragraph.

Numerical interpretation of Notre-Dame de Paris provides new insight as the Reader of Hugo's words. 'Reading' the novel emphasises differences between paragraphs in chapters and books, and this data is able to be visually represented through a new form of 'writing'. By 'writing' the novel I am converting numbers into a spatial register of lines, tracing out the data which the novel holds. A continuous line is used for each of the fifty-nine chapters, drawn to reflect the length of every paragraph within its respective chapter. This is a rule-based system in which each word is accounted for in its addition to the length of the line representing the paragraph. Using this system I was able to discover a diagrammatic representation of his novel, leaving the spaces between the
Figure 30: Data recording of the novel Notre-Dame de Paris. All fifty-nine chapters within the eleven books of the novel are analysed. These recording show the number of words per paragraph.

116. Imperica, Stefanie Posavec: Artists and Data.

11. For the purpose of the design work I used the Penguin Classics English translation of the novel, firs published in 1978 and translated by John Sturrock. 

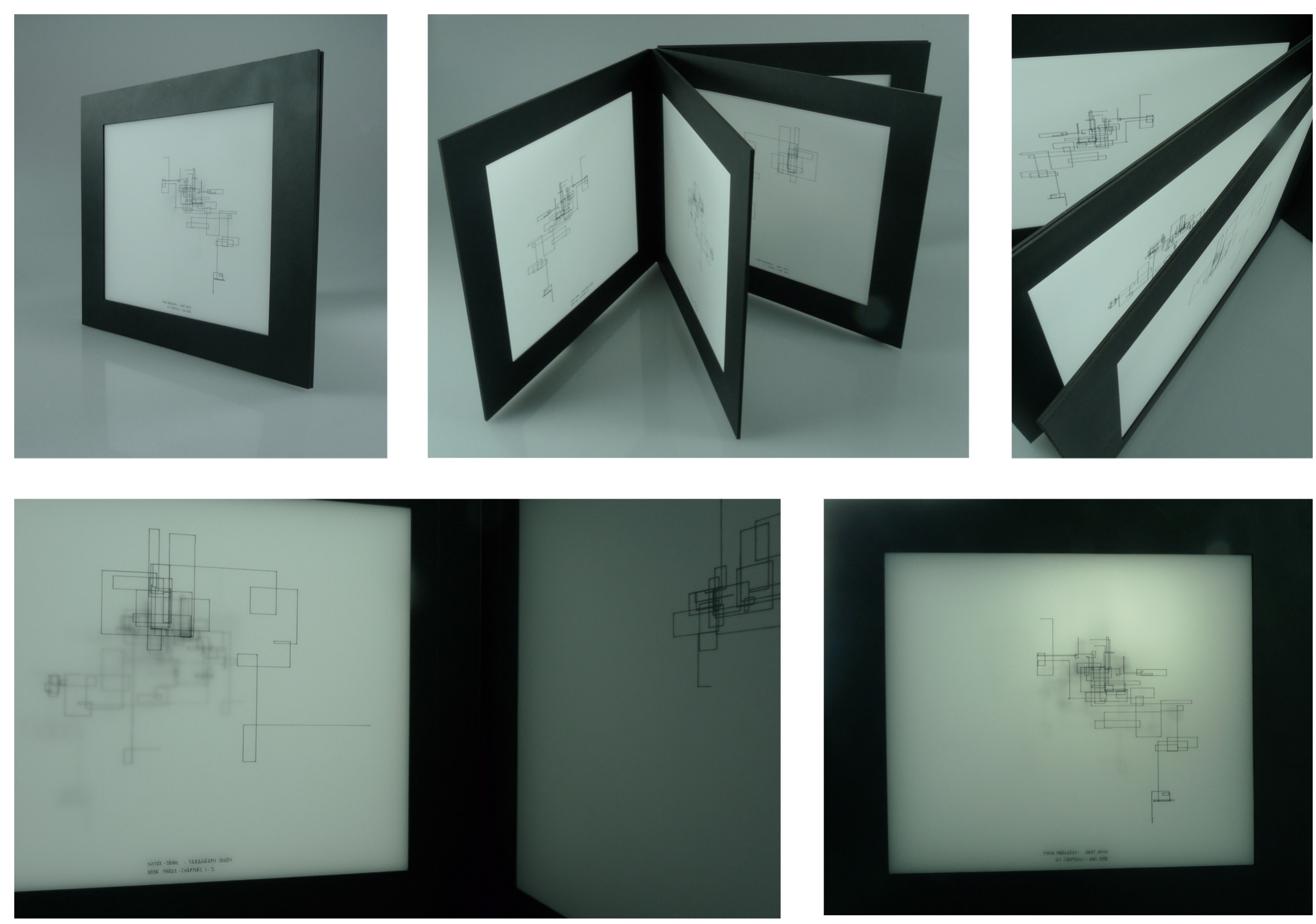
diagrammes as the opportunity for interpretation by the reader.

By layering these diagrammes I reveal a comparison between the architecture of Hugo's words within each of the eleven books of the novel. As multiple diagrammes layer up, the clarity of lines of earlier books begin to fade, maintaining varying degrees of presence within the overall image. This reflects a literary reading of the nove where the ideas and information gained earlier stay with the reader, to varied extents, as they progress through the words, helping to form a holistic impression on the reader. By viewing these re-'writings' of the novel layered up, it is possible to engage with the spaces created between the diagrammes. Architecture is not limited to the lines of the diagrammes. It can be seen around and amongst them.

The act of binding these images returns the diagrammes to their original textual form - the pages of NotreDame de Paris. Physical space is created between these diagrammes, bound to the pages but offering enormous opportunity for interpretation. This opportunity allows for further conversion of the novel; a more qualitative reading of the architecture.
Figure 31: (top row) The diagrammes of the first five books of Notre-Dame de Paris are boun together. Space is created in-between the pages an relationships between books are visualised. These relationships are not limited to their order in the book. The bind allows the pages to be fully opene out, and a reading through and between all five books can occur. The diagrammes of Book Five are able to twist 360 degrees to layer up with the diagramme of Book One.

(lower row) Light emphasises the presence of previous diagrammes behind the current diagramme. A build up of knowledge is occuring. 


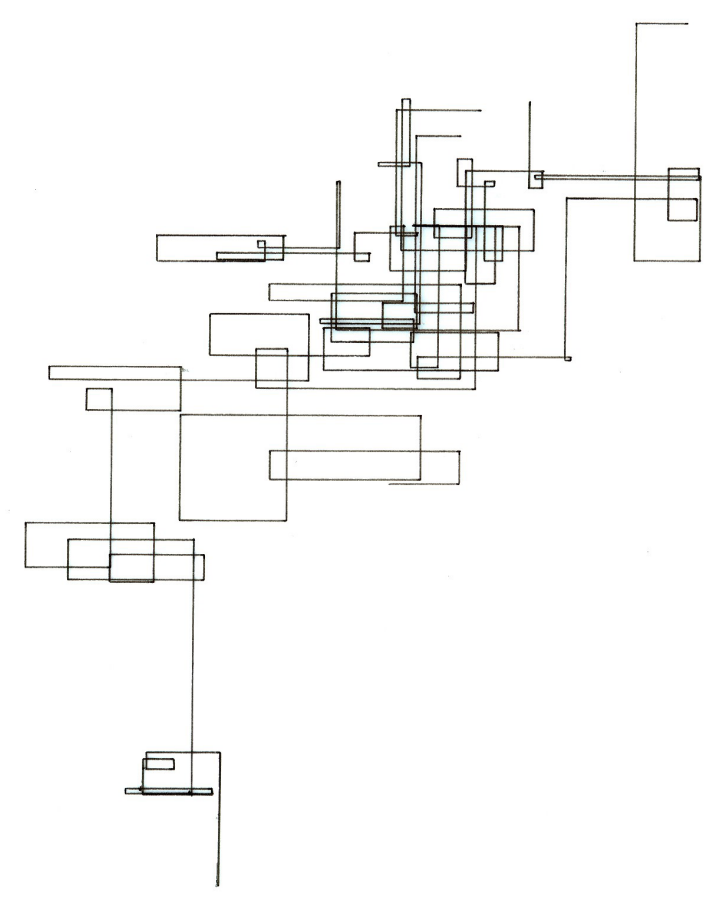

Notre-Dame de Paris

Book One - Chapters 1-6 



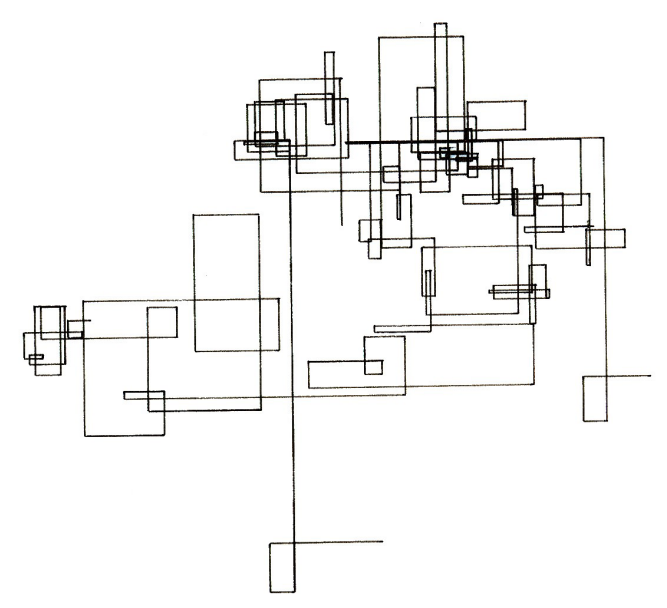

Notre-Dame de Paris

Book Two - Chapters 1-7 



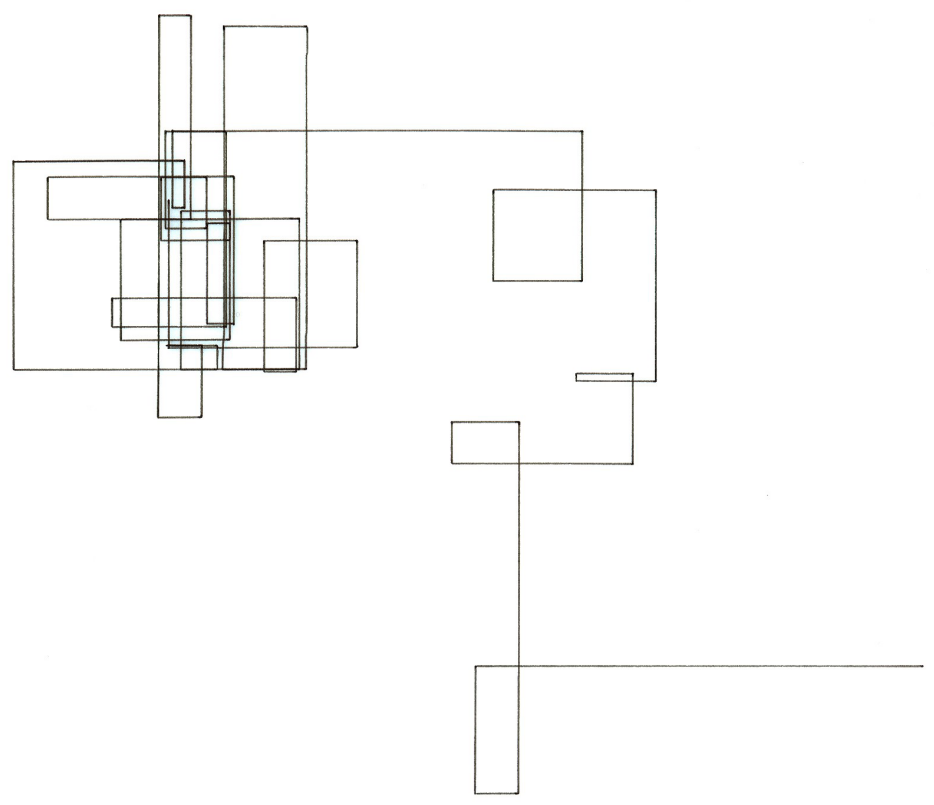

Notre-Dame de Paris

Book Three - Chapters 1-2 



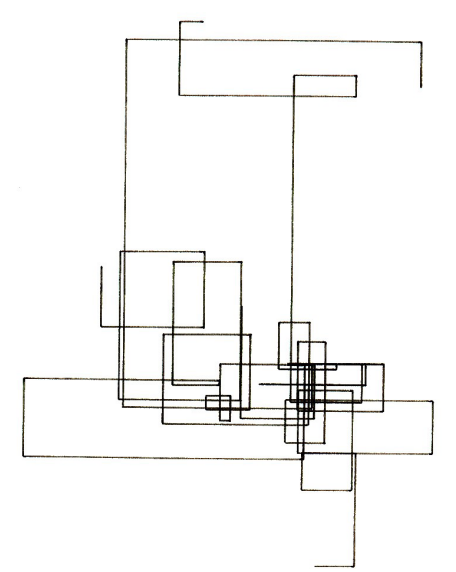

Notre-Dame de Paris

Book Four - Chapters 1-6 



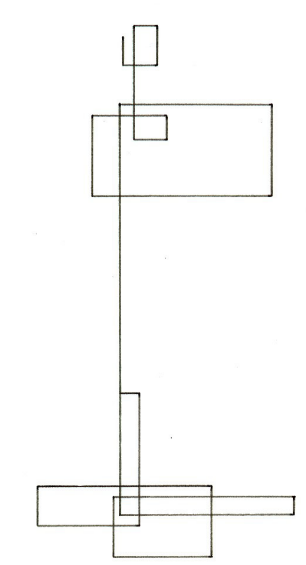

Notre-Dame de Paris

Book Five - Chapter 1 



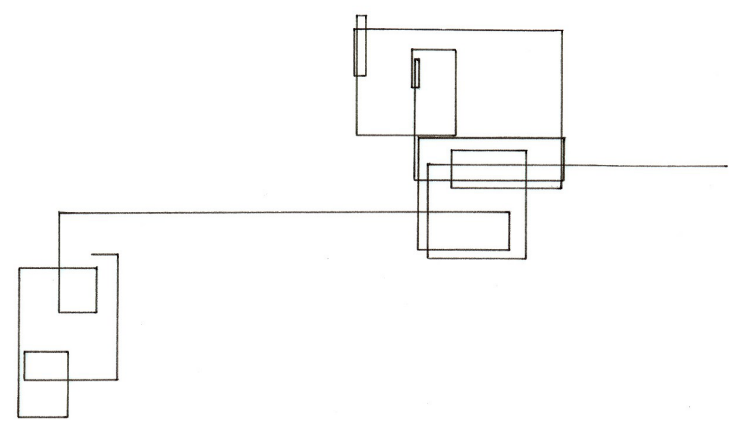

Notre-Dame de Paris

Book Five - Chapters 2 - 'This Will Kill That' 



\section{Discussion}

The act of conversion is of crucial importance to the outcome. When interpreting the diagrammes it could be suggested that the qualities of the original do not transfer, given the quantitative, processbased conversion from the novel to the diagramme. However, in saying that, the data obtained from the novel is still dealt with in a subjective way, even though it is gathered through quantitative means. As the designer, I made decisions about how to represent the data, which ultimately determine the form of the resultant diagrammes. These diagrammes are schematic abstractions of Hugo's novel which offer a further understanding of the words. The methodological use of the textual data allowed me to discover architecture latent in the novel, using a process which could be applied to any other piece of writing. It uncovers meaningful results unique to each text: "Looking at something ordinary in a new way makes it extraordinary." "118 The diagrammes in this two-dimensional format lack physical mass and materiality. However, this does not discredit the architecture discovered. Instead, it identifies the opportunity for development; pursuing further the qualitative understanding which represents my personal reading of

Hugo's words.
118. Maria Popova, Data Visualization: Stories for the Information Age, 2009, Bloomberg, Available: http:// www.businessweek.com/innovate/content/aug2009/ id20090811 137179.htm, 3 August 2010 


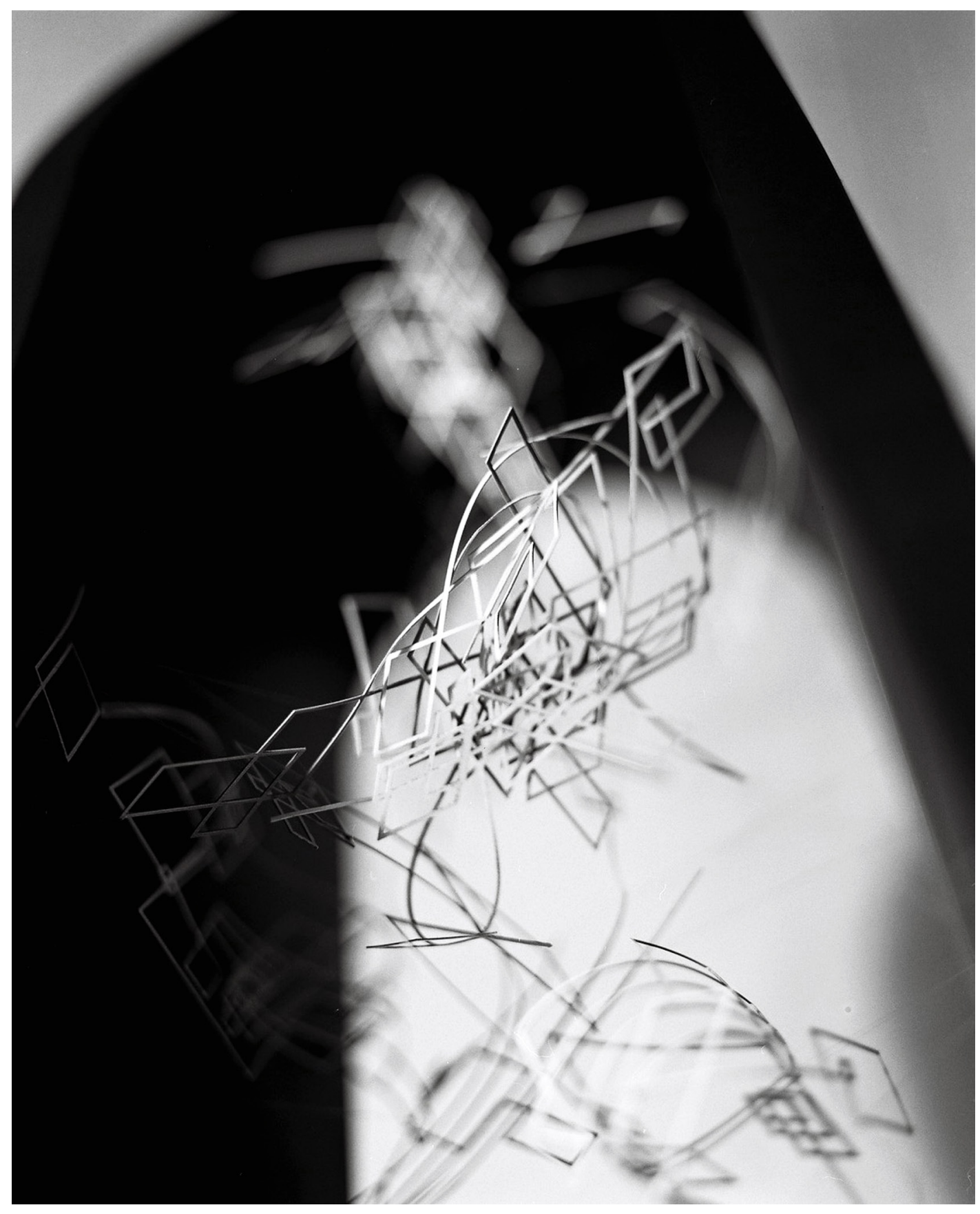




\subsection{Diagramming Notre-Dame de Paris - Gothic Arch}

The diagrammes created as visualisations of Notre-Dame de Paris reveal architecture inherent in Hugo's words. They present a way in which to shift architecture from the imagination into a visual expression. I propose here that this visual expression is not limited to drawing, but can take on a physical, constructed presence. This constructed presence occurs through my invention of the physical diagramme; the 'physigramme'. The constructed developments of the physigramme allow further development and expression of a personal interpretation of the novel. The drawing of the diagrammes was a conversion of quantitative data. By developing the construction of the physigramme I uncover qualitative impressions, based on my reading of the novel. The architecture revealed expresses the unique outcomes made available when pursuing a reading which varies from the typical literary approach. The developed physigramme maintains the experimental and propositional nature, providing evidence of the potential of text as a director for architecture.

The Gothic arch supports my exploration of the physigramme. The arch is a structural expression which represents the essence of Hugo's aims within the novel. Hugo made clear his support of a shift from Romanesque architecture to Gothic architecture. This, of course, meant a shift from the rounded arch to the freer style of the pointed arch, which was able to reach nearly double the elevation without requiring any increase in width. ${ }^{119}$ The enhanced opportunities this provided for architecture was, in Hugo's mind, a reflection of society moving towards democracy; a shift away from theocracy. The proportions and size of the arch I constructed emphasises the vertical. It reflects Hugo's humanist philosophies. The shape used is that of an equilateral Gothic Pointed arch, representing the preference of Pugin. ${ }^{120}$ The pointed arch also reflects the stance I have taken in this research through my intent to open up the possibilities of the architecture 'thesis by design' output.

Figure 32: Looking up towards the top of the arch. Own photograph.

119. A.W.N Pugin, Contrasts, 2nd ed. (Leicester Leicester University Press, 1836) 4.

120. Pugin, Contrasts. 


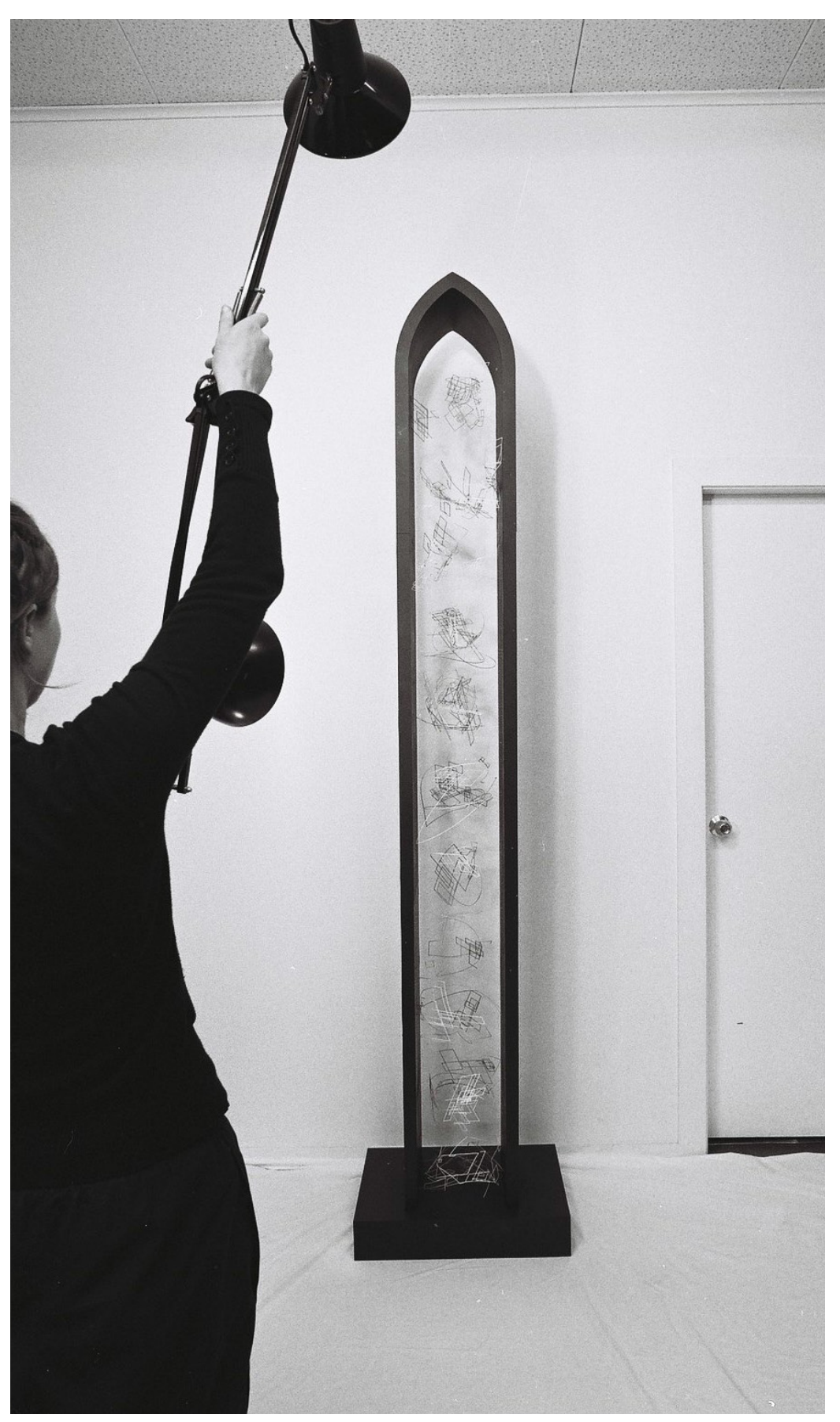


The diagrammes which formed a visual representation of Notre-Dame de Paris are shifted into a three-dimensional reading through the introduction of the isometric convention of drawing. My intention with these isometric diagrammes is to implicitly express the relationship between the values behind the pointed arch and the formation of Hugo's novel. By suspending these diagrammes of the novel within the arch this reciprocal relationship is physically represented. My personal authority as the reader of the novel is reflected through my design of each three-dimensional representation within the arch. The shapes and spaces formed are a result of my reading of the characters and plot and their relationship to the Cathedral. The elevation view of the arch clearly distinguishes the eleven books of the novel. Book One starts at the base of the physigramme and the following books ascend numerically, with Book Eleven at the point of the arch. Each 'Book' section of the physigramme contains its chapters from the novel; anywhere between two and eight chapters for each book.

I propose that the design of this constructed physigramme is further revealing, through a personal reading, the architecture latent within the novel. The design of the spaces within the individual suspended diagrammes occurs through a methodical reading of Notre-Dame de Paris, with each book reflecting my personal interpretation of the events that occur within the novel. Some books contain chapters which are very tightly developed, progressively building and layering up information. Other chapters use long, drawn out paragraphs which slow the momentum for the reader and do not significantly develop the plot. Some chapters are dedicated quite clearly to the architecture of Notre-Dame Cathedral. Others are connected in more ambiguous ways.

The chapters of Book Nine develop the relationship which the gypsy girl, Esmeralda, has with the cathedral The first four chapters reveal a softening of Esmeralda's attitude to the cathedral as she begins to form reliance and a feeling of security about the structure. However, this security is extinguished for Esmeralda in chapters 

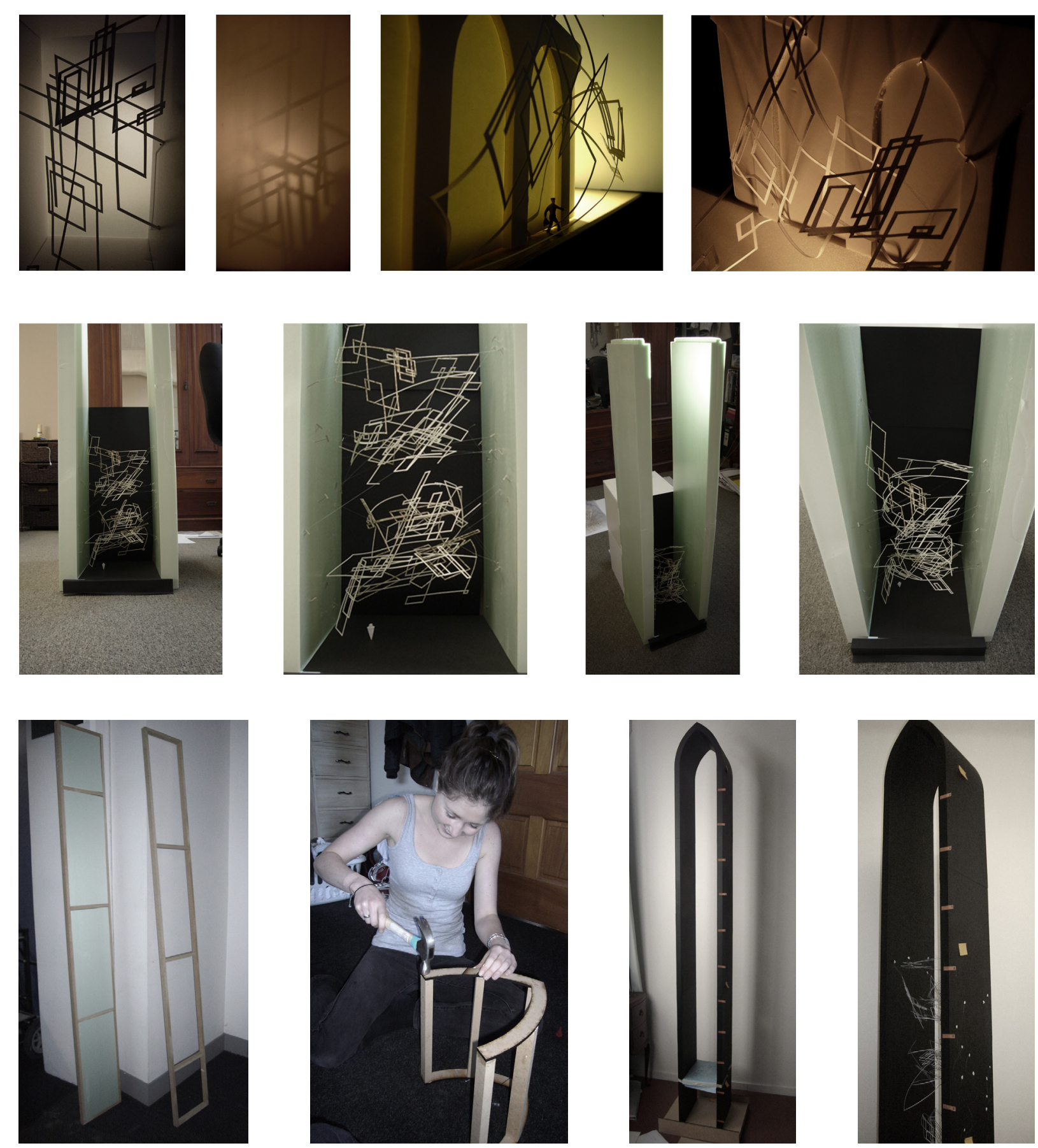
five and six of Book Nine through the aggressive and threatening actions of Dom Claude Frollo. In Book Ten, Quasimodo's relationship with the cathedral undergoes a major shift as he defaces the building - "his sacred universe" $^{, 21}$, in an attempt to protect Esmeralda from harm. The relationships between cathedral and character are prevalent throughout the novel and not only assist in the development of the plot, but also reinforce Hugo's dedication to increasing the awareness of Gothic architecture. It is ideas such as these which inform my design of space within the physigramme.

Although in elevation view the eleven books of the novel are easily identifiable, other vantage points present varied distinction between books. Again, like the layering up of drawings described in the previous section, the individual diagrammes, viewed from different angles, merge together the ideas within the novel. The elevation view presents a 'writing' of the entire novel. From a distance the viewer observes objectively, up close they visually inhabit the intricacies of space. It is essential to the process that the viewer be aware of the origins of data which created the design of these spaces. This allows an understanding of the meaning behind the representation. However, it is not necessary that the viewer have read the novel. The aesthetic defining the spaces is successfully able to engage imaginative participation with the physigramme.

The construction and scale of the physigramme also encourages engagement from the viewer. The scale and method of construction further reflect the integrity of this as architectural experimentation. The full height is that of a standard room, 2.4 metres tall, introducing a human scale to the representation of Hugo's novel. It is constructed in a similar way to a typical timber framed house with rigid foam insulation and plasterboard-like cladding, painted black. In doing this, I am pursuing the construction of architecture, rather than constructing a model of architecture. I am engaging with the architecture of the novel in a tangible way.
Figure 34: (top row of images). Experimentation with spatial qualities within diagrammes.

Figure 35: (middle row). Mock up mode experimenting with expressing varied interpretations between books within the novel.

Figure 36: (bottom row). The constuction of the arch and process of diagramming.

121. Crystal Downing, "Architecture as Synecdoche: A Poetics of Trace," Pacific Coast Philology 23.1/2 (1988): 17. 

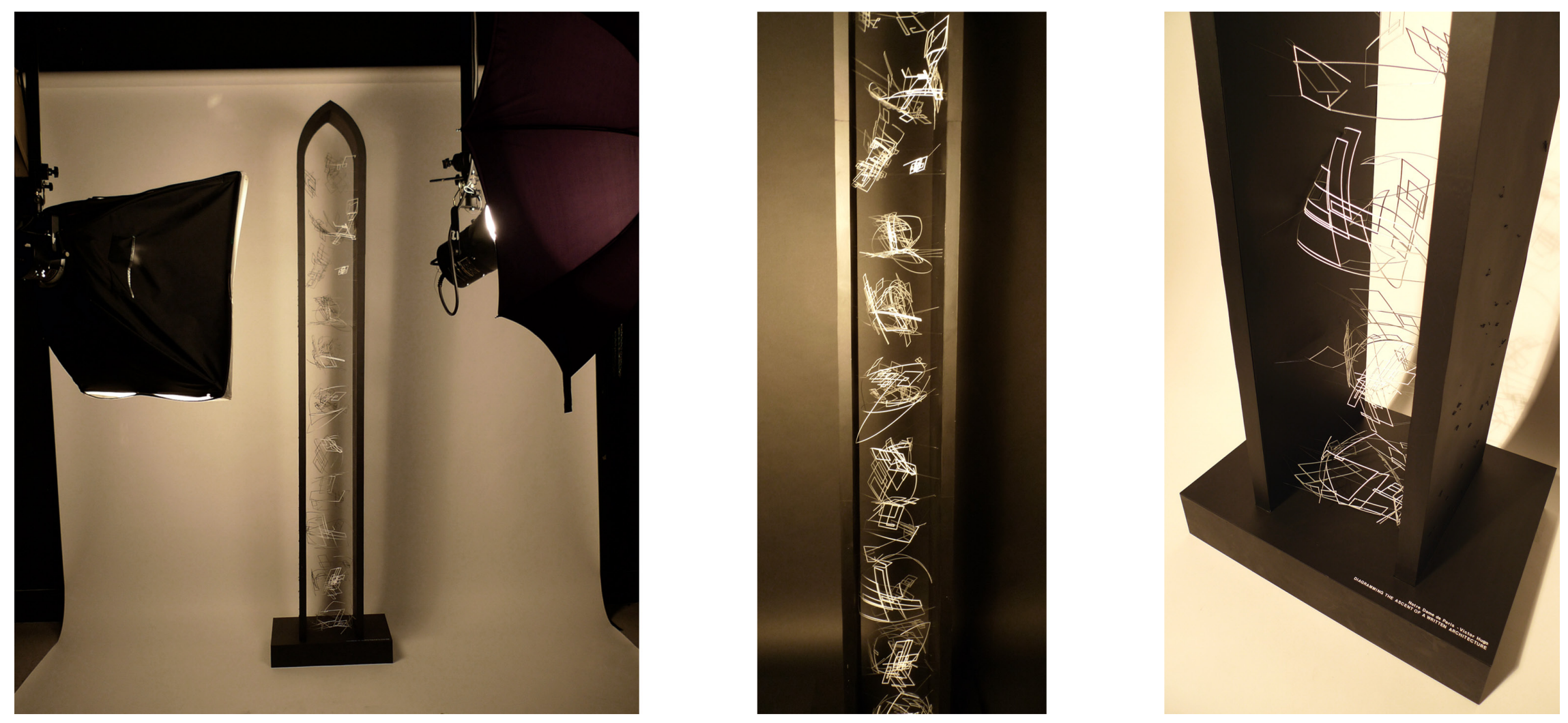


\section{Discussion}

The multiple transformations which this conversion of the novel has undertaken provides texture for the architectural outcome. There is fine grained detail in the spaces that are a result of the subsequent reading of a previous reading. The multiplicity of these readings does, however, raise the question of judgement: when and where does the process of reading and conversion stop. The architecture within the arch is reflective of the project at this particular stage: it is poised; suspended in a certain state it requires some form of direction. At a distance, the suspended architecture of the diagrammes appears to defy gravity. This reflects the essence of the research in its resistance to comply with architectural norms. To maintain an evocative and imaginative quality,

I believe it is necessary to resist shifting towards a typical architectural translation. There is consistently an urge for architectural work to revert back to a recognisable outcome. Instead, I am highlighting an imaginative engagement with the architecture of Notre-Dame de Paris. 


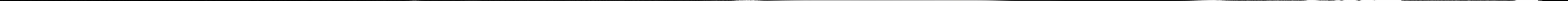




\subsection{Spatial Photographs}

The images taken from the physigramme are intended to focus on particular narratives of significance that occur within the novel. They further explore, through experimentation with depth-of-field and focus, the spatial qualities which were designed within the individual diagrammes of the Gothic arch. The images allow greater control to focus the understanding of space within the physigramme. Rather than closing down the opportunity for interpretation as a result of this inward focus, the outcome is in fact an opening up of opportunity for imaginative participation by the viewer.

The images attempt to highlight the qualities of space within the physigramme by drawing the viewer into the image. They provide snapshots of spaces which suggest inhabitation by emphasising depth. Blurring and focusing at different points explores scale which is no longer restricted, as it had been in the constructed physigramme.

The contrast between the diagrammes and the black arch is accentuated. It assists in the dramatic aesthetic of the images, developing spaces which provoke the imaginative engagement of the viewer.

Additional intervention takes place in a selection of these images. The intention of this is to elaborate on my own personal reading of the narrative, in particular the characters varied relationships to the environment of Notre Dame Cathedral. This is seen for instance in Books Seven and Nine, where Esmeralda's experience of the cathedral is based on uncertainty and fear. Unlike the safe haven which the cathedral provides for Quasimodo, Esmeralda feels trapped in a prison. By introducing the figure of Esmeralda into the spaces created from Books Seven and Nine, a human scale is introduced which alludes to the overwhelming and unfamiliar territory which Esmeralda finds herself confined within. The viewer of the image is forced towards my interpretation of the experience which Esmeralda has within the spaces of Notre Dame Cathedral

Figure 38: Book Seven - This space is designed and represented through a reading of Esmeralda an the events she is caught up in at this stage of the novel. There is a sense of foreboding and fear to this space, which is emphasised by the development of a meandering pathway and the figure of Esmeralda moving through. I title this image; Esmeralda's Downfall. 


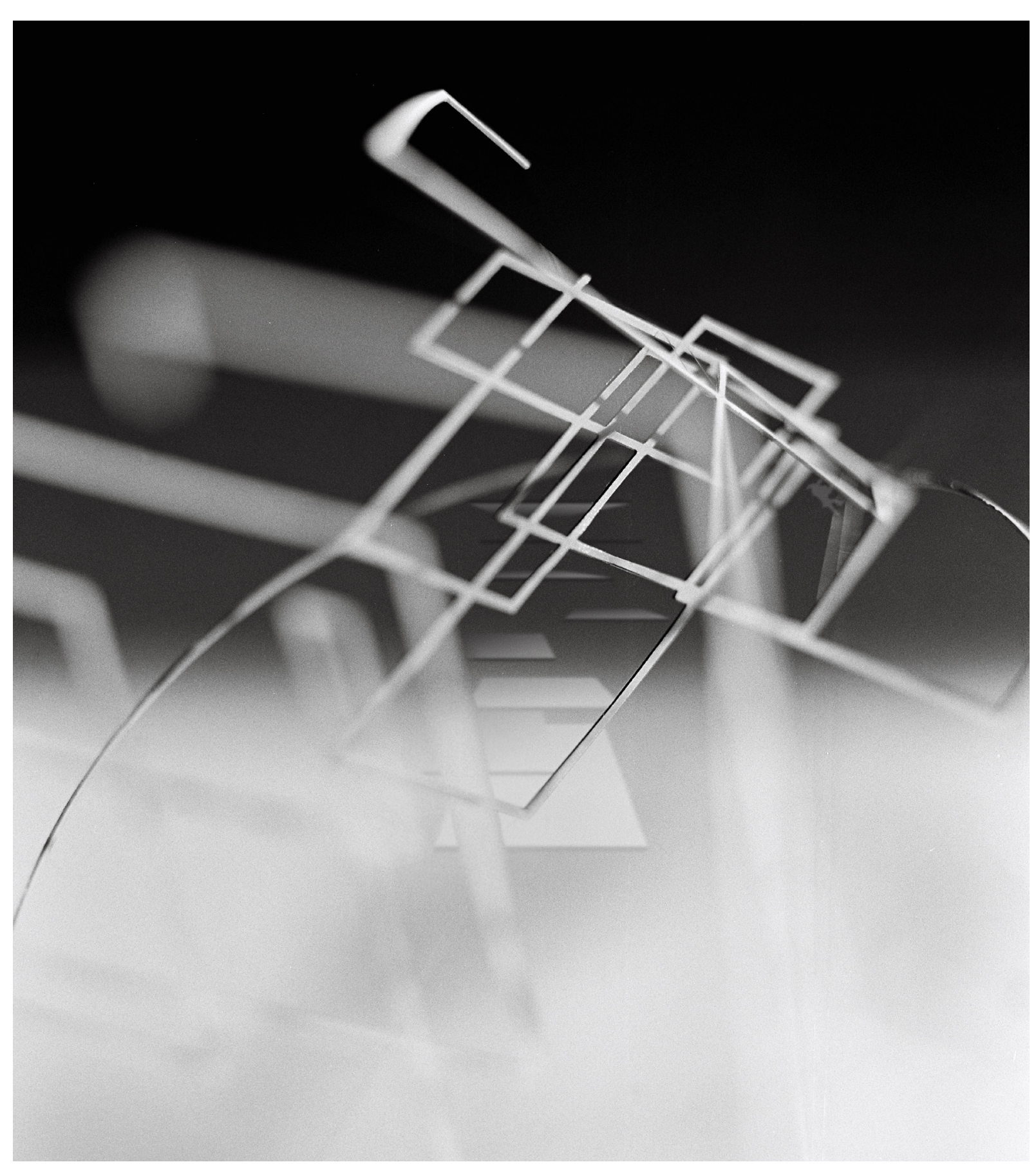




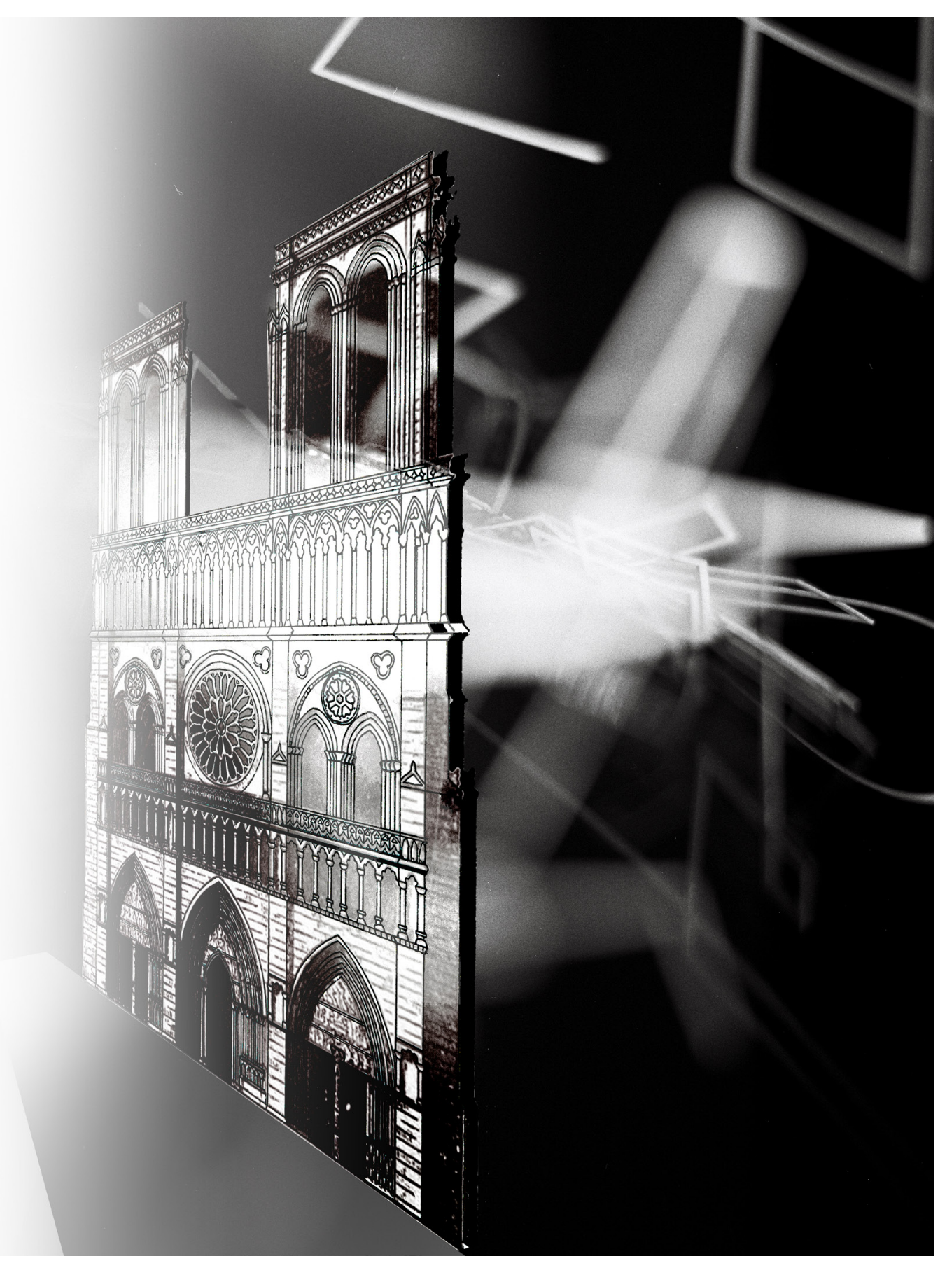

Figure 39: (opposite) Book Four - This book describes and develops the character Quasimodo and his relationship to the Cathedral. The building is a safe haven for Quasimodo, it is the only space in which he is happy. Quasimodo experiences the architecture in almost purely vertical directions, his freedom of expression was through his agility. He is able to scale the towers and 'speak' through the sounds of the bells - which are the only sounds he can still hear.

Figure 40: Book Ten - In Book Ten Quasimodo is willing to deconstruct his only space of security, the Cathedral, in his attempt to protect Esmeralda. 


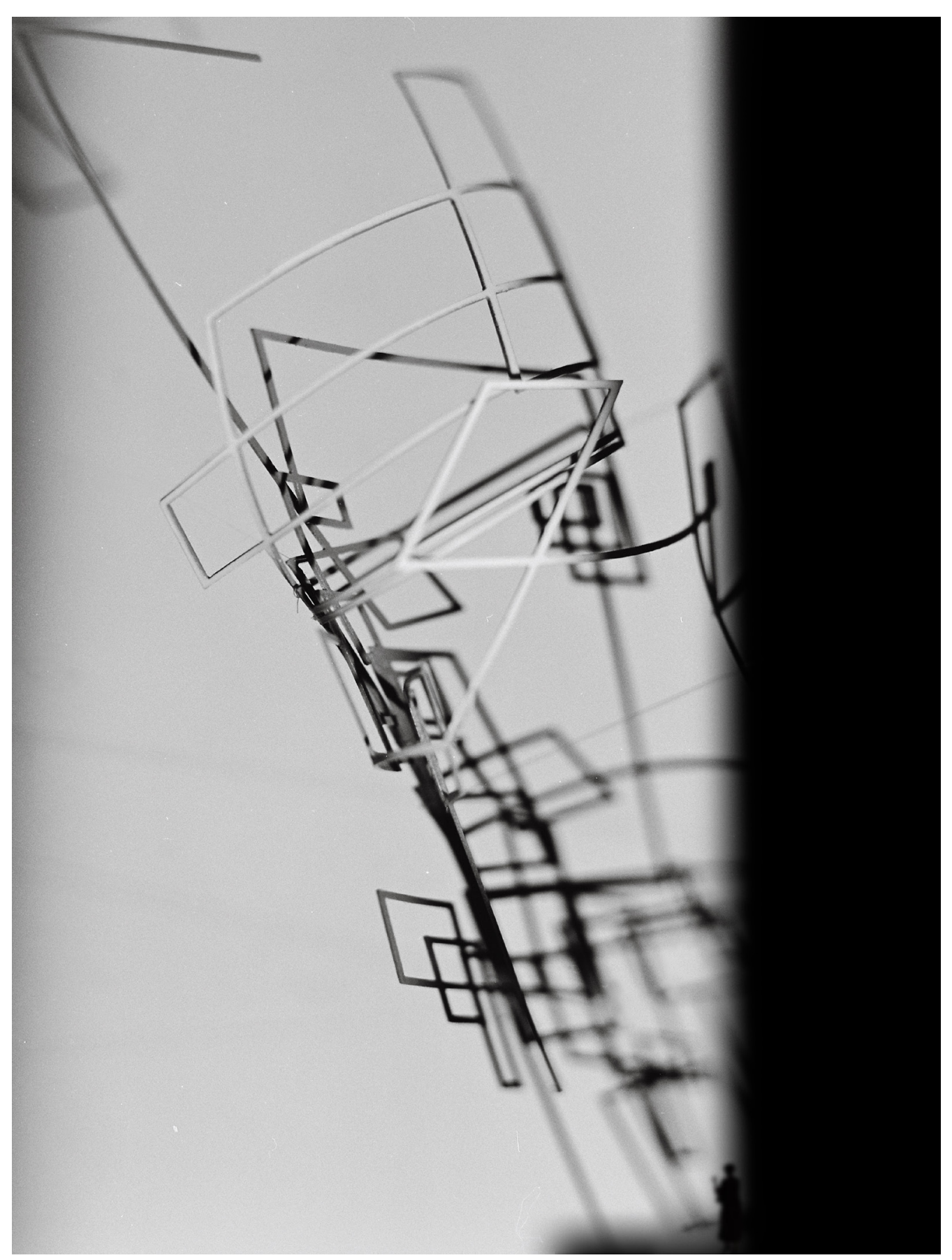




\section{Discussion}

Although the additional intervention in this selection of images is generally quite subtle, they do present the issue again of judgement. At what point should the intervention stop and the work be released to the reader for interpretation? The inclusion of the figure of Esmeralda in several of the images successfully presents my personal understanding of scale and spatial quality. These characteristics could, however, be seen as limitations

Although discreet, the suggestions are perhaps too contrived, creating a heavy-handed impact on the interpreter's understanding of the spaces. My design of the physigramme was informed by my reading of the narrative

Therefore in itself, the physigramme successfully expresses the relationships between character and cathedral

Further intervention is not necessary.
Figure 41: Book Nine - Esmeralda's relationship with the Cathedral develops positively as she begins to recognise the safety it and Quasimodo provide for her. This connection with the Cathedral turns for the worse when Claude Frollo discovers her presence. Her reliance on the building is destroyed. 


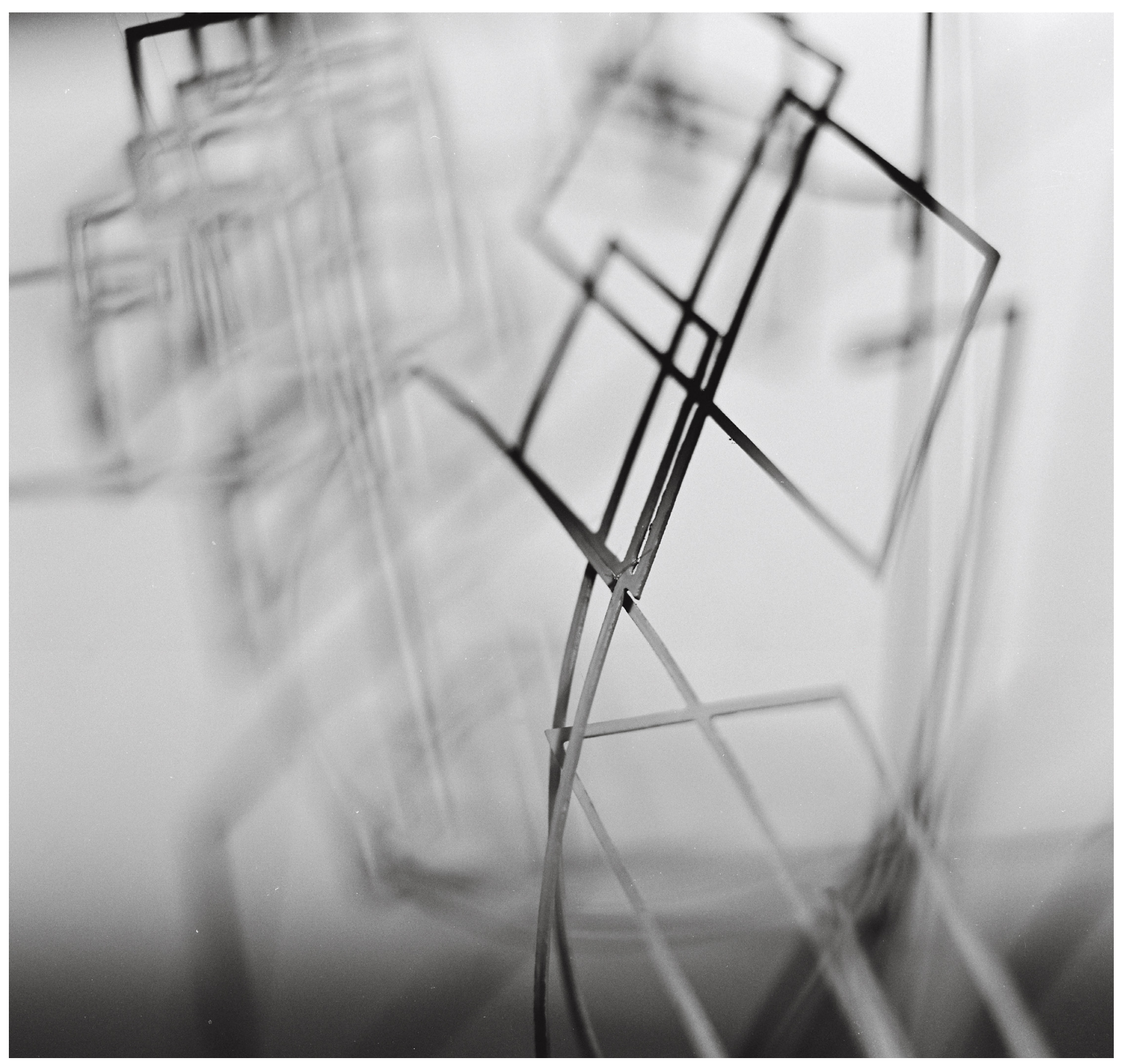




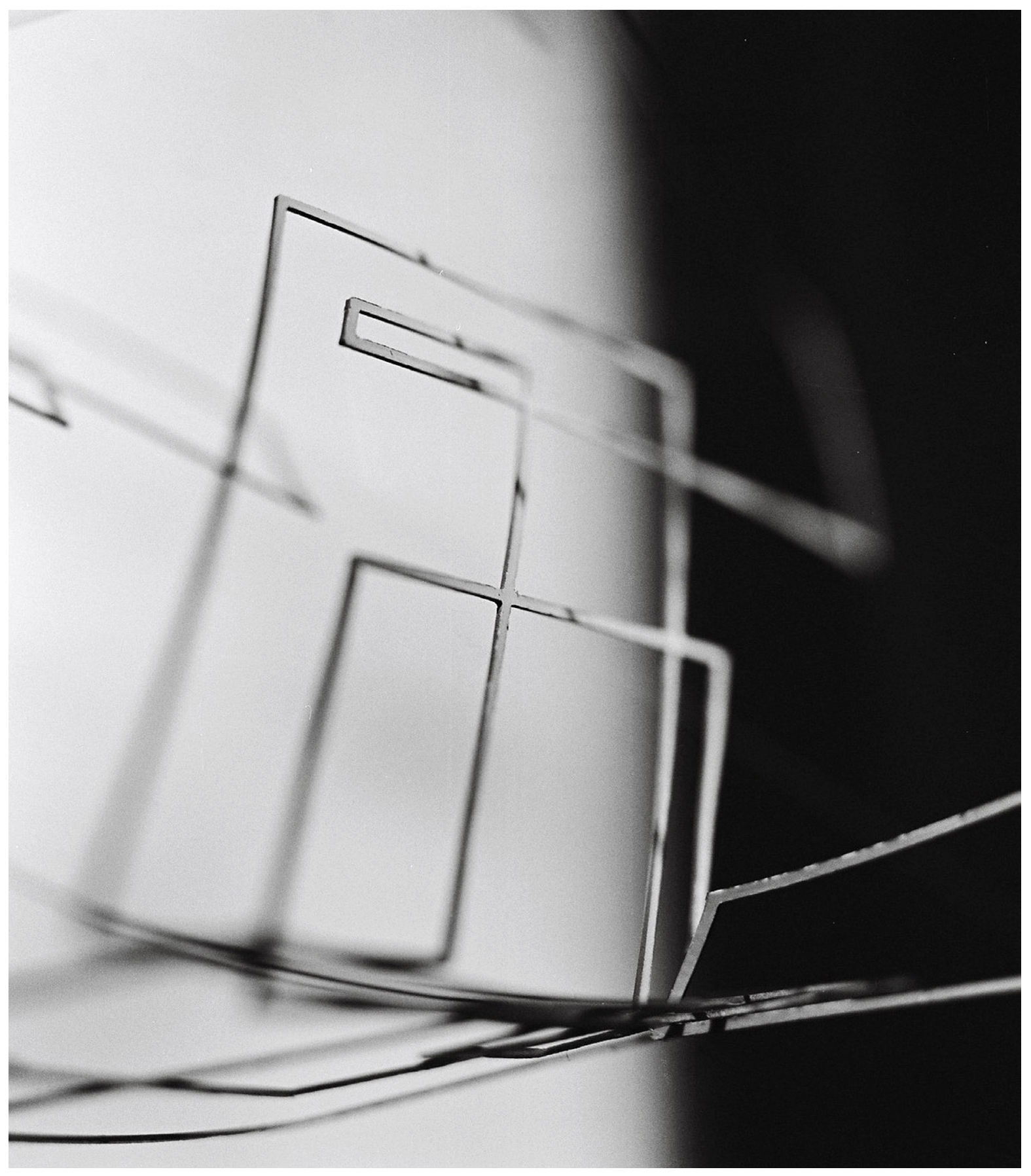

Figure 42: (opposite) Book Six - The Recluse in the Hole. The character's stories align.

Figure 43: Book Four - Quasimodo. 


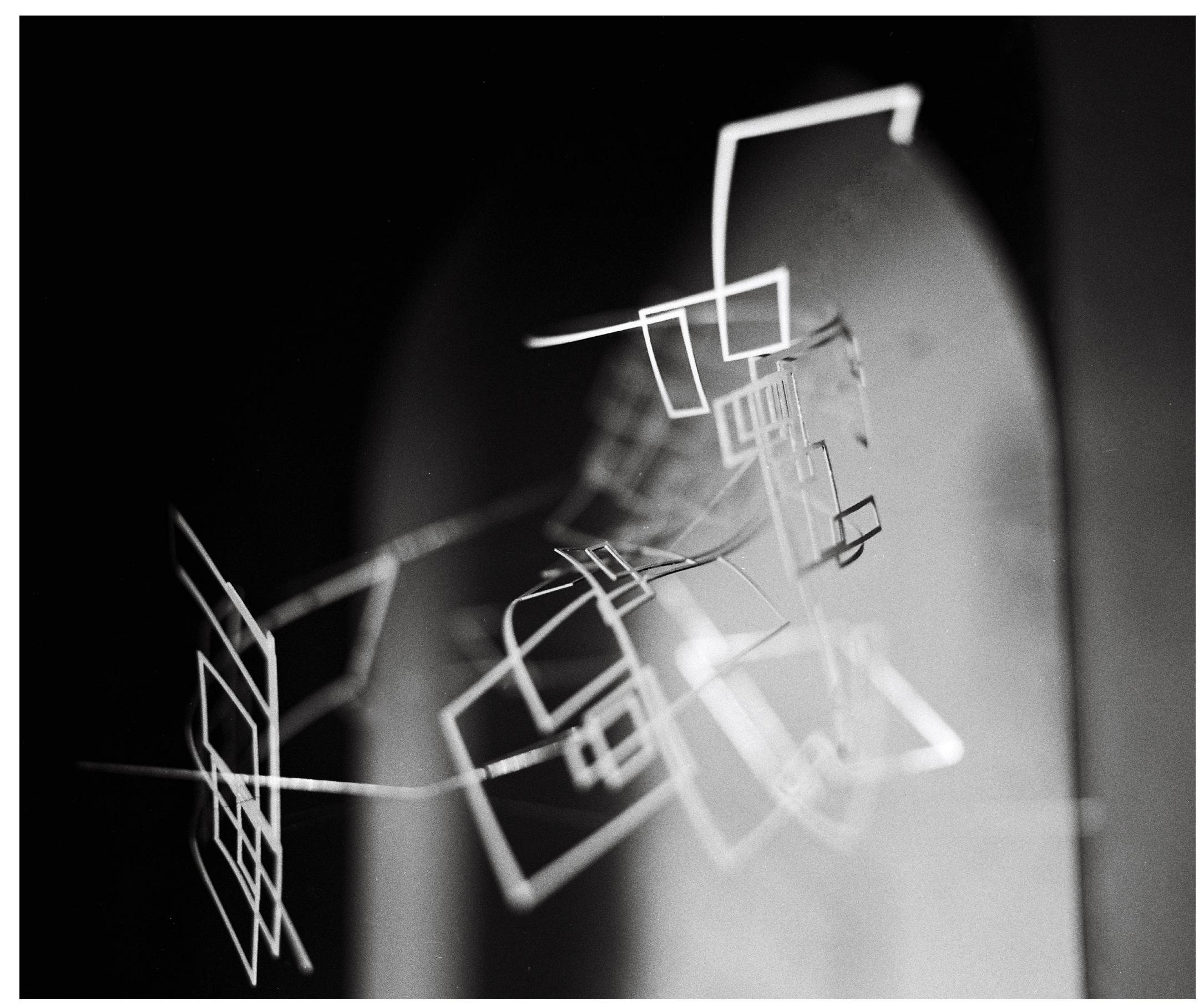




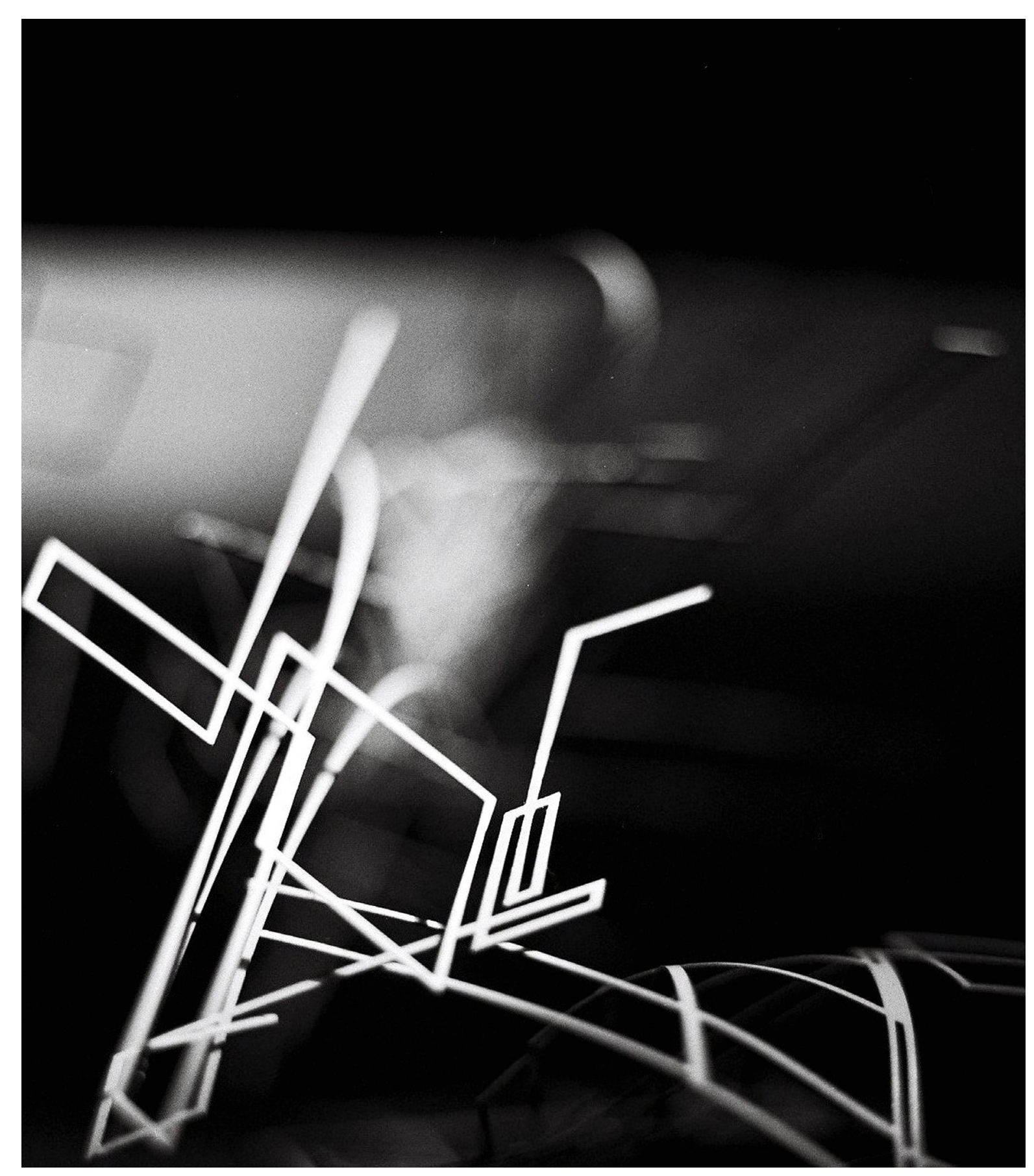

Figure 44: (opposite) Book Eleven - Claude Frollo's 


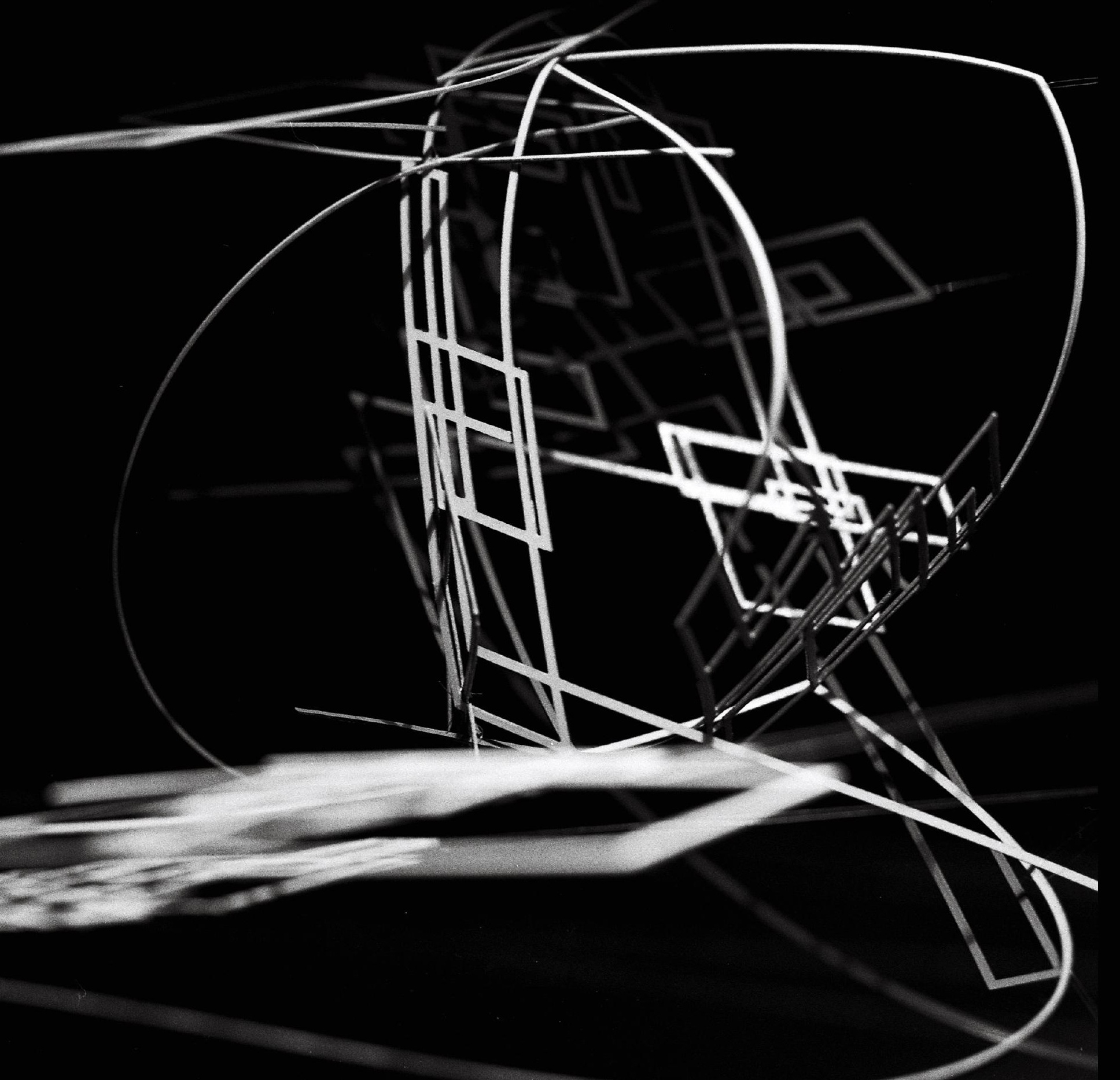




\section{Esmeralda}

The sun tickles my face as I twirl and weave my way around the laughter, smiles and cheers. My feet touch lightly onto the smooth paving stones, helping lift me back into the warm air as I jump and twist, as though gravity wishes not to impose on my happiness.

The paving stones lead me everywhere; I can move anywhere and receive delighted applause.

The cold jolts my body awake and I find myself amongst a vast darkness. I remember back to my time on the warm paving stones, it feels like an eternity ago as the hard rock I lay on chills me to the bone. The endless shadows discourage me further; the cold, deadly statues stare down onto me, offering no comfort in my time of need. It is not only the statues I fear are staring down on me. I look out to the paving stones below; a vast and impossible distance separates me from my past happiness, the dense, cold walls suffocate me. 


\section{Conclusion}

This research has tested the validity of print as an experimental tool for architectural research and design. Victor Hugo expressed his concern that print will kill architecture in his novel Notre-Dame de Paris (1831). That concern has been questioned by uncovering architecture latent in text - in particular the text of Notre-Dame de Paris. A new way of interpreting and representing architecture in connection with text has been established, utilising a range of formats which express the potential inherent in this relationship. Text is considered a design tool. It enables an exploration of a new form of architectural design through experimental and creative means, and then provides for a critical position in which the design work can be understood.

Hugo was a major public figure and his novel Notre-Dame de Paris enjoyed huge success. His praise for Gothic architecture had significant influence over the popular revolution of the style. Architecture was considered by Hugo to be a representation of society's ideas and progress. His concerns for the fate of architecture following the invention of the printing press were allocated an entire chapter, explaining Dom Claude Frollo's outburst, ‘This will kill that!" Responses to Hugo's ideas reflected the influence which the novel had at the time, however as this research has established, the significance of Hugo and Notre-Dame de Paris justify further exploration in response to the novel.

Through developing a position on the relationship between text and architecture in a contemporary theory context, the potential of text as a design tool is established. It is argued that the author is an architect, constructing architectural space within text which is then offered to the reader for interpretation. The reader is able to build their 
own interpretation of the space, based on personal reading which is influenced by understanding and experiences of architecture. The reader is not limited by the architect's/author's intentions.

Experimentation with text reveals the imaginative possibilities of writing and architecture. Using Notre-Dame de Paris as direction for the design work, a new form of 'reading' the novel occured which provided a developed insight into Hugo's words. Visualisation of this reading, through a re-'writing', uncovered architecture latent within the novel. Physical exploration of this architecture is possible through multiple conversions, expressing the architecture of Notre-Dame de Paris, in entirely unique ways.

The opportunity which writing and architecture provide for architecture is not limited to the novel of NotreDame de Paris. Architecture can be uncovered in all novels. This thesis has identified a way in which to 'read' and 'write' architecture that engages imaginative participation in text. Text has allowed the interpretation of architecture which is able to be visually represented. It has also been established as a tool for the design of 'written' architecture, through the use of creative writing. Writing is then able to be used from a critical distance, providing a lens through which to analyse design experimentation in a formal context.

This research revealed a relationship between text and architecture which has always existed - but was yet to be uncovered. Hugo's descriptions of Notre-Dame Cathedral reflect his love and dedication for architecture, and his intentions in raising society's awareness and appreciation for meaningful architecture. But perhaps what is more significant in the expression of his ideas is the architecture that is not so explicity defined. Perhaps providing for a personal discovery of architecture was Hugo's intention all along. 


\section{Reference List}

Anstey, Tim, Katja Grillner, and Rolf Hughes, eds. Architecture and Authorship. Vol. 1. London: Black Dog Publishing 2007.

Barthes, Roland. "The Death of the Author.” Trans. Heath, Stephen. Image Music Text. 1st ed. London: Fontana/Collins, 1977.

Barthes, Roland. The Grain of the Voice: Interviews 1962-1980. Trans. Coverdale, Linda. Vol. 1. New York: Hill and Wang, 1985.

Benjamin, Walter. "The Work of Art in the Age of Mechanical Reproduction.” Illuminations. Ed. Arendt, Hannah. New York: Schocken Books, 1936.

Boucher-Rivalain, Odile. "Attitudes to Gothic in French Architectural Writings of the 1840s." Architectural History 41 (1998): 145-52.

Brombert, Victor. Victor Hugo and the Visionary Novel. Harvard University Press, 1984.

Carpo, Mario. Architecture in the Age of Printing. Trans. Benson, Sarah. Cambridge, Massachusetts: The MIT Press, 1998.

Centre, Guernsey Information. "Victor Hugo". Guernsey, Channel Islands. 6 May 2010. $<$ http://www.victorhugo.gg/contact-us/>.

Downing, Crystal. “Architecture as Synecdoche: A Poetics of Trace.” Pacific Coast Philology 23 1/2 (1988): 13-21.

Drexler, Arthur, ed. The Architecture of the Ecole Des Beaux-Arts. London: Martin Secker \& Warburg Ltd, 1977.

Edwards, Samual. Victor Hugo - a Biography. New York: David McKay Company, Inc., 1971.

Foucault, Michel. "What Is an Author?” Critical Theory since 1965. Eds. Adams, Hazard and Leroy Searle. Florida: University Presses of Florida, 1989. 138-48. 
Grillner, Katja. "Abstract: Writing Architecture out of Focus". The Bartlett School of Architecture, UCL, 2004. Critical Architecture. 20 August 2010. $<$ http://www.bartlett.ucl.ac.uk/architecture/events/conferences/ grillner.htm>.

Grillner, Katja. "Fluttering Butterflies, a Dusty Road, and a Muddy Stone: Criticality in Distraction."

Critical Architecture. Eds. Rendell, Jane, et al. Vol. 1. Abingdon, Oxon: Routledge, 2007. 135-42.

Grillner, Katja. "The "Halt at the Door of the Boot Shop"." 0.1 Akad - Experimental Research in Architecture and Design - Beginnings. Eds. Grillner, Katja, Per Glembrandt and Sven-Olov Wallenstein. Vol. 1. Stockholm: AKAD through AXL Books, 2005.

Grillner, Katja. "In the Corner of Perception-Spatial Experience in Distraction.” arq: Architectural Research Quarterly 93-4 (2006): 245-54.

Grillner, Katja. "The Textual Artefact in Research by Architectural Design.” Working Papers in Art and Design 3 (2004).

Grillner, Katja. "Writing and Landscape - Setting Scenes for Critical Reflection." The Journal of Architecture 8 2 (2003): 239-49

Hill, Jonathan. "Building a Drawing and Drawing a Building." Nordic Journal of Architectural Research 4 (2002): 19 .

Howe, Jeffery. "Le Corbusier - Villa Savoye". Boston College, Art on the Web. 30 October 2010. <http://www.bc.edu/bc_org/avp/cas/fnart/Corbu.html.>

Hugo, Victor. Notre-Dame De Paris. Trans. Sturrock, John. Ed. Sturrock, John. London: Penguin Books, 1978.

Imperica. "Stefanie Posavec: Artists and Data". Oxford, 2010. Perini Networks Europe Ltd. 3 November 2010. $<$ http://www.imperica.com/viewsreviews/artistsdata $>$.

Levine, Neil. "The Book and the Building; Hugo's Theory of Architecture and Labrouste's Bibliotheque SteGenevieve." The Beaux-Arts and Nineteenth-Century Architecture. 1982. Ed. Middleton, Robin. London: Thames and Hudson, 1977.

Lewis, Michael J. The Gothic Revival. New York: Thames \& Hudson, 2002. 
Lunn-Rockliffe, Katherine. "Death and the Aesthetic of Continuity: Reading Victor Hugo's Contemplations." French Studies LXII 1 (2008): 13-25.

McLaren, Brian. "Under the Sign of the Reproduction.” Journal of Architectural Education (1984-) 452 (1992): 98-106.

Mauras, Andre'. Victor Hugo. Trans. Hopkins, Gerard. London: Jonathan Cape, 1956.

Mumford, Lewis. Sticks and Stones: A Study of American Architecture and Civilization. 1924. 2nd ed. New York: Dover, 1955.

Pevsner, Nikolaus. Some Architectural Writers of the Nineteenth Century. Oxford: Clarendon Press, 1972.

Popova, Maria. "Data Visualization: Stories for the Information Age". 2009. Bloomberg. 3 August 2010. $<$ http://www.businessweek.com/innovate/content/aug2009/id20090811_137179.htm>.

Posavec, Stefanie. "About Me: Stefanie Posavec”. London, 2007. Indexhibit. 19 July 2010. $<$ http://www.itsbeenreal.co.uk/index.php?/about-me/>.

Posavec, Stefanie. "Writing without Words". London, 2007. Indexhibit. 19 July 2010. $<$ http://www.itsbeenreal.co.uk/>.

Pugin, A.W.N. Contrasts. 2nd ed. Leicester: Leicester University Press, 1836.

Rawes, Peg, and Jane Rendell. "Spatial Imagination.” Ed. Architecture, Bartlett School of. London: Bartlett School of Architecture, 2005. Vol. 1.

Robb, Graham. Victor Hugo. London: Picador, 1997.

Rendell, Jane. "From Architectural History to Spatial Writing." Rethinking Architectural Historiography. Eds. Arnold, Dana, Elvan Altan Ergut and Belgin Turan Ozkaya. 1st ed. Oxon: Routledge, 2006. 135-50.

Rendell, Jane. "Introduction: Architecture-Writing." Critical Architecture. Eds. Rendell, Jane, et al. Vol. 1. Abingdon, Oxon: Routledge, 2007. 87-91.

Rendell, Jane. "Writing in Place of Speaking.” Transmission: Speaking and Listening. Eds. Kivland, Sharon and Lesley Sanderson. Sheffield: Sheffield Hallam University, 2003. 
Rendell, Jane. "To miss the desert". London, 2009. 6 May 2010.

$<$ http://www.janerendell.co.uk/to-miss-the-desert. $>$

Rendell, Jane, et al., eds. Critical Architecture. Vol. 1. 3 vols. Abingdon, Oxon: Routledge, 2007.

Simms, Elspeth. “Theorizing the Local.” Wellington: Victoria University of Wellington, 2007.

Stephens, Bradley. "Reading Walter Benjamin's Concept of the Ruin in Victor Hugo's Notre-Dame De Paris." French Studies LXI 2 (2007): 155-66.

Sturrock, John. “Chronology.” Notre-Dame De Paris. Ed. Sturrock, John. London: Penguin Group, 2004. 495-8

Sturrock, John. “Introduction.” Notre-Dame De Paris. Ed. Sturrock, John. London: Penguin Group, 1978. 7-24.

Trachtenberg, Marvin, and Isabelle Hyman. Architecture, from Prehistory to Post-Modernism :The Western Tradition. N.J: New York: Englewood Cliffs, 1986

Walker, Paul. "Semiotics and the Discourse of Architecture." University of Auckland, 1987.

Wright, Frank Lloyd. The Future of Architecture. New York: New American Library, 1953.

Wright House. Fallingwater pictures: "Kaufmann house above waterfall, Frank Lloyd Wright". 30 October 2010. <http://www.wright-house.com/frank-lloyd-wright/fallingwater-pictures/22SW-pathfallingwater.html.> 


\section{Appendix}

Diagrammes of entire novel - all used in the 'Physigramme',

Notre-Dame de Paris:

Book 1 - Chapter
The Great Hall
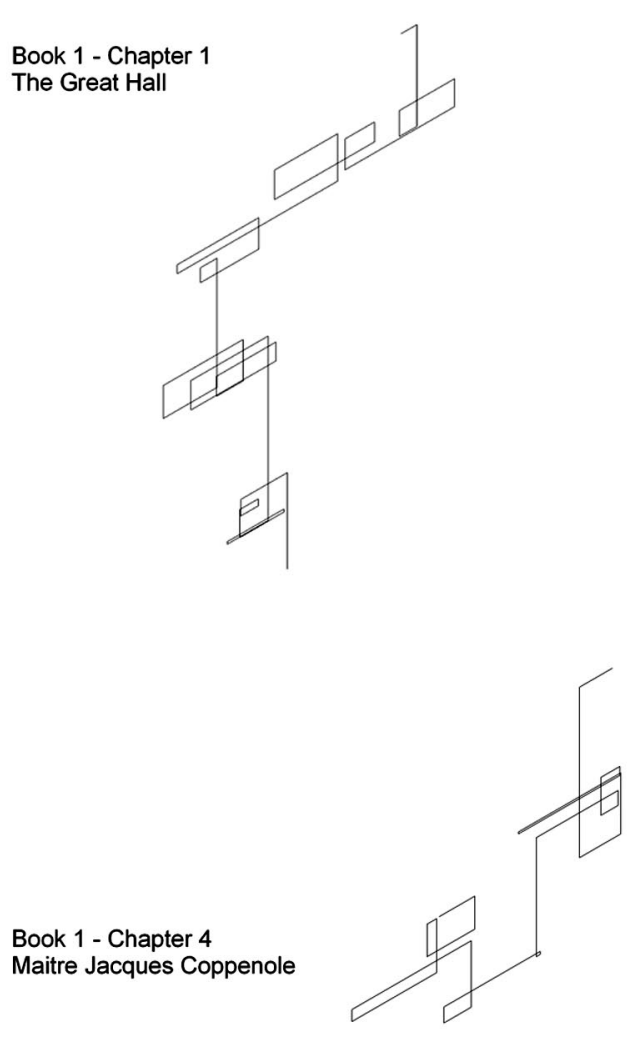

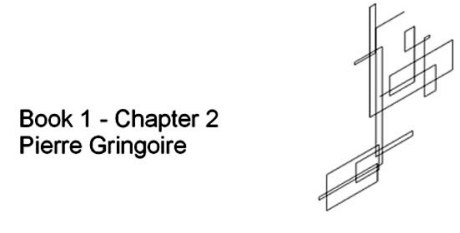

Book 1 - Chapter 3

the Cardina
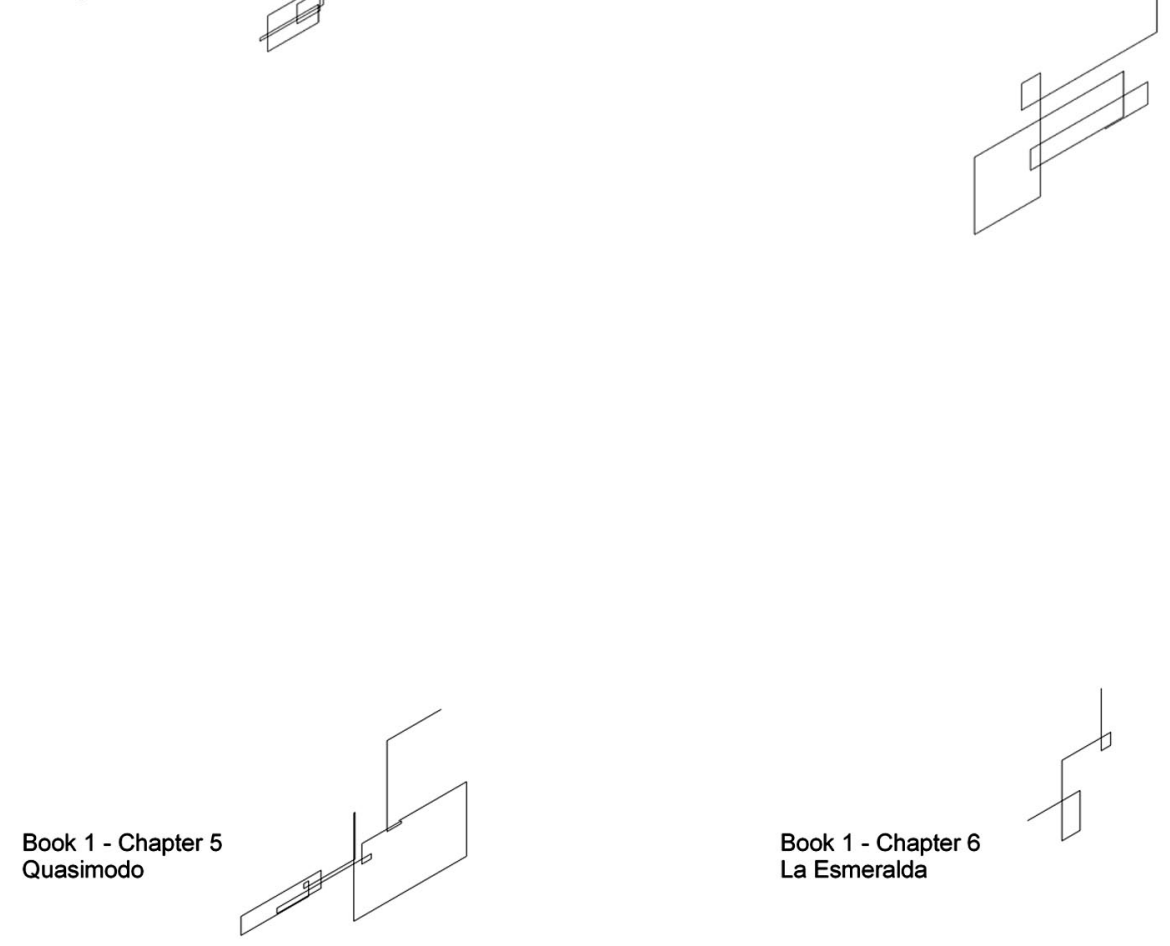

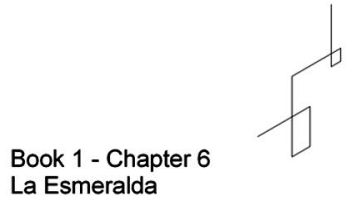


Book 2 - Chapter 1

Out of Charybdis on to Scylla

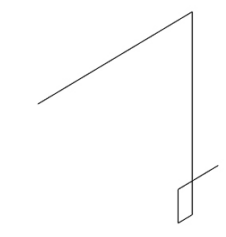

Book 2 - Chapter 4 Drawbacks of fol
Pretty Woman

Book 2 - Chapter 5

The Drawbacks (Contd)

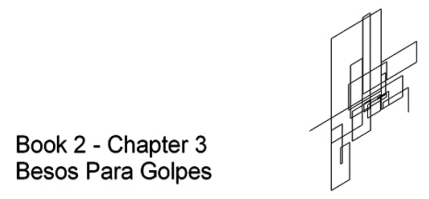

Book 2 - Chapter 6

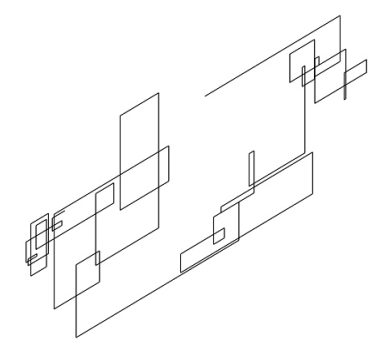

Book 2 - Chapter 7
A Wedding Night

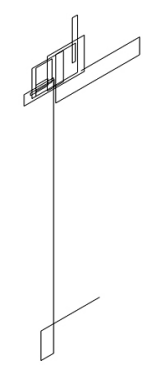



Book 3-Chapter 1

Book 3 - Chapter 2 A Bird's Eye View of Paris

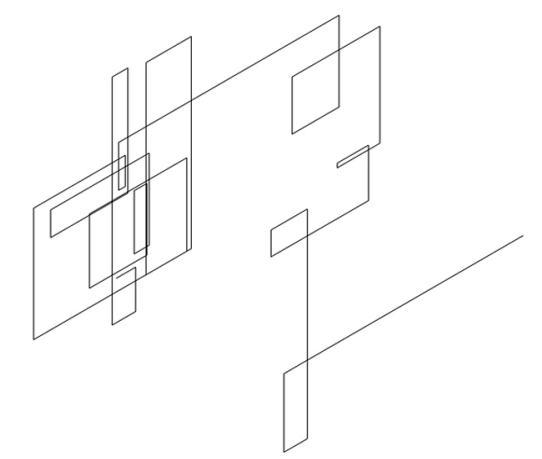

The Kind Souls

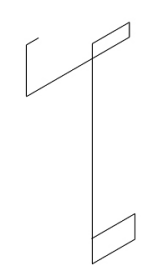

Book 4 - Chapter 2

Claude Frollo

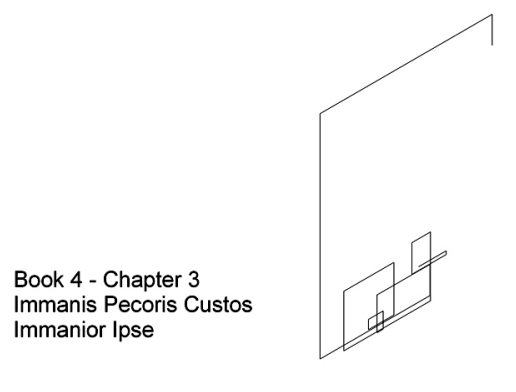

Book 4 - Chapter 6

Unpopularity

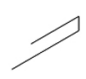

Book 4 - Chapter 4

Book 4 - Chapter 5
Claude Frollo (contd)

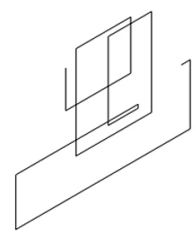


Bok 5. Chapter1
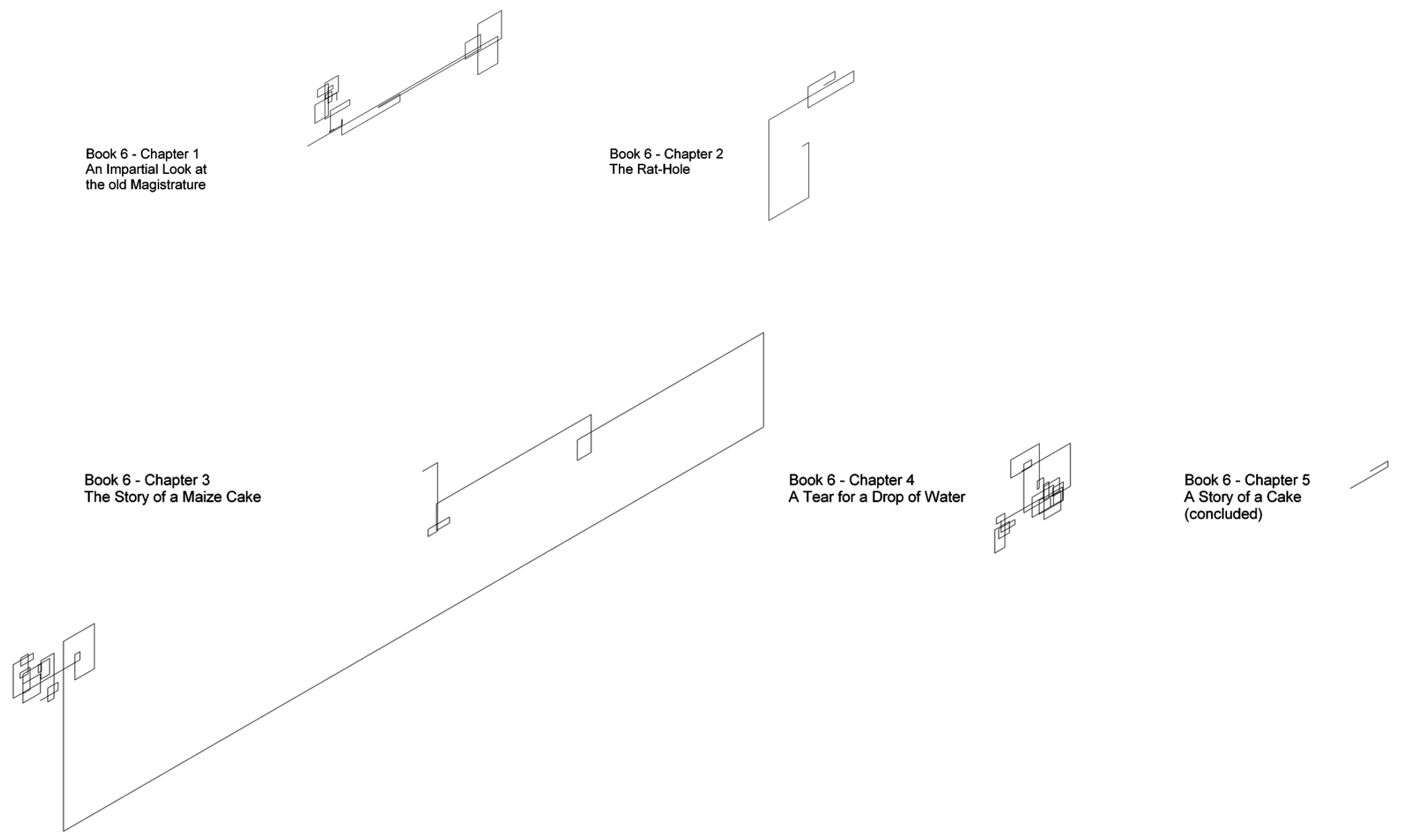

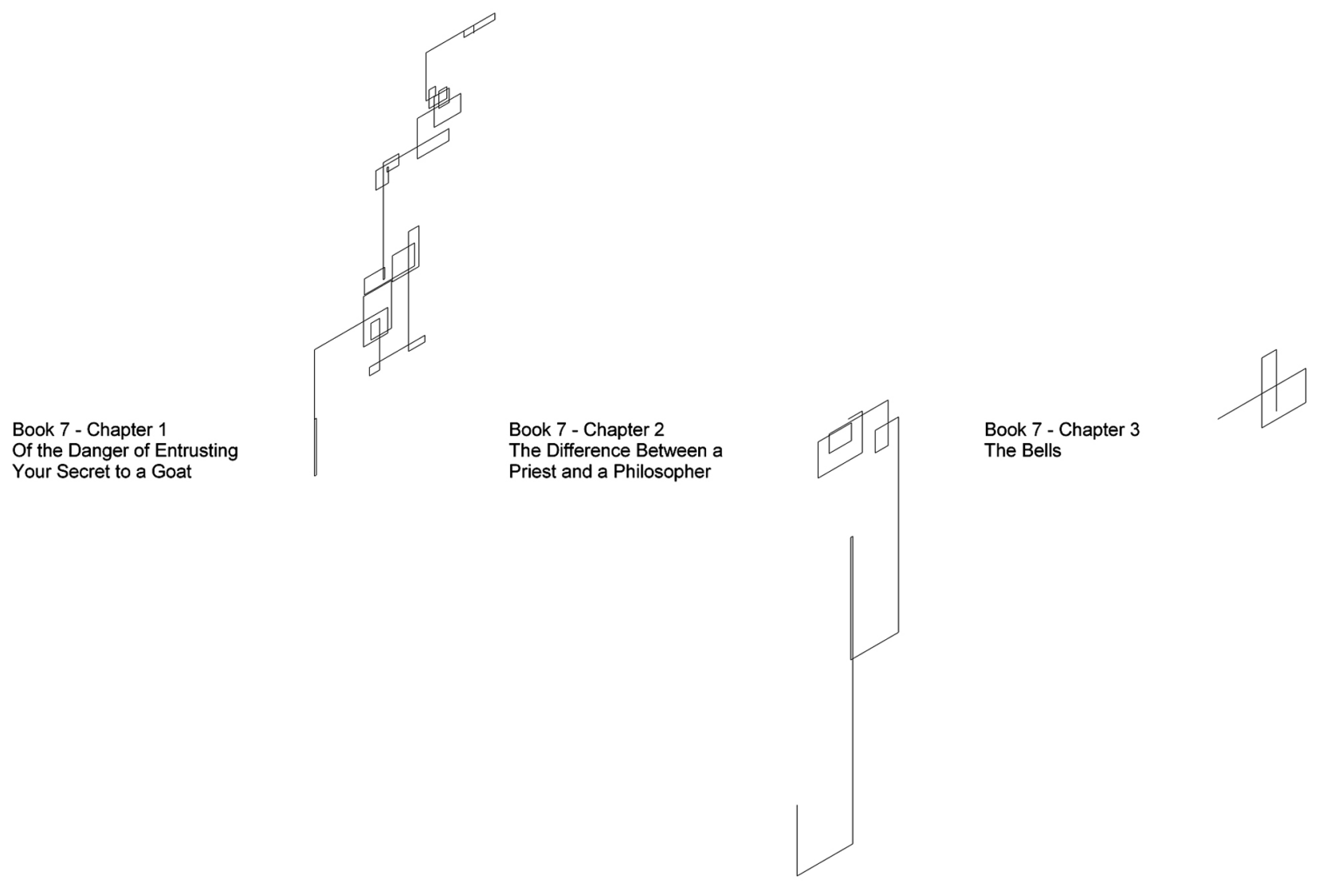

Book 7-Chapter 4
ANATKH
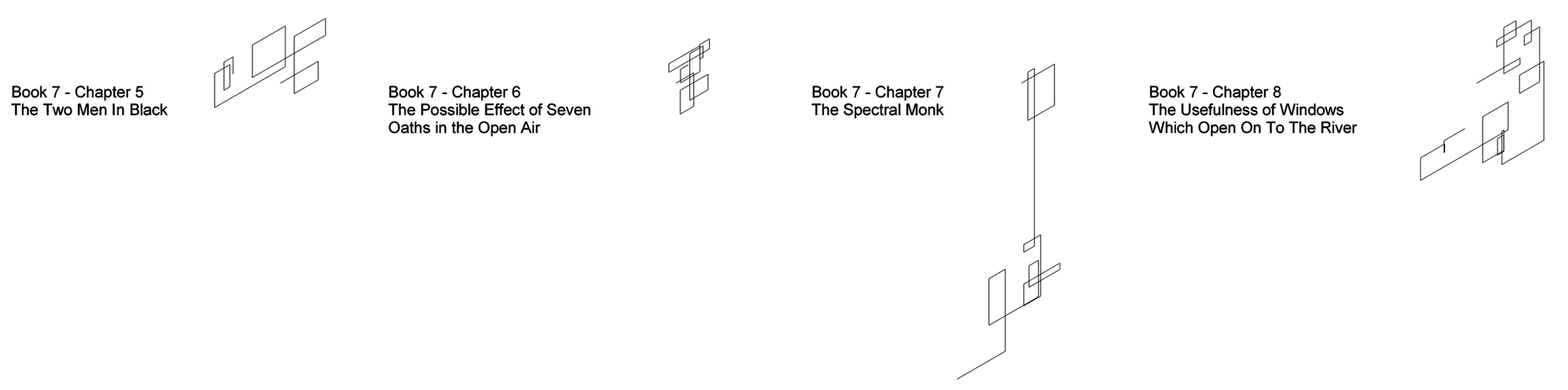


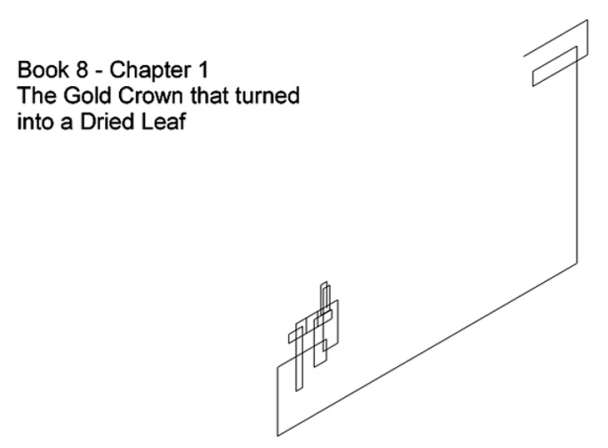

Book 8 - Chapter 2
The Gold Crown that turned
into a Dried Leaf (contd)

Book 8 - Chapter 3
The Gold crown that turned
into a Pred Leaf
(concluded)

手

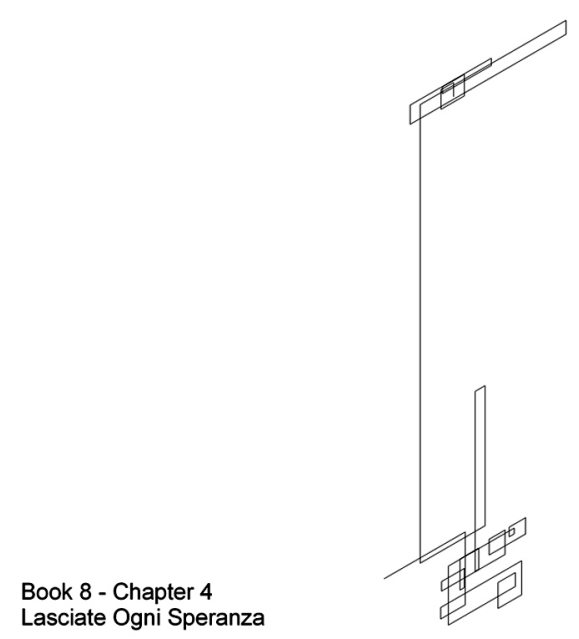

Book 8 - Chapter 5
The Mother

Book 8 - Chapter 6
Three Men's Hearts
Differently Formed

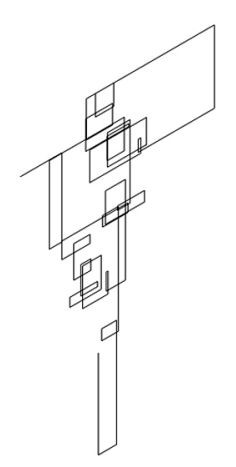

Appendix

163 
Book 9 - Chapter 1

Fever

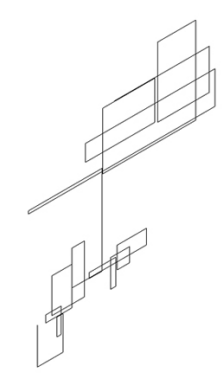

Book 9 - Chapter 2

Hunchbacked, One-Eyed, Lame

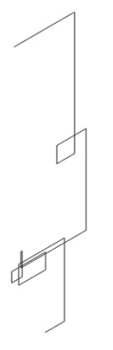

Book 9 - Chapter 3

Deaf

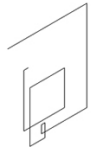

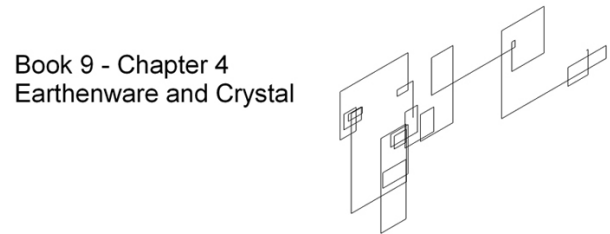

Book 9 - Chapter 5

The Key of the Porte-Rouge
The Key of the Porte-Rouge

(contd) 

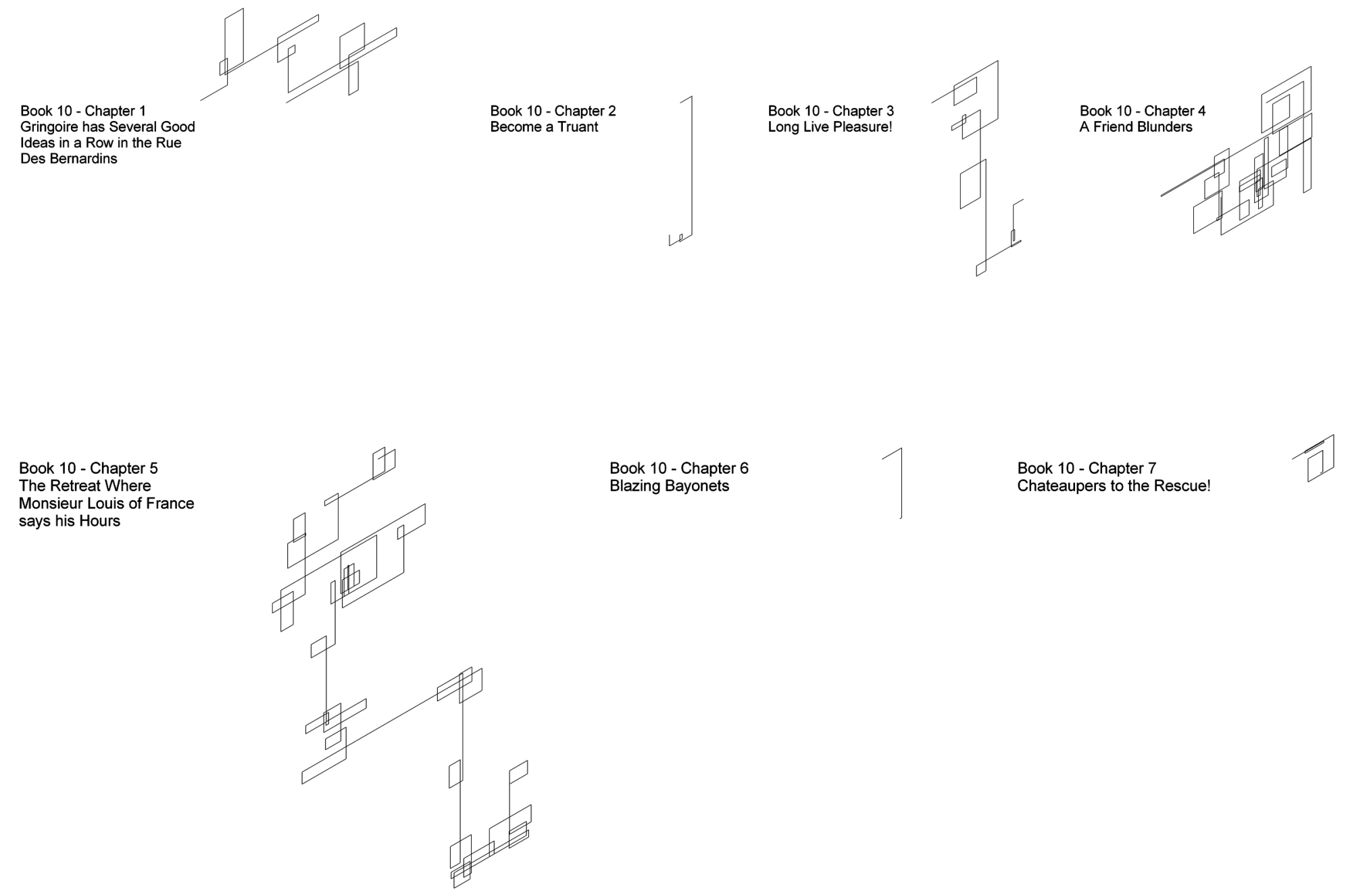

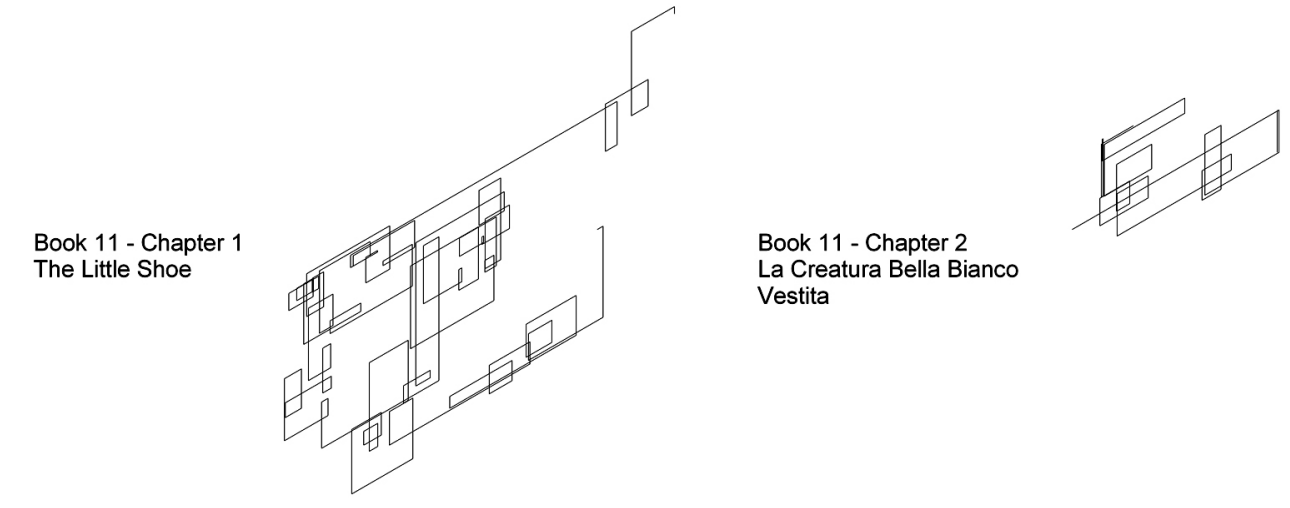

La Creatura Bella Bianco

Book 11 - Chapter 3

Phoebus's Marriage

Book 11 - Chapter 4

Quasimodo's Marriage 